\title{
BALANÇO DE RADIAÇÃO SOLAR DE ONDAS CURTAS EM TRES DENSIDADES DE PLANTIO DO MILHO (Zea mays, L. var. Cargill 501)
}

\author{
CARLOS MIGUEL ROMERO DOMENACK \\ Engenheiro agrónomo
}

Orientador: Dr. Jesus Marden dos Santos

Disserłação apresentada à Escola Superior de Agricultura "Luiz de Queiroz", da Universidade de São Paulo, para obtenção do tífulo de Mestre om Agrometeorologia.

\author{
$P|R A C| C A B A$ \\ Estado de São Paulo - Brasil \\ Fevereiro, 1980
}


ii.

Com todo carinho a meus pais

VICTOR MIGUEL e AURA ELIZABETH

A MINHA HOMENAGEM.

À minha amada esposa CACILDA

a meus queridos filhos:

CARLOS JOSE

JAIME ALFREDO

RITA CACILDA

D E D I C 0 . 


\section{AGRADECIMENTOS}

Meus mais profundos agradecimentos às seguintes pessoas e entidades: .

Ao meu orientador e Coordenador do Curso de Pós Graduação de Agrometeorologia, Dr. Jesus Marden dos Santos pela sua valiosa orientação, críticas e acertadas sugestões aquí apresentadas.

Aos professores do Departamento de Física e Meteorologia da ESALQ-USP pelos seus valiosos ensinamentos e ami zade proporcionada.

Ao professor Paulo Roberto de Camargo e Castro, pela sua col-aboração no presente trabalho.

Á Universidad Nacional Agraria - La Molina Lima, Perū, pela oportunidade oferecida para minha capaçitação.

À Organização Meteorológica Mundial das Nações Unidas pela bolsa de estudos proporcionada a qual foi possível realizar meus estudos.

Aos colegas e amigos Alvaro Jaramillo Robledo e Norberto Vilas Boas da Silva pela sua colaboração desinteress a da.

Aos colegas do Curso de Pós-Graduação de Agrome teorologia pela sua atenção particular e clima de amizade frequentemente mantida.

À Sra. Aurea Benedita Michelotto, Secretāria do Departamento pela sua colaboração durante o curso.

Às Sras. Celina Magalhães e Luciana Fornari, funcionārios das NN.UU. no Rio de Janeiro pelo seu interesse e preocupação em tudo o relacionado com minha bolsa de estudos.

Finalmente, a todos quanto, de uma forma ou de outra, concorreram para a realização deste trabalho. 
SIMBOLOGIA UTILIZADA

- Os símbolos utilizados neste trabalho, são aque les recomendados pela Organização Meteorológica Mundial.

K $\downarrow$ - densidade do fluxo de radiação solar global, de onda curta, no sentido de cima para baixo e que atinge uma superfície plana e horizontal.

$\mathrm{K} \uparrow$ - densidade do fluxo de radiação solar global, de on da curta, no sentido de bàixo para cima e que é re fletido por uma superfície qualquer.

$\mathrm{K}_{\mathrm{D}} \downarrow$ - densidade do fluxo de radiação solar direta, de on da curta, no sentido de cima para baixo e que atinge uma superfície plana e horizontal.

$\mathrm{K}_{\mathrm{d}} \downarrow$ - densidade do fluxo de radiação solar difusa, de onda curta, no sentido de cima para baixo e que atin ge uma superfície plana e horizontal.

$\mathrm{K}_{\mathrm{D}} \uparrow$ - densidade do fluxo de radiação solar direta, de onda curta, no sentido de baixo para cima e que e re fletido por uma superfície qualquer.

$\mathrm{K}_{\mathrm{d}} \uparrow$ - densidade do fluxo de radiação solar difusa de onda curta, no sentido de baixo para cima e que é refletido por uma superfície qualquer.

$\mathrm{K}^{*}$ - densidade de fluxo do balanço de radiação solar, de onda curta. 
L $\downarrow$ - densidade do fluxo de radiação de onda longa, de cima para baixo (da atmosfera para a superfície).

Lt - densidade de fluxo de radiação de onda longa, de baixo para cima (da superfície para a atmosfera).

PI $\downarrow$ - irradiância fotossintética, de cima para baixo, que atinge a cobertura vegetal.

PI $\uparrow$ - irradiância fotossintética refletida pela cobertura vegetal.

$\mathrm{PI}^{*}$ - balanço de irradiância fotossintética.

$\alpha$ - albedo.

Q - fluxo correspondente ao balanço global de radiação (onda curta e longa).

Os simbolos $\mathrm{K}_{8} \downarrow, \mathrm{K}_{8} \uparrow, \mathrm{K}_{\mathrm{D} 8} \downarrow, \mathrm{K}_{\mathrm{D} 8} \uparrow, \mathrm{K}_{\mathrm{d} 8} \downarrow, \mathrm{K}_{\mathrm{d} 8} \uparrow \mathrm{e}$ $\mathrm{K}_{8}^{*}$, têm os mesmos significados que as definições $\mathrm{jā}$ mencionadas com a diferença de que se referem à faixa de radiação com comprimentos de onda superiores a $0,7 \mu \mathrm{m}$.

$\mathrm{K}_{\mathrm{T}} \downarrow$ e $\mathrm{K}_{\mathrm{T} 8} \downarrow$ correspondem às densidades dos fluxos de radiação de ondas curtas e infra-vermelha próxima respectivamente, que são transmitidas através da cobertura vegetal no sentido de cima para baixo. 
vi.

$\begin{array}{llllll}\bar{I} & N & D & I & C & E\end{array}$

$\underline{\text { Página }}$

1. RESUMO $\ldots \ldots \ldots \ldots \ldots \ldots \ldots \ldots \ldots \ldots \ldots \ldots \ldots \ldots \ldots \ldots \ldots \ldots \ldots \ldots \ldots$

2. INTRODUÇÃO $\ldots \ldots \ldots \ldots \ldots \ldots \ldots \ldots \ldots \ldots \ldots \ldots \ldots \ldots \ldots \ldots \ldots \ldots \ldots$

3. REVISÃO BIBLIOGRÁFICA $\ldots \ldots \ldots \ldots \ldots \ldots \ldots \ldots \ldots \ldots$

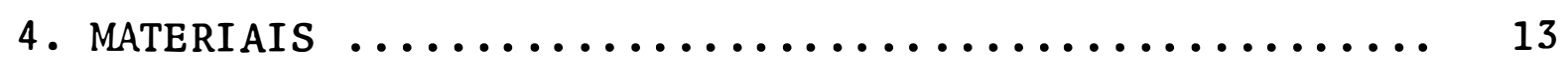

4.1. Localização do campo experimental ........... 13

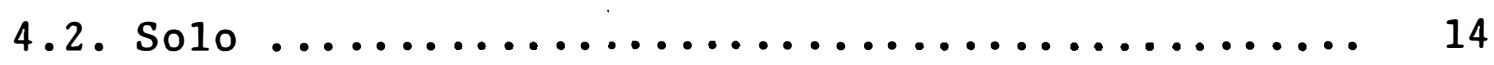

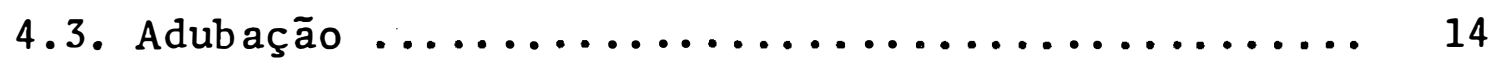

4.4. Variedade utilizada ................... 15

4.5. Equipamentos de medida ................ 15

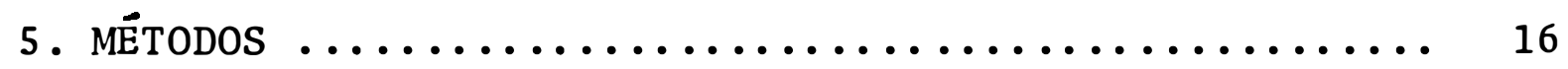

5.1. Prāticas culturais ................... 16

5.2. Balanço da radiação solar global de ondas

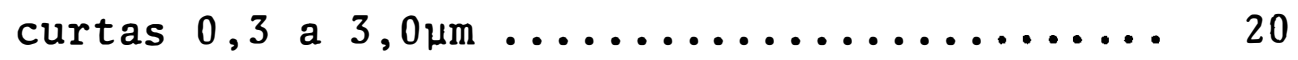

5.3. Balanço da irradiância fotossintética ........ 21

5.4. Determinação da altura, ārea foliar, índi

ce de área foliar, matéria seca das

plantas e produção de grãos ............ 25

6. RESUltadoS E DISCUSSÃo $\ldots \ldots \ldots \ldots \ldots \ldots \ldots \ldots \ldots \ldots$

7. CONCLUSÕES $\ldots \ldots \ldots \ldots \ldots \ldots \ldots \ldots \ldots \ldots \ldots \ldots \ldots \ldots \ldots \ldots \ldots$

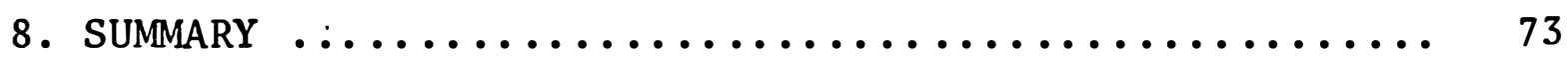

9. Literatura CitAdA $\ldots \ldots \ldots \ldots \ldots \ldots \ldots \ldots \ldots \ldots \ldots \ldots \ldots \ldots$ 
1. RESUMO

0 estudo teve como objetivo conhecer o balanço dos fluxos de radiação solar de ondas curtas $(0,3$ a $3,0 \mu \mathrm{m})$ e dos fluxos de radiação fotossinteticamente ativa $(0,3 \mathrm{a} 0,7 \mu \mathrm{m})$ relacionando-os ao crescimento do milho (Zea mays L. var. Cargill 501), em três densidades de plantio.

0 experimento consistiu dos seguintes tratamentos:

a) espaçamento de $1,00 \mathrm{~m} \times 0,20 \mathrm{~m}$ com $50.000 \mathrm{plantas} / \mathrm{ha}$

b) espaçamento de $1,00 \mathrm{~m} \times 0,50 \mathrm{~m} \times 0,20 \mathrm{~m}$ com $66.667 \mathrm{plan}$ tas/ha

c) quincôncio, com plantas distanciadas em triângulos equiláteros de lado igual a $0,34 \mathrm{~m}$ e com uma popula ção de $98.039 \mathrm{plantas} / \mathrm{ha}$.

Para a determinação dos fluxos de radiação uti- 
lizaram-se dois piranômetros Eppley, um com filtro RG-8 e outro sem filtro com cúpula transparente WG-7.

Conclui-se que:

- A relação entre a radiação infra-vermelha próxima e a radia ção solar global que atingem a cobertura vegetal de uma cul tura de milho é da ordem de $46 \%$.

- As maiores porcentagens de radiação solar global e fotossin teticamente ativa retidas pela cobertura vegetal corresponderam aos tratamentos de maior densidade de população com 85 e $96 \%$ para as duas faixas do espectro e para o tratamento $1,00 \mathrm{~m} \times 0,20 \mathrm{~m}$ correspondeu uma retenção de 80 e $94 \%$.

- As maiores porcentagens de radiação solar global e fotossin teticamente ativa medidas na superfície do solo corresponderam à parcela de menor densidade de população com 26 e $16 \%$ respectivamente e nos tratamentos $1,00 \mathrm{~m} \times 0,50 \mathrm{~m} \times 0,20 \mathrm{~m}$ e quincôncio corresponderam 21 e $12 \%$ para as duas faixas do espectro.

- Os albedos de radiação solar global para os tratamentos quin côncio, $1,00 \mathrm{~m} \times 0,20 \mathrm{~m}$ e $1,00 \mathrm{~m} \times 0,50 \mathrm{~m} \times 0,20 \mathrm{~m}$ foram: 18 , 17 e $16 \%$.

- A amplitude do albedo da radiação solar global no tratamento $1,00 \mathrm{~m} \times 0,20 \mathrm{~m}$ foi de 13 a $26 \%$ Para o tratamento $1,00 \mathrm{~m} \times 0,50 \mathrm{~m} \times 0,20 \mathrm{~m}$ observou-se uma variação de 11 a $24 \%$ e para o tratamento quincôncio de 15 a $23 \%$.

- Para os três tratamentos os menores valores de albedo da radiação solar global corresponderam as horas próximas ao meio do dia, sendo os valores máximos observados de manhã e à tarde.

- As plantas de maior altura $(244,3 \mathrm{~cm})$ corresponderam ao tratamento com maior população, enquanto que no tratamento de 
menor densidade $(1,00 \mathrm{~m} \times 0,20 \mathrm{~m})$ a altura média foi de $221,0 \mathrm{~cm}$.

- o tratamento quincôncio apresentou o maior índice de ārea foliar com 7,2 . O tratamento $1,00 \mathrm{~m} \times 0,50 \mathrm{~m} \times 0,20 \mathrm{~m}$ apresentou um valor igual a 4,9, sendo de 3,5 o I.A.F. do tratamento $1,00 \mathrm{~m} \times 0,20 \mathrm{~m}$.

- A maior produção de matéria seca por unidade de ārea corres pondeu ao tratamento quincôncio com $2.798 \mathrm{~g} / \mathrm{m}^{2}$, seguindo os tratamentos $1,00 \mathrm{~m} \times 0,50 \mathrm{~m} \times 0,20 \mathrm{~m}$ com $1,964 \mathrm{~g} / \mathrm{m}^{2}$ e finalmente o tratamento $1,00 \mathrm{~m} \times 0,20 \mathrm{~m}$ com $1.726 \mathrm{~g} / \mathrm{m}^{2}$.

- A maior taxa de crescimento do cultivo correspondeu ao tratamento quincôncio com $31,8 \mathrm{~g} / \mathrm{m}^{2} \cdot \mathrm{dia}$, seguindo os tratamentos $1,00 \mathrm{~m} \times 0,50 \mathrm{~m} \times 0,20 \mathrm{~m}$ e $1,00 \mathrm{~m} \times 0,20 \mathrm{~m}$ com 23,3 e $19,6 \mathrm{~g} / \mathrm{m}^{2} \cdot$ dia respectivamente. 
2. INTRODUÇÃO

0 homem tem desenvolvido estudos para compreender os mecanismos que controlam o sistema solo-planta-atmosfera, vinculados aos problemas da produtividade biológica das plantas. Estes esforços são motivados pelos perigos que representa uma escasses de alimentos.

A produtividade de uma planta, como a de qual quer outro ecossistema depende de uma série de interrelações complexas entre o sêr vivo e o ambiente. Estas interrelações nas plantas, conforme o seu potencial genético, manifesta se através de processos fisiológicos que repercutirão em seu desenvolvimento.

Muitos estudos indicam que a fotossintese e a produção de uma cultura, em condições de campo, são limitadas pèla quantidade de radiação fotossinteticamente ativa, interceptada pela planta. Tem-se observado, que existem muitas pesquisas relacionadas à densidade e épocas de plantio sem as 
determinações da quantidade de energia e de sua distribuição na comunidade vegetal. Muitas vezes resultados contraditórios em uma mesma localidade, para épocas diferentes, poderiam ser explicados pela quantificação da distribuição de energia na cobertura vegetal.

0 estudo do balanço de radiação solar em um cam po cultivado é importante por estar diretamente relacionado à capacidade metabólica da cultura e às modificações dos elementos do microclima no interior da área plantada. 0 conhecimen to da distribuição dos fluxos da radiação na cobertura vegetal, permite caracterizar a quantidade de energia disponível para os processos físicos, químicos e biológicos que ocorrem na planta.

Neste trabalho, o objetivo principal consistiu no estudo do balanço dos fluxos de radiação solar de ondas cur tas em três densidades de plantio do milho (zea mays L. var. Cargill 501). Estudou-se a quantidade, qualidade e distribui ção dos fluxos de energia solar que atingem e penetram no cultivo, assim como os fluxos de energia que a planta utiliza em todos os seus estágios de desenvolvimento. 


\section{REVISÃO BIBLIOGRĀFICA}

No ambiente em que as plantas desenvolvem-se, o elemento de maior importância é a radiação solar, que influe na evapotranspiração e na atividade fotossintética, processos que se encontram intimamente vinculados à produção da cultura. Hales (1927), mencionado por YAO (1977), foi quem assinalou a contribuição da radiação solar no processo de nutrição das plantas.

A energia solar que incide sobre um organismo, segundo EVANS (1966), pode variar em intensidade, composição espectral e distribuição espacial, fazendo com que a caracter $\underline{i}$ zação do ambiente luminoso seja muito complexa. No meio em que as plantas se desenvolvem a insolação, o comprimento do dia e os fluxos de radiação são variáveis que dependem da latitude e da época do ano. As variāveis que dependem do cultivo refe rem-se aos coeficientes de transmissão e absorção para a radia ção solar. As determinações das densidades de fluxo da fração PHAR e do indice de ārea foliar permitem estudar o rendi- 
mento primário da cultura, segundo SAEKI (1963), MONTEITH (1965) e SANTOS (1978). A caracterização mostra-se mais complexa desde que se considerem as diferentes faixas do espectro de emissão de radiação solar ao nível do solo e suas relações com a côr, estrutura e idade das folhas, Ross (1975).

Em uma comunidade vegetal o processo fotossinté tico apresenta flutuações horárias motivadas pelas variações nos fluxos da PHAR, especialmente nos níveis inferiores da planta, MOSS et alii. (1961). No milho, a produção fotossinté tica, para determinadas faixas do espectro de emissão de radia ção solar, aumenta quase linearmente com o fluxo de PHAR, CHANG (1968).

LOPES (1973), trabalhando com milho em Viçosa, observou que a radiação solar global média, durante o período experimental, foi alta e apresentou apreciáveis oscilações nos valores horários e diários, motivadas pela alta nebulosidade na época de chuvas. Este fato provocou uma diminuição na fotossíntese líquida, mais acentuada nos tratamentos de maior população por causa do maior sombreamento.

Em sua pesquisa sobre balanço de radiação solar em milho, SANTOS (1978), faz menção que o processo fotossintético que se desenvolve na cobertura vegetal, não depende apenas da ação da fotossíntese, característica das folhas, mas também da posição das folhas em relação à direção do fluxo da radiação solar incidente, da intensidade dos fluxos de radiação direta e difusa, do sombreamento mútuo entre as folhas, da cobertura do solo e do teor de $\mathrm{CO}_{2}$ na atmosfera que envolve a cobertura vegetal.

A distribuição dos fluxos de radiação solar global dentro de uma comunidade é, segundo VERHAGEN et alii. (1963), uma função da altura do sol. Na maioria das culturas e florestas a medida que diminui o ângulo zenital, os fluxos de radiação direta transmitidos pela cobertura vegetal são maio- 
res que os da radiação difusa, ANDERSON (1970).

A penetração e a distribuição da irradiância fo tossintética na folhagem de milho são dados essenciais para o entendimento da produçã̃o fotossintética da cultura, SINCLAIR e LEMON (1974). Observaram sob condições de céu limpo, a variação de PI no interior da folhagem apresenta dois níveis de máxima irradiância, um desses níveis foi ligeiramente menor que o total de radiação acima da cultura o que representa a ocorrência de "sunflecks" penetrando através da folhagem. 0 segundo nível de máxima irradiância foi muito menor que o primeiro e correspondia à radiação difusa no interior da cobertura vegetal. A observação de uma área menor com "sunflecks" indica uma melhor simetria e maior uniformidade na distribuição da folhagem o que se obtém no plantio em quincôncio. DUNCAN (1967), jā havia assinalado que plantas de milho, igualmente espaçadas em uma área de plantio, apresentavam uma situa ção de tendência para a ótima interceptação dos fluxos de radiação solar.

A penetração da radiação através da comunidade vegetal depende da quantidade de folhas, do sombreamento mútuo entre as folhas, de sua idade, tamanho, orientação e de seu estado sanitário, ROSS (1975).

Com relação à ārea foliar WATSON (1952), susten ta que é o mais importante parâmetro morfológico, porque a variação na produção de matéria seca está a ela associada. Che gando a afirmar que um dos principais objetivos no melhoramento genético é o aumento da área foliar da planta, por outro la do também afirma, que em uma cultura bem adubada e irrigada um aumento na área foliar não aumentará necessariamente a produção de matéria seca.

Tanto o ângulo das folhas como a densidade de população afetam a área foliar. A média da área foliar diminui com o aumento da densidade de população no plantio, HOYT e 
BRADFIELD (1962) •

Muitos estudiosos são de opinião que o conceito da ārea foliar é um tanto arbitrário pois além das folhas, outros órgãos da planta participam da fotossíntese, e que todos estes órgãos respiram. Afirmam, ainda, que é conveniente con siderar a área foliar em consequência de sua importância como principal órgão fotossintético. A eficiência pela qual a folhagem da planta intercepta e usa a radiação solar é sempre um fator limitante no processo fotossintético e na produção de matéria seca, WILLIAMS et alii (1965a, 1965b).

Tem-se desenvolvido conceitos referentes ao IAF ótimo e crítico. Monsi e Saeki (1953) citado por SAEKI (1963) provaram, teoricamente, a existência do IAF ótimo o que foi posteriormente confirmado em forma experimental por DAVID SON e DONALD (1958). O IAF ótimo corresponde ao ideal, em que a planta adquire seu máximo rendimento. KASANAGA e MONSI (1954) calcularam, para uma comunidade vegetal composta somen te por folhas ensolaradas, que o IAF ótimo é 3 , e para uma comunidade com folhas sombreadas e ensolaradas o IAF ótimo é 5 . Brougham (1958) citado igualmente por Saeki, definiu o IAF crí tico como o índice no qual $95 \%$ da luz incidente é interceptada pela planta, ao meio dia.

A medida que aumenta o IAF a absorção da ener gia luminosa e a taxa de produção de matéria seca também aumen tam, até um determinado limite, para depois diminuir, STERN et alii (1962); LOOMIS e WILLIAMS (1963) e BLACK (1963). Concordam, também, que o IAF é função da intensidade da radiação solar incidente em proporções adequadas, para cada espécie e variedade da cultura e com a estação do ano.

A taxa de crescimento do cultivo é definida por Watson, segundo citação de WILLIAMS et alii (1965b), como a acumulação de matéria seca para um tempo dado (dw/dt) e para uma área de terreno referida. $\bar{E}$ um conceito muito útil pois 
integra a produção de matéria seca à unidade de ārea, sendo es tas as mais comuns das medidas agronômicas. Williams comenta a opinião de Watson que as diferentes respostas na taxa de crescimento do cultivo com relação ao incremento do IAF devese às diferentes maneiras da disposição foliar das espécies.

Em pesquisas desenvolvidas sobre densidade de cultivos com relação a radiação solar AUBERTIN e PETERS (1961), determinaram a radiação líquida em uma cultura de milho, em parcelas com igual densidade de população mas com diferentes espaçamentos entre sulcos $(51 \mathrm{~cm}$ e $102 \mathrm{~cm})$. Planificaram o tra balho de tal forma que, quanto maior o espaçamento entre sulcos menor a separação das plantas entre fileiras. Os resulta dos mostraram que a radiação líquida no tratamento de $1.02 \mathrm{~cm}$ entre sulcos, foi maior tanto sobre como sob o cultivo, mas a energia absorvida pela planta foi maior no tratamento com $51 \mathrm{~cm}$ entre sulcos. Estas diferenças foram atribuídas à influência da distribuição espacial das plantas e seus hábitos de cresci:mento. 0 sombreamento mútuo da própria cobertura vegetal e a aplicação de produtos com propriedades refletivas, originaram um aumento no coeficiente de reflexão da radiação solar, reduzindo a radiação líquida sobre a cultura.

LINVILL e DALE (1975), estudaram os efeitos da radiação líquida de ondas curtas e condições de umidade do solo no crescimento e desenvolvimento do milho, em duas épocas de plantio e duas populações, uma de $42 \mathrm{mil}$ plantas/ha e a outra de $62 \mathrm{mil}$ plantas/ha. Concluiram que não houve uma diferença significativa na radiação líquida, na prodhção de grãos e na umidade do solo entre as duas populações. 0 espaçamento mais amplo e de menor população permitiu maior penetração de radiação solar a ser absorvida pelo solo. Conhecendo-se que a densidade de plantio e sua geometria afetam as medidas de radiação líquida em culturas de milho, os autores alertaram para a possibilidade de terem cometido erros pelos seguintes motivos: heterogeneidade da população, calibração instrumen- 
tal não precisa, poucas repetições e falta de dados na exigência de ägua para a cultura.

Tem-se desenvolvido diversos trabalhos sobre produção de matéria seca chegando-se à conclusão que altas den sidades de plantas provocam um mútuo sombreamento, que é responsāvel pela reduzida produção das folhas inferiores. Podese aumentar a eficiência da planta se as folhas superiores per mitirem a passagem da radiação solar através da folhagem, HOYT e BRADFIELD (1962); VERHAGEN et alii (1963); ALLISON (1964); ALLISON e WATSON (1966); WHIGHAM e WOOLLEY (1974).

Em uma estimativa do potencial de produtividade das culturas, LOOMIS e WILLIAMS (1963), baseados na quantidade total de energia solar que pode ser utilizada pelas plantas, no processo fotossintético e considerando as perdas por albedo, absorção inativa e respiração, chegaram teoricamente a calcular para uma superfície que recebe $500 \mathrm{cal} / \mathrm{cm}^{2} \cdot$ dia de radiação solar global a produção de matéria seca orgânica de $71 \mathrm{~g} / \mathrm{m}^{2}$. dia. Se os constituintes orgânicos representam $8 \%$ do peso seco (apro ximadamente $6 \mathrm{~g} / \mathrm{m}^{2} \cdot \mathrm{dia}$ ), o potencial de produtividade será então de $77 \mathrm{~g} / \mathrm{m}^{2} \cdot$ dia. Na prática a máxima produção de matéria seca encontrada em plantio normal de milho é de $52 \mathrm{~g} / \mathrm{m}^{2}$.dia pa ra um período de trabalho de 12 dias, WILLIAMS et alii. (1965a).

Segundo ALVIM e ALVIM (1969), que determinaram a eficiência fotossintética do milho e feijoeiro em diversas populações consorciadas e isoladas, observaram que a taxa de produção de matéria seca aumenta em proporção direta à densida de de plantas atingindo o valor máximo de $57,7 \mathrm{~g} / \mathrm{m}^{2} \cdot$ dia, na den sidade de $100 \mathrm{plantas} / \mathrm{m}^{2}$.

Realizaram-se estudos de laboratório que demons traram que as plantas podem converter, aproximadamente $10 \%$ de energia luminosa incidente em energia química correspondentes a substâncias orgânicas. Na prática tem-se encontrado somen- 
te um pouco mais de $2 \%$ sob condições ideais. WILLIAMS e JOSEPH (1974) comentam que existem muitas razões para explicar que esta porcentagem é menor que $2 \%$ quando se tem: baixa temperatura, baixa eficiência de conversão luminosa, pequena porcentagem da superfície do terreno coberta e baixa umidade no solo.

Geralmente, o peso seco é usado pelos pesquisadores, para definir a produção. Deve-se levar em conta que os principais fatores responsāveis pela produção de matéria se ca são a ārea foliar, a taxa de assimilação líquida e a radiação solar global incidente, MONTEITH (1969).

Tratando-se, especificamente, da produção de matéria seca das espigas DUNGAN et alii (1958), especificam que a produção diminui linearmente em altas densidades de plan tio, que é o resultado da baixa produção de carbohidratos pela planta, mas a produção aumenta por área cultivada para as popu lações mais densas. 0 principal fator causador da diminuição do número, dimensões e produção de espigas por planta é o sombreamento mútuo das plantas, que provêm de um aumento de população, PRINE e SCHRODER (1964); GALVÃo et alii (1969).

O albedo em uma superfície de Paspalum notatum não difere grandemente com os valores de albedo conseguidos pa ra as superfícies verdes naturais, sendo o valor médio de $17 \%$, SANTOS (1957).

GRAHAM e KING (1961), determinaram o valor do albedo de uma cobertura de milho, observando que o mesmo varia com a hora do dia, com a idade da planta, com a época do ano e com a umidade do solo. Os coeficientes mais altos são conseguidos nas horas da manhã e nas últimas horas da tarde, sendo portanto menores ao meio dia. Outros estudos mostraram que ocorre um decréscimo no valor do albedo com a diminuição do ân gulo zenital de aproximadamente $30 \%$ (MONTEITH, 1959; MONTEITH e SZEIC, 1961). O valor médio do albedo em uma cultura de mi tho é da ordem de 16 a $19 \%$ (SANTOS, 1978). 
4. MATERIAIS

\subsection{Localização do campo experimental}

A pesquisa efetuou-se no campo experimental do Departamento de Física e Meteorologia da Escola Superior de Agricultura "Luiz de Queiroz", da Universidade de São Paulo, situado a leste do Campus da Escola e com acesso pela rodovia da' Usina Monte Alegre.

Segundo o Serviço de Geodésia do Instituto Geográfico as parcelas experimentais estão localizadas nas coorde nadas geogräficas seguintes.

Latitude $22^{\circ} 42^{\prime} 30^{\prime \prime} \mathrm{Sul}$

LONGITUDE: $47^{\circ} 38^{\prime} 00^{\prime \prime}$ Oeste

ALTITUDE $576 \mathrm{~m}$ sobre o nivel do mar 
4.2. Solo

O solo corresponde ao grande grupo de Terra Roxa Estruturada da série Luiz de Queiroz (RANZANI et alii, 1966) e apresenta um perfil homogêneo, bastante permeável, com lençol freático localizado a vários metros de profundidade. pH médio é de 6,1. O teor de carbono orgânico na camada superficial é $1,5 \%$ diminuindo com a profundidade até um valor de $0,5 \%$ a $165 \mathrm{~cm}$. A densidade apresenta-se bastante uniforme, com valor médio de $2,71 \mathrm{~g} / \mathrm{cm}^{3}$. A porosidade total varia de 0,484 a $0,562 \mathrm{~cm}^{3} / \mathrm{cm}^{3}$ entre as profundidades de 15 e $165 \mathrm{~cm}$, segundo REICHARDT et alii (1976) e REICHARDT e LIBARDI (1974) que estudaram também as principais características físicas do solo, mostradas na tabela 1 .

Tabela 1. Características físicas do solo

\begin{tabular}{|c|c|c|c|c|c|}
\hline \multirow{2}{*}{\multicolumn{2}{|c|}{$\begin{array}{l}\text { Profundidade } \\
(\mathrm{cm})\end{array}$}} & \multicolumn{3}{|c|}{ Composição Granulométrica } & \multirow{2}{*}{ Classe Textural } \\
\hline & & $\because$ Argila & $\because$ Limo & $\because$ Areia & \\
\hline 0 & $-\quad 30$ & 60 & 17 & 23 & argila \\
\hline 30 & -60 & 63 & 23 & 14 & argila \\
\hline 60 & -90 & 55 & 26 & 19 & argila \\
\hline 90 & -120 & 52 & 26 & 22 & $\operatorname{argila}$ \\
\hline 120 & -150 & 54 & 24 & 22 & argila \\
\hline 150 & -180 & 49 & 28 & 23 & argila \\
\hline
\end{tabular}

4.3. Adub ação

No plantio foi efetuada uma adubação bāsica de NPK na seguinte proporção: $8,0 \mathrm{~g} / \mathrm{m}$ de uréia a $46 \% ; 50,0 \mathrm{~g} / \mathrm{m}$ de superfosfato simples a $20 \%$ e $5,0 \mathrm{~g} / \mathrm{m}$ de cloreto de potás- 
sio a $60 \%$. Aos 40 dias aplicou-se uréia a $46 \%$ em cobertura numa quantidade correspondente a $16 \mathrm{~g} / \mathrm{m}$.

\subsection{Variedade utilizada}

Utilizou-se a variedade CARGILL 501, híbrido du plo, precoce, adaptado às condições tropicais, com boa resistência ao acamamento e de boa produção.

\subsection{Equipamentos de medida}

Os fluxos de radiação $\mathrm{K} \downarrow, \mathrm{K} \uparrow, \mathrm{K}_{8} \downarrow, \mathrm{K}_{8} \uparrow$, albedo e a radiação solar transmitida através da cobertura vegetal $\mathrm{K}_{\mathrm{T}} \downarrow$ e $\mathrm{K}_{\mathrm{T} 8} \downarrow$, foram obtidas mediante dois piranômetros de preci são de fabricação norteamericana, construídos pela EPPLEY LABORATORY INC., de Newport. 0 sensor destes instrumentos . consiste em uma termopilha de junções múltiplas, protegido por duas hemisferas concêntricas de vidro ótico Schott, polido. A substituição da hemisfera externa por filtros pode ser efetuada facilmente. 0 piranômetro apresenta compensação elétrica por causa da dependência da sensibilidade em relação à tempera tura ambiental.

Um dos piranômetros foi utilizado com uma hemis fera transparente WG-7 que permite a passagem da radiação de comprimentos de onda de 0,285 a $2,800 \mu \mathrm{m}$ e o outro com filtro RG-8 que deixa passar a radiação de comprimentos de onda superiores a $0,7 \mu \mathrm{m}$.

terísticas técnicas:

Os piranômetros apresentavam as seguintes carac

Piranômetro com domo WG-7, Ne 11936 F3, com resistência interna de $660 \mathrm{ohms}$ a $24^{\circ} \mathrm{C}$ e compensação para tempe 
raturas entre $-20^{\circ} \mathrm{C}$ a $+40^{\circ} \mathrm{C}$. Comparações realizadas com os padrōes de referência forneceram uma resposta de $6,89 \mathrm{mV} / \mathrm{cal} \cdot \mathrm{cm}^{-2} \cdot \mathrm{min}^{-1}$.

Piranômetro com domo RG-8, $\mathrm{N}^{\circ}$ de série $13566 \mathrm{~F}_{3}$, com resistência interna de 715 ohms a $25^{\circ} \mathrm{C}$ e compensação para temperaturas entre $-20^{\circ} \mathrm{C}$ a $+40^{\circ} \mathrm{C}$. As comparações com os padrões de referência forneceram uma resposta de $6,42 \mathrm{mV} / \mathrm{cal} \cdot \mathrm{cm}^{-2} \cdot \mathrm{min}^{-1}$.

Como sistema de adquisição de dados foi usado um potenciômetro portātil $\mathrm{N}^{\circ} 700009$, tipo 44228 , fabricado pe1a CAMBRIDGE INSTRUMENT CO., da Inglaterra. A capacidade do potenciômetro é de dois canais, podendo obter-se duas medidas em tempos relativamente curtos, com uma precisão de $\pm 0,1 \%$ da leitura realizada ou $5 \mu \mathrm{V}$.

A secagem das diferentes partes da planta foi realizada em duas estufas, de marca FANEM e FABBE (modelo 171), ambas com ventilação forçada.

Para a pesagem das amostras da planta e de sementes empregou-se balanças elétricas com aproximação de $10 \mathrm{mg}$ e $100 \mathrm{mg}$ respectivamente.

A umidade das sementes foi obtida de acordo com a técnica internacional recomendada, empregando-se o divisor Gamet, marca BURROWS, que homogeniza e divide a amostra média, obtendo-se duas repetições. 
16.

5. MÉTODOS

\subsection{Präticas culturais}

A pesquisa foi planejada para três tratamentos com diferentes densidades de plantio, as parcelas plantadas eram de dimensões de $20 \mathrm{~m}$ de comprimento por $10 \mathrm{~m}$ de largura $\left(200 \mathrm{~m}^{2}\right)$, sendo separadas de $1 \mathrm{~m}$. Os sulcos foram orientados na direção Norte-Sul. 0 plantio foi efetuado no dia 24-11-78. Os tratamentos foram os seguintes:

\section{Tratamento}

Parcela considerada de plantio normal ou testemunha, com separação entre sulcos de $1,00 \mathrm{~m}$ e entre as plantas de $0,20 \mathrm{~m}$. 0 número total de plantas nos $200 \mathrm{~m}^{2}$ foi de 1.000 e um número teórico de 50.000 plantas por hectare. 


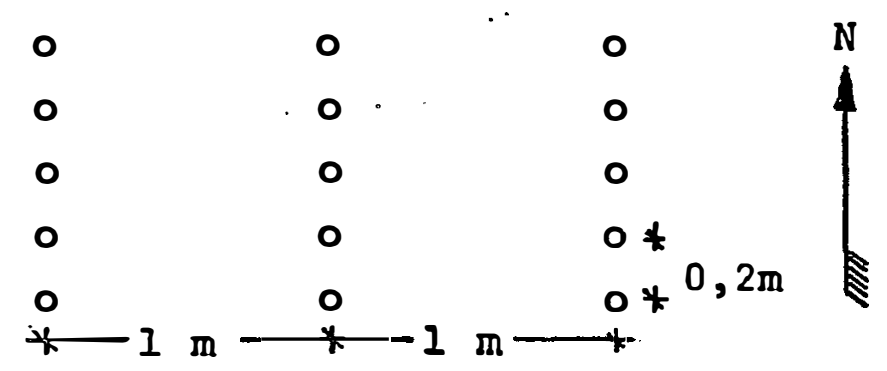

2: Tratamento

Parcela com duas linhas distanciadas uma da outra de $0,50 \mathrm{~m}$ e este conjunto distanciado $1,00 \mathrm{~m}$ de um outro de duas linhas, a separação entre plantas era de $0,20 \mathrm{~m}$. 0 número total de plantas nos $200 \mathrm{~m}^{2}$ foi de 1.333 , perfazendo um número teórico de 66.667 plantas por hectare.

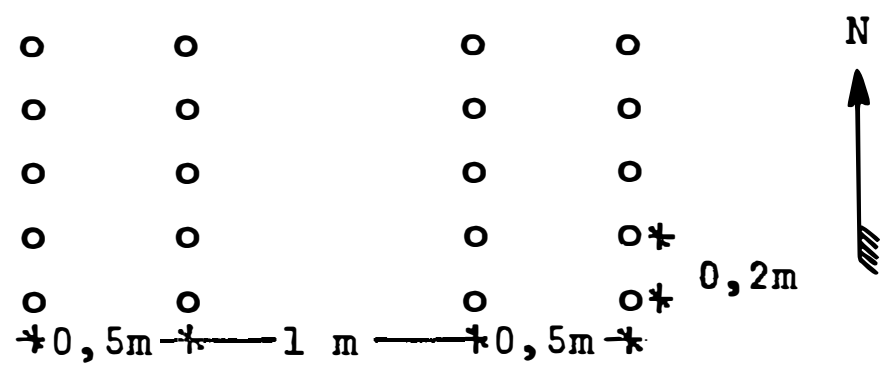


$\mathrm{Na}$ parcela denominada de quincôncio, as plantas distribuiram-se equidistantemente formando triângulos equiláte ros de tal forma que por todos os lados as plantas encontravam se alinhadas. 0 lado dos triângulos tinha 0,3 ș. 0 número total de plantas nos $200 \mathrm{~m}^{2}$ foi de 1.960 perfazendo um número teórico de 98.039 plantas por hectare.

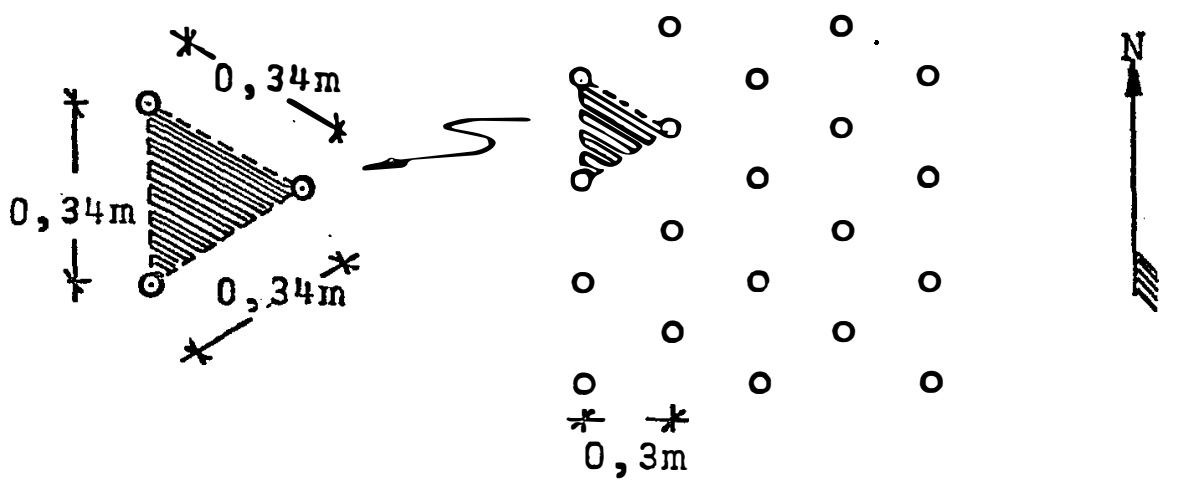

As parcelas estavam localizadas no campo experi mental, de acordo com o esquema da fig." 1 .

Em cada parcela planejou-se uma bordadura de $1,00 \mathrm{~m}$, não se considerando as plantas situadas dentro destas āreas.

Ao efetuar-se o plantio colocou-se duas sementes por cova, realizando-se o desbaste no dia 18-12-78, deixan do-se uma planta por cova. Ao notar-se um ligeiro ataque da lagarta do cartucho, spodoptera frugiperda, efetuou-se uma pul verização com folidol no dia 19-12-78. Durante o experimento foram necessárias duas capinas. 


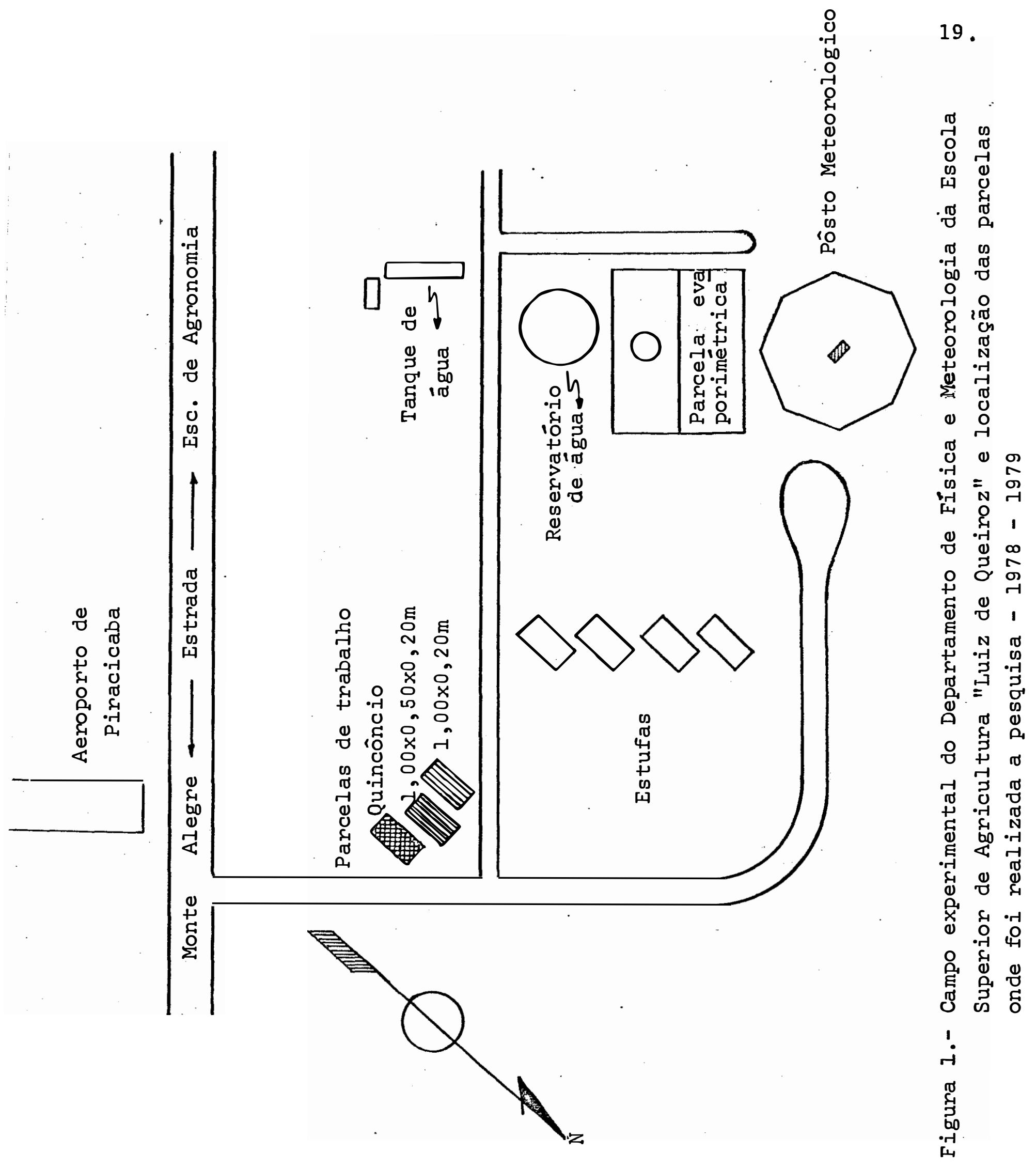




\subsection{Balanço da radiação solar global de ondas} curtas 0,3 a $3,0 \mu \mathrm{m}$.

A equação utilizada no cálculo do balanço de ra diação solar global de onda curta sobre uma superfície plana e horizontal é a seguinte:

$$
Q^{*}=(1-\alpha)\left(K_{D} \downarrow+K_{d} \downarrow\right)+(L \downarrow+L \uparrow)
$$

Desde que o balanço de radiação solar global de ondas curtas é dado por:

$$
K^{*}=(1-\alpha)\left(K_{D} \downarrow+K_{d} \downarrow\right)
$$

e o balanço de radiação de ondas longas igual a:

$$
L^{*}=(L \downarrow-L \uparrow)
$$

A equação (1) pode ser assim expressa:

$$
Q^{*}=K^{*}+L^{*}
$$

$\mathrm{Na}$ pesquisa é de interesse a equação (2), que corresponde ao balanço de radiação solar global de ondas curtas. Desenvolvendo esta equação e considerando os albedos específicos para cada um dos fluxos, tem-se:

$$
K^{*}=K_{D} \downarrow-\alpha_{D} K_{D}++K_{d} \downarrow-\alpha_{d} K_{d}
$$

Como

$$
\begin{aligned}
& \alpha_{D \mathrm{D}^{\downarrow}}=\mathrm{K}_{\mathrm{D}^{\uparrow}} \quad \mathrm{e} \\
& \alpha_{\mathrm{d}} \mathrm{K}_{\mathrm{d}^{\downarrow}}=\mathrm{K}_{\mathrm{d}^{\uparrow}}
\end{aligned}
$$


Substituindo (6) e (7) em (5), a expressão fica:

$$
\mathrm{K}^{*}=\mathrm{K}_{\mathrm{D}^{\downarrow}}-\mathrm{K}_{\mathrm{D}^{\uparrow}}^{\uparrow}+\mathrm{K}_{\mathrm{d}^{\downarrow}}-\mathrm{K}_{\mathrm{d}}^{\uparrow}
$$

Agrupando a expressão, segundo os sentidos dos fluxos:

$$
K^{*}=\left(K_{D^{\dagger}}+K_{d^{\dagger}}\right)-\left(K_{D} \uparrow+K_{d} \uparrow\right)
$$

Como

$$
\begin{aligned}
& K_{\uparrow}=K_{D} \downarrow+K_{d} \downarrow \quad e \\
& K_{\uparrow}=K_{D} \uparrow+K_{d} \uparrow
\end{aligned}
$$

Substituindo as expressões (10) e (11) em (9), tem-se finalmen te:

$$
\mathrm{K}^{*}=\mathrm{K} \downarrow-\mathrm{K} \uparrow
$$

A equação (12) expressa o balanço de radiação de ondas curtas considerando-se as densidades de fluxos de radiação solar direta e difusa, em forma conjunta, pois o piranô metro utilizado com domo WG-7 vai permitir a passagem de comprimentos de onda $(\lambda)$ na faixa 0,3 a $3,0 \mu \mathrm{m}$.

\subsection{Balanço da irradiância fotossintética}

A radiação fotossinteticamente ativa (PHAR) é a faixa que corresponde ao espectro da radiação emitida ou recebida entre os comprimentos de onda de $0,4-0,7 \mu \mathrm{m}$. Foi neces sário determinā-1á para saber como estes fluxos de radiação se comportavam através da cobertura vegetal. A diferença das densidades dos fluxos de radiação solar utilizando piranômetros com e sem filtro, permitiram a estimativa dos valores da irradiância fotossintética (PI), que é a energia radiante 
$(0,4-0,7 \mu \mathrm{m})$ incidente na unidade de tempo sobre a unidade de superfície, SANTOS (1978).

Considerando-se os fluxos de radiação medidos com piranômetros acoplados com filtro RG-8 temos, conforme mos trado na equação (9), a seguinte expressão:

$$
\mathrm{K}_{8}^{*}=\left(\mathrm{K}_{\mathrm{D} 8} \downarrow+\mathrm{K}_{\mathrm{d} 8} \downarrow\right)-\left(\mathrm{K}_{\mathrm{D} 8} \uparrow+\mathrm{K}_{\mathrm{d} 8} \uparrow\right)
$$

o que resulta em:

$$
K_{8}^{*}=K_{8} \uparrow-K_{8} \uparrow
$$

Fazendo-se a diferença das equações (12) e (14) teremos:

$$
\mathrm{K}^{*}-\mathrm{K}_{8}^{*}=(\mathrm{K} \downarrow-\mathrm{K} \uparrow)-\left(\mathrm{K}_{8} \downarrow-\mathrm{K}_{8} \uparrow\right)
$$

Eliminando-se os parênteses:

$$
\mathrm{K}^{*}-\mathrm{K}_{8}^{*}=\mathrm{K} \downarrow-\mathrm{K} \uparrow-\mathrm{K}_{8} \downarrow+\mathrm{K}_{8} \uparrow
$$

E reag rupando:

$$
K-K_{8}^{*}=\left(K \downarrow-K_{8} \downarrow\right)-\left(K \uparrow-K_{8} \uparrow\right)
$$

Finalmente:

$$
\mathrm{PI}{ }^{*}=\mathrm{PI}+-\mathrm{PI} \uparrow
$$

Pode-se expressar graficamente os fluxos obtidos pelos piranômetros com domos WG-7 e RG-8, o que é mostrado na fig. 2 . 


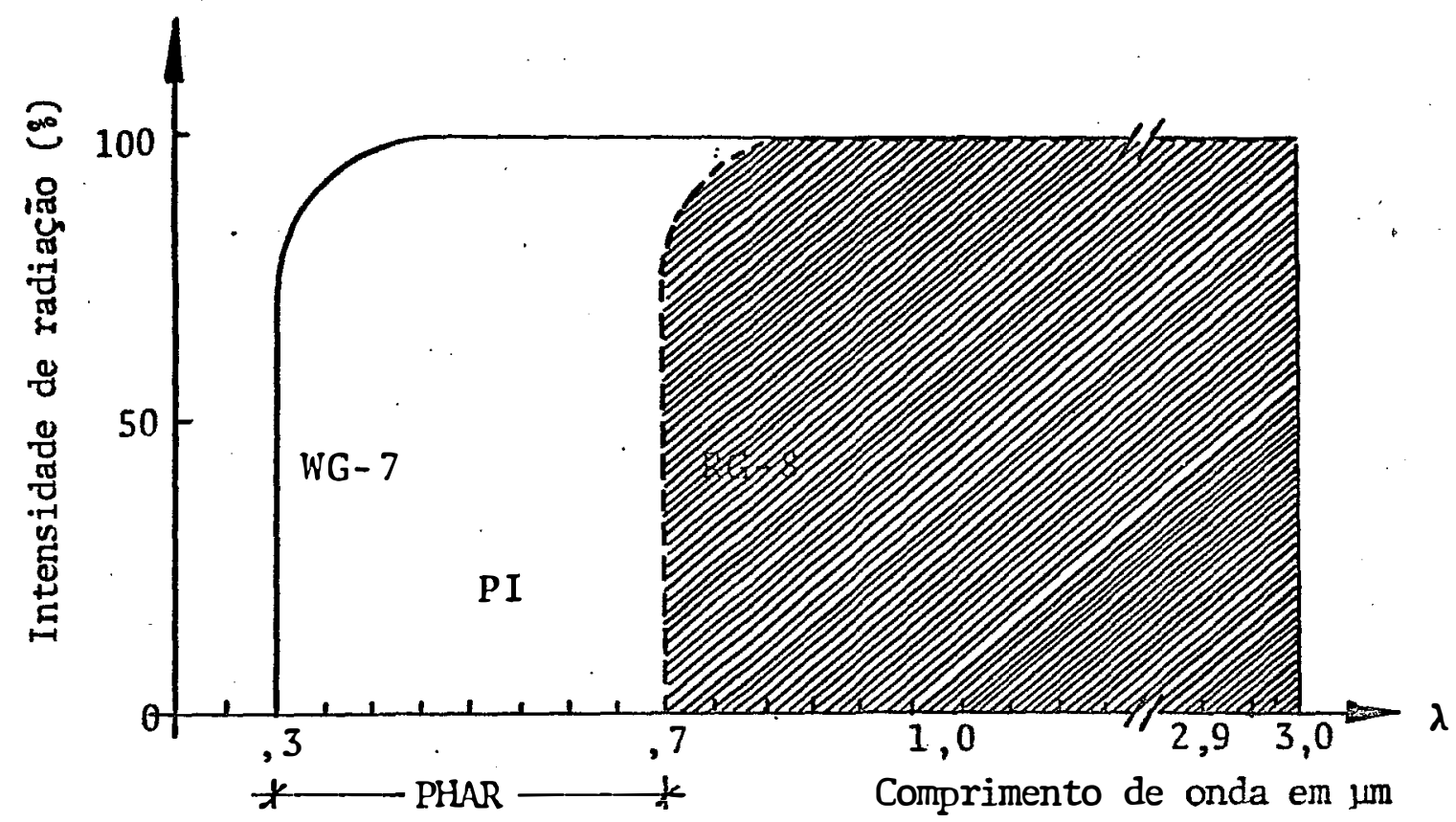

Fig. 2. (-) - Intensidade de radiação obtida pelo piranômetro sem filtro (com domo transparente WG-7), entre os comprimen tos de onda $(\lambda) 0,3$ a $3,0 \mu \mathrm{m}$.

(---) - Intensidade de radiação obtida pelo piranômetro com filtro RG-8 que de $\underline{i}$ xa passar somente comprimentos de onda $(\lambda)$ superiores a $0,7 \mu \mathrm{m}$.

A diferença das āreas fechadas pelas curvas apresentaram, como saldo, uma superfície que corresponde à irradiância fotossintética (PI).

Pelas expressōes analíticas deduz-se que foi necessário medir as densidades dos fluxos de radiação sobre a cobertura vegetal, tanto da radiação solar global de ondas cur tas de cima para baixo $(K \downarrow)$ e as de sentido contrário $(K \uparrow)$, as sim como da radiação com comprimentos de onda superiores de $0,695 \mu \mathrm{m}$ também de cima para baixo $\left(K_{8} \downarrow\right)$ como de baixo para cí ma $\left(\mathrm{K}_{8} \uparrow\right)$. Os instrumentos encontravam-se aproximadamente a $1,00 \mathrm{~m}$ sobre as plantas (figs. $3 a$ e $3 b$ ). 


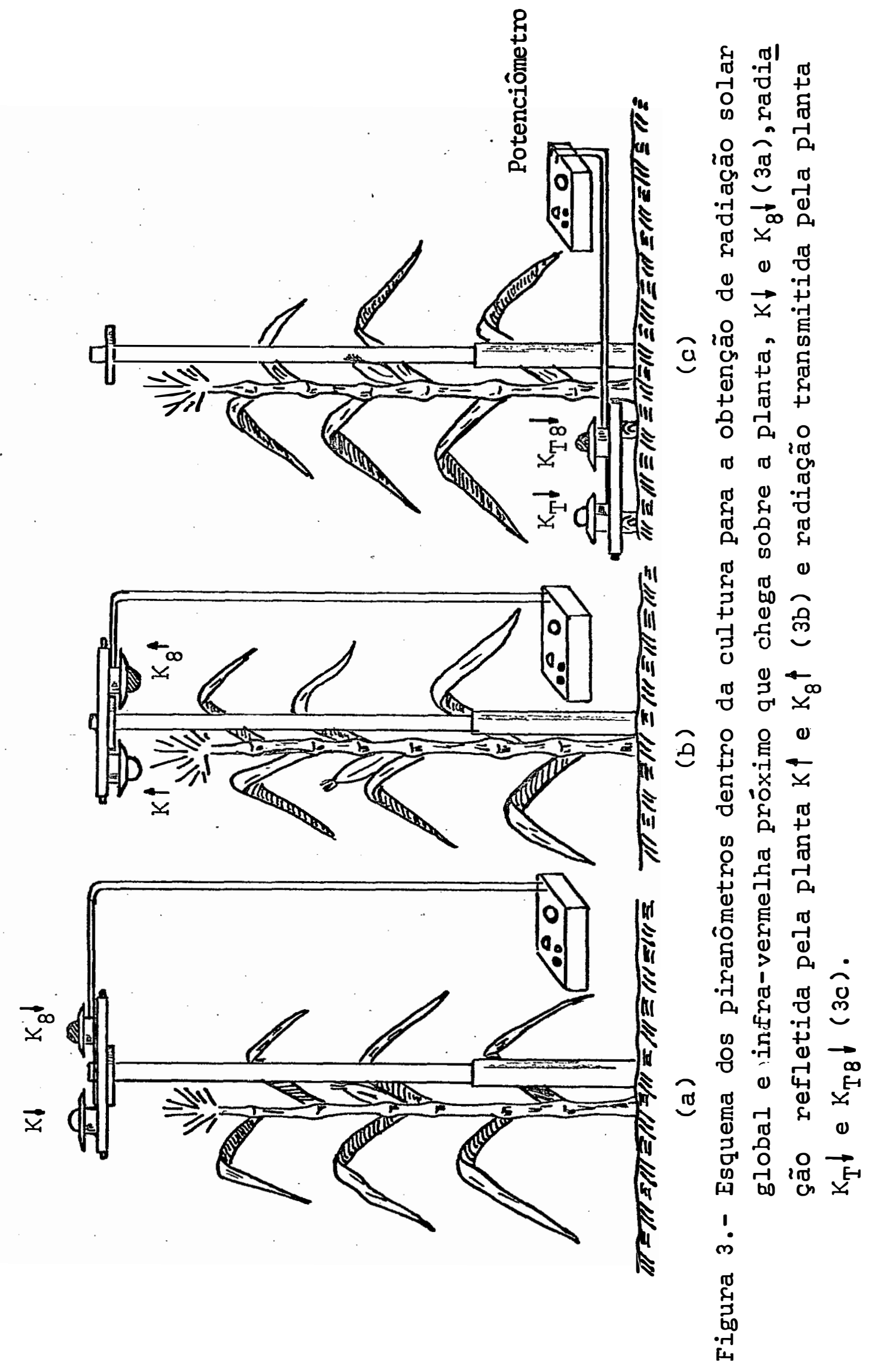


Os piranômetros foram instalados numa base retangular de madeira completamente plana, onde os instrumentos foram nivelados e fixados com parafusos. Colocava-se este conjunto na extremidade de um mastro de ferro galvanizado de 4,00m de comprimento sobre outra base metálica plana dé forma circular. A base de madeira prendia-se ao mastro por intermé dio de um orifício na parte central (fig. 4).

Além da determinação das densidades dos fluxos mencionados, foram realizadas medidas ao nível do solo utilizando-se os mesmos piranômetros, colocando-se a base de madeira sobre 4 estacas previamente niveladas (fig. 3c) com o objetivo de determinar os fluxos de radiação solar que conseguiam atravessar a cobertura vegetal. Estes valores foram obtidos sempre à sombra, considerando-se que as medidas de radiação nos "sunflecks" deveriam ser aproximadamente iguais às leituras feitas sobre as plantas.

As leituras dos fluxos de radiação para cada tratamento efetuaram-se a cada 30 minutos em dias descobertos, e durante um período de dois dias.

5.4. Determinação da altura, ārea foliar, 'índice de ārea foliar, matéria seca das plantas e produção de grãos.

A partir do dia 20-12-78 até o 01-03-79 efetuaram-se 6 amostragens, em intervalos de 14 dias, utilizandose para cada amostragem o seguinte critério: tomava-se, ao acaso, 10 plantas que serviriam para a determinação da altura, área foliar, índice de área foliar e matéria seca. Para a altura das plantas media-se seu comprimento desde a superfície do solo até a base da última folha em sua inserção.

A ārea foliar determinou-se medindo o comprimen to e a maior largura da lâmina foliar, o produto destes dois 

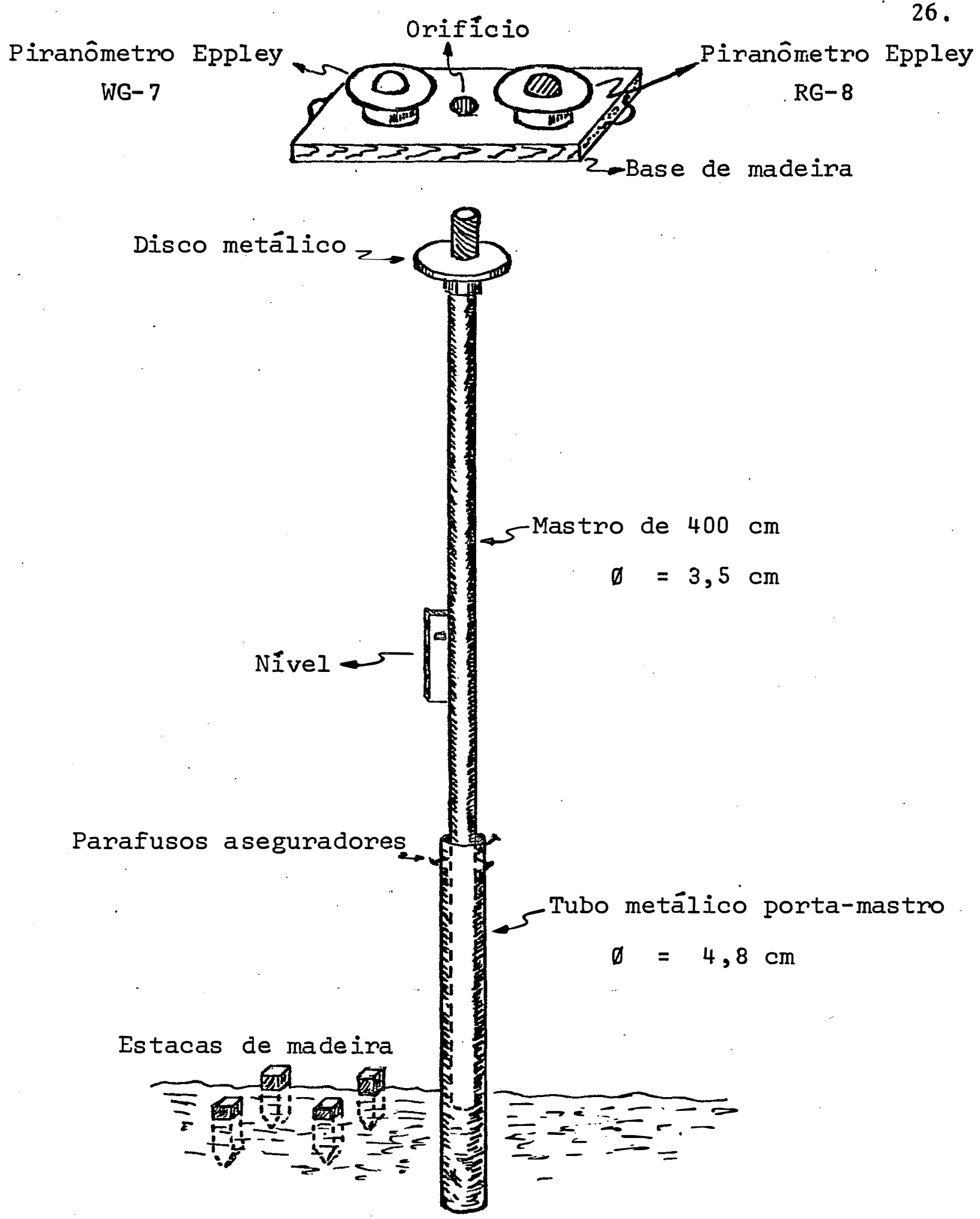

Figura 4.- Detalhe do mastro e base de madeira para os piranômetros Eppley. 
valores multiplicados por um fator que, segundo FRANCIS et alii. (1969), é de 0,75, corresponderia à área da folha.

0 quociente da ārea foliar média estimada, pela ärea de solo explorada por uma planta, em cada tratamento, for neceu o indice de área foliar em $\mathrm{cm}^{2}$ de folhagem por $\mathrm{cm}^{2}$ de solo.

Para a determinação da matéria seca das diferen tes partes da planta em cada um dos tratamentos foi usado o método de pesagem do material seco em relação ao tempo. As partes consideradas foram: folhas, caule, panícula, espiga e palha da espiga. As amostras foram secas em estufas a $70^{\circ} \mathrm{C}$ por um período de tempo de 120 horas.

$\mathrm{Na}$ determinação da produção de grãos em cada um dos tratamentos em $\mathrm{kg} / \mathrm{ha}$ considerou-se uma área de $10 \mathrm{~m}^{2}$ (super fície considerada como uma amostra representativa de toda a parcela). Colheu-se as espigas desta área, calculando-se pos teriormente em forma proporcional a produção para uma hectare. Das espigas obteve-se também seu comprimento, diâmetro e peso médio, assim como o rendimento em peso dos grãos por hectare. Para uma comparação de produção entre tratamentos determinouse a porcentagem de umidade dos grãos mediante o método de pesagem e secagem em estufa a $105^{\circ} \mathrm{C} \pm 3^{\circ} \mathrm{C}$ durante 24 horas. 
As medidas dos fluxos de radiação solar global de ondas curtas e infra-vermelha próxima realizadas no campo, acima e sob a cultura de milho mostram-se nas tabelas 2 a 7 . Nota-se, em todos os quadros, que da radiação solar que chega no topo da cultura uma parte dela é absorvida e a outra é refletida e transmitida através da cobertura vegetal, chegando à superfície do solo um pequeno fluxo de energia, apreciando-se claramente um gradiente energético dentro da cultura.

A variação média da radiação solar global e da radiação acima de $0,7 \mu \mathrm{m}$ que chega sobre as plantas, se indicam nas tabelas 8 a 10 , assim mesmo mostram-se a relação $\frac{\overline{\mathrm{K}}_{8} \downarrow}{\overline{\mathrm{K}} \downarrow}$ que expressa a quantidade de radiação que se encontra na faixa do infra-vermelha próxima com relação à energia global, esta rela ção é da ordem de 0,49 , isto quer dizer, que quase a metade da radiação solar encontra-se na faixa do infra-vermelha (fig. 5). A quantidade obtida difere em aproximadamente 4\%: do valor cal- 
culado no hemisfério norte pelo Smithsonian Radiation Biology Laboratory em diferentes lugares da América, segundo citado por SANTOS (1978) e difere em 0,01 unidades com o valor calculado pelo mesmo autor em sua pesquisa com milho, utilizando a varie dade Piranão.

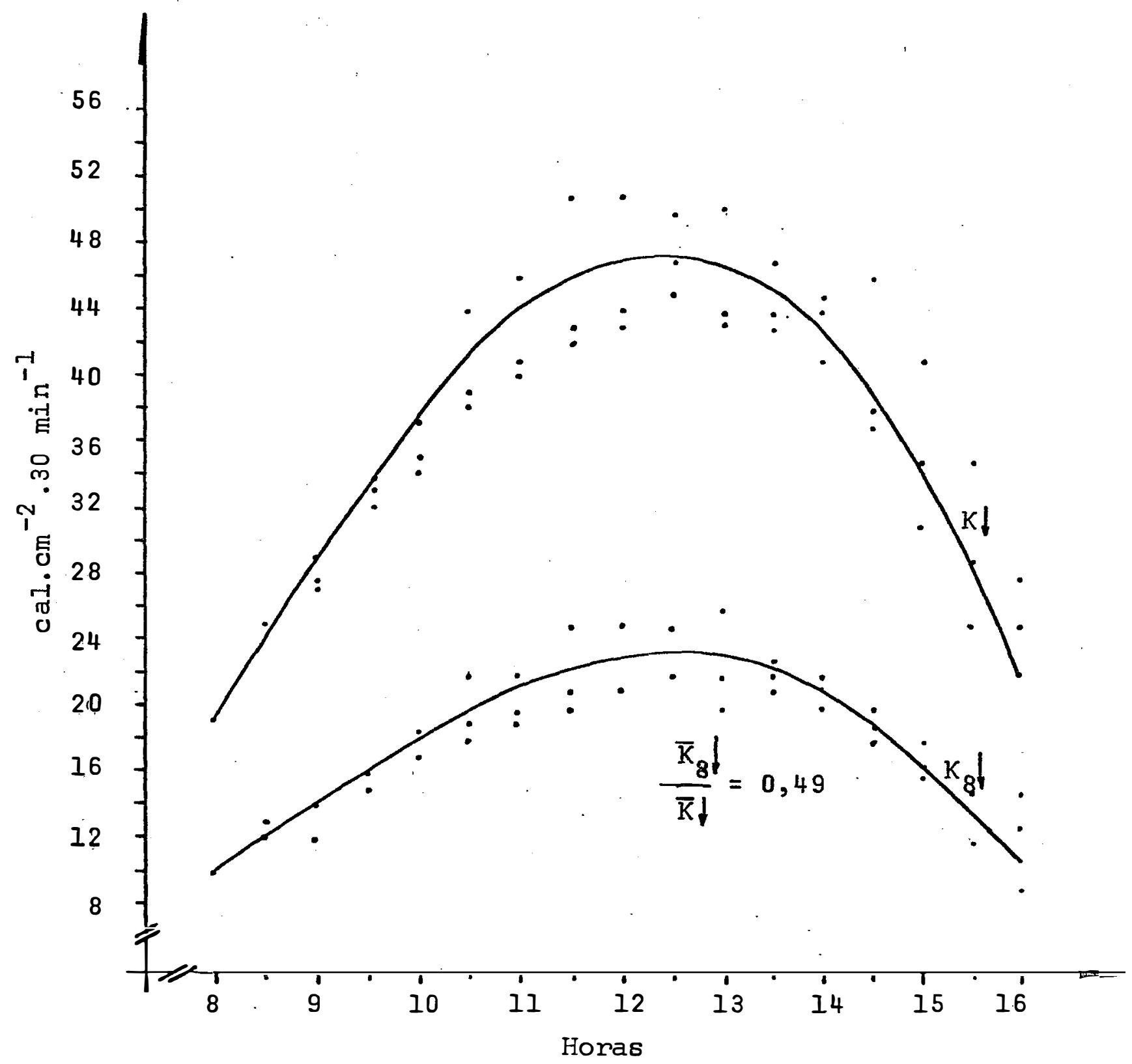

Figura 5.- Variação média dos fluxos $K_{\downarrow}$ e $k_{8} \downarrow$, em milho (média de seis dias de observação). 
Tabela 2. Densidade dos fluxos de radiação global e fotossinte ticamente ativa $\left(\mathrm{cal} \cdot \mathrm{cm}^{-2} \cdot \mathrm{min}^{-1}\right)$ do dia 27-02-79 para milho (zea mays L. var. Cargill 501), no tratamento $1,00 \mathrm{~m} \times 0,50 \mathrm{~m} \times 0,20 \mathrm{~m}$.

\begin{tabular}{rrrrrrrr}
\hline \multirow{2}{*}{ HORA } & \multicolumn{2}{c}{ Rad. acima da cobertura vegetal } & \multicolumn{2}{c}{ Rad. na sup. do solo } \\
\cline { 2 - 7 } & \multicolumn{1}{c}{$\mathrm{K} \mathrm{K}_{8}{ }^{\dagger}$} & $\mathrm{K} \uparrow$ & $\mathrm{K}_{8}{ }^{\dagger}$ & $\mathrm{K}_{\mathrm{T}}{ }^{\dagger}$ & $\mathrm{K}_{\mathrm{T} 8}{ }^{\dagger}$ \\
\hline $8: 00$ & 0,582 & 0,323 & 0,141 & 0,129 & 0,107 & 0,105 \\
$8: 30$ & 0,761 & 0,399 & 0,170 & 0,147 & 0,119 & 0,103 \\
$9: 00$ & 0,875 & 0,445 & 0,169 & 0,168 & 0,138 & 0,140 \\
$9: 30$ & 1,073 & 0,495 & 0,164 & 0,130 & 0,100 & 0,081 \\
$10: 00$ & 1,156 & 0,559 & 0,172 & 0,154 & 0,123 & 0,096 \\
$10: 30$ & 1,297 & 0,603 & 0,188 & 0,156 & 0,138 & 0,109 \\
$11: 00$ & 1,340 & 0,629 & 0,187 & 0,156 & 0,117 & 0,084 \\
$11: 30$ & 1,411 & 0,640 & 0,186 & 0,150 & 0,119 & 0,092 \\
$12: 00$ & 1,436 & 0,650 & 0,146 & 0,141 & 0,118 & 0,076 \\
$12: 30$ & 1,528 & 0,711 & 0,181 & 0,132 & 0,117 & 0,103 \\
$13: 00$ & 1,391 & 0,652 & 0,158 & 0,119 & 0,104 & 0,082 \\
$13: 30$ & 1,436 & 0,695 & 0,197 & 0,182 & 0,127 & 0,125 \\
$14: 00$ & 1,463 & 0,683 & 0,212 & 0,189 & 0,155 & 0,149 \\
$14: 30$ & 1,437 & 0,659 & 0,201 & 0,173 & 0,146 & 0,147 \\
$15: 00$ & 1,329 & 0,591 & 0,189 & 0,131 & 0,147 & 0,117 \\
$15: 30$ & 1,150 & 0,503 & 0,177 & 0,129 & 0,134 & 0,111 \\
$16: 00$ & 0,909 & 0,482 & 0,143 & 0,120 & 0,097 & 0,078 \\
\hline
\end{tabular}


Tabela 3. Densidade dos fluxos de radiação global e fotossinte ticamente ativa $\left(\mathrm{cal} \cdot \mathrm{cm}^{-2} \cdot \mathrm{min}^{-1}\right)$ do dia 28-02-79 para milho (zea mays L. var. Cargill501), no trata mento $1,00 \mathrm{~m} \times 0,50 \mathrm{~m} \times 0,20 \mathrm{~m}$.

\begin{tabular}{|c|c|c|c|c|c|c|}
\hline \multirow{2}{*}{ HORA } & \multicolumn{4}{|c|}{ Rad. acima da cobertura vegetal } & \multicolumn{2}{|c|}{ Rad. na sup. do solo } \\
\hline & $K \downarrow$ & $\mathrm{K}_{8}{ }^{+}$ & $\mathrm{K} \uparrow$ & $K_{8} \uparrow$ & $\mathrm{K}_{\mathrm{T}}$ & $\mathrm{K}_{\mathrm{T} 8}{ }^{\downarrow}$ \\
\hline $8: 00$ & 0,684 & 0,345 & 0,167 & 0,143 & 0,123 & 0,119 \\
\hline $8: 30$ & 0,829 & 0,411 & 0,186 & 0,165 & 0,151 & 0,145 \\
\hline $9: 00$ & 0,911 & 0,489 & 0,215 & 0,204 & 0,184 & 0,172 \\
\hline $9: 30$ & 1,107 & 0,549 & 0,218 & 0,206 & 0,142 & 0,133 \\
\hline $10: 00$ & 1,202 & 0,601 & 0,210 & 0,190 & 0,157 & 0,156 \\
\hline $10: 30$ & 1,299 & 0,642 & 0,216 & 0,196 & 0,166 & 0,169 \\
\hline $11: 00$ & 1,344 & 0,681 & 0,215 & 0,206 & 0,163 & 0,148 \\
\hline $11: 30$ & $1,510^{\circ}$ & 0,754 & 0,234 & 0,208 & 0,199 & 0,166 \\
\hline $12: 00$ & 1,482 & 0,740 & 0,238 & 0,213 & 0,222 & 0,168 \\
\hline $12: 30$ & 1,626 & 0,761 & 0,237 & 0,208 & 0,181 & 0,159 \\
\hline $13: 00$ & 1,453 & 0,672 & 0,162 & 0,145 & 0,148 & 0,104 \\
\hline $13: 30$ & 1,506 & 0,729 & 0,233 & 0,214 & 0,273 & 0,163 \\
\hline $14: 00$ & 1,481 & 0,753 & 0,240 & 0,211 & 0,249 & 0,215 \\
\hline $14: 30$ & 1,471 & 0,681 & 0,213 & 0,207 & 0,240 & 0,181 \\
\hline $15: 00$ & 1,387 & 0,607 & 0,195 & 0,175 & 0,213 & 0,153 \\
\hline $15: 30$ & 1,204 & 0,509 & 0,185 & 0,171 & 0,182 & 0,117 \\
\hline $16: 00$ & 0,951 & 0,488 & 0,147 & 0,138 & 0,099 & 0,086 \\
\hline
\end{tabular}


Tabela 4. Densidade dos fluxos de radiação global e fotossinte ticamente ativa $\left(\mathrm{cal} \cdot \mathrm{cm}^{-2} \cdot \mathrm{min}^{-1}\right)$ do dia 09-03-79 para milho (zea mays L. var. Cargill501), no trata mento Quincôncio.

\begin{tabular}{|c|c|c|c|c|c|c|}
\hline \multirow{2}{*}{ HORA } & \multicolumn{4}{|c|}{ Rad. acima da cobertura vegetal } & \multicolumn{2}{|c|}{ Rad. na sup. do solo } \\
\hline & $\mathrm{K} \downarrow$ & $K_{8}{ }^{\downarrow}$ & $\mathrm{K} \uparrow$ & $K_{8}{ }^{\uparrow}$ & $\mathrm{K}_{\mathrm{T}}{ }^{t}$ & $\mathrm{~K}_{\mathrm{T} 8}{ }^{+}$ \\
\hline $8: 00$ & 0,660 & 0,334 & 0,134 & 0,124 & 0,109 & 0,073 \\
\hline $8: 30$ & 0,815 & 0,424 & 0,176 & 0,156 & 0,125 & 0,122 \\
\hline $9: 00$ & 0,905 & 0,458 & 0,186 & 0,166 & 0,133 & 0,116 \\
\hline $9: 30$ & 1,068 & 0,517 & 0,195 & 0,180 & 0,138 & 0,142 \\
\hline $10: 00$ & 1,149 & 0,590 & 0,202 & 0,190 & 0,145 & 0,138 \\
\hline $10: 30$ & 1,278 & 0,633 & 0,214 & 0,189 & 0,167 & 0,149 \\
\hline $11: 00$ & 1,343 & 0,655 & 0,206 & 0,175 & 0,174 & 0,131 \\
\hline $11: 30$ & 1,376 & 0,667 & 0,211 & 0,194 & 0,170 & 0,136 \\
\hline $12: 00$ & 1,434 & 0,706 & 0,219 & 0,193 & 0,178 & 0,138 \\
\hline $12: 30$ & 1,467 & 0,697 & 0,211 & 0,180 & 0,156 & 0,138 \\
\hline $13: 00$ & 1,383 & 0,681 & 0,216 & 0,195 & 0,154 & 0,121 \\
\hline $13: 30$ & 1,412 & 0,704 & 0,226 & 0,186 & 0,163 & 0,149 \\
\hline $14: 00$ & 1,292 & 0,665 & 0,209 & 0,153 & 0,136 & 0,103 \\
\hline $14: 30$ & 1,141 & 0,579 & 0,201 & 0,154 & 0,116 & 0,100 \\
\hline $15: 00$ & 0,990 & 0,494 & 0,193 & 0,156 & 0,096 & 0,095 \\
\hline $15: 30$ & 0,802 & 0,401 & 0,168 & 0,147 & 0,087 & 0,081 \\
\hline $16: 00$ & 0,605 & 0,292 & 0,139 & 0,099 & 0,065 & 0,057 \\
\hline
\end{tabular}


Tabela 5. Densidade dos fluxos de radiação global e fotossinte ticamente ativa $\left(\mathrm{cal} \cdot \mathrm{cm}^{-2} \cdot \mathrm{min}^{-1}\right)$ do dia 10-03-79 para milho (Zea mays L. var. Cargil1501), no trata mento Quincôncio.

\begin{tabular}{rccccccc}
\hline HORA & \multicolumn{2}{c}{ Rad. acima da cobertura vegetal } & \multicolumn{2}{c}{ Rad. na sup. do solo } \\
& \multicolumn{1}{c}{$\mathrm{K} \downarrow$} & $\mathrm{K}_{8}{ }^{\dagger}$ & $\mathrm{K} \uparrow$ & $\mathrm{K}_{8}{ }^{\dagger}$ & $\mathrm{K}_{\mathrm{T}}{ }^{\downarrow}$ & $\mathrm{K}_{\mathrm{T}}{ }^{\downarrow}$ \\
\hline $8: 00$ & 0,584 & 0,310 & 0,140 & 0,132 & 0,093 & 0,073 \\
$8: 30$ & 0,785 & 0,380 & 0,162 & 0,140 & 0,133 & 0,112 \\
$9: 00$ & 0,923 & 0,458 & 0,178 & 0,164 & 0,141 & 0,120 \\
$9: 30$ & 1,040 & 0,507 & 0,195 & 0,172 & 0,146 & 0,128 \\
$10: 00$ & 1,123 & 0,562 & 0,196 & 0,178 & 0,167 & 0,132 \\
$10: 30$ & 1,232 & 0,593 & 0,204 & 0,181 & 0,179 & 0,137 \\
$11: 00$ & 1,359 & 0,637 & 0,200 & 0,195 & 0,158 & 0,131 \\
$11: 30$ & 1,414 & 0,683 & 0,219 & 0,182 & 0,164 & 0,142 \\
$12: 00$ & 1,456 & 0,712 & 0,217 & 0,195 & 0,176 & 0,124 \\
$12: 30$ & 1,515 & 0,779 & 0,241 & 0,198 & 0,212 & 0,162 \\
$13: 00$ & 1,523 & 0,769 & 0,242 & 0,215 & 0,162 & 0,123 \\
$13: 30$ & 1,442 & 0,738 & 0,222 & 0,202 & 0,177 & 0,145 \\
$14: 00$ & 1,428 & 0,687 & 0,255 & 0,179 & 0,174 & 0,141 \\
$14: 30$ & 1,283 & 0,663 & 0,171 & 0,156 & 0,158 & 0,150 \\
$15: 00$ & 1,086 & 0,568 & 0,229 & 0,202 & 0,146 & 0,109 \\
$15: 30$ & 0,860 & 0,461 & 0,180 & 0,159 & 0,097 & 0,087 \\
$16: 00$ & 0,615 & 0,330 & 0,141 & 0,119 & 0,075 & 0,067 \\
\hline
\end{tabular}


Tabela 6. Densidade dos fluxos de radiação global e fotossinte ticamente ativa $\left(\mathrm{cal} \cdot \mathrm{cm}^{-2} \cdot \mathrm{min}^{-1}\right)$ do dia 03-03-79 para milho (zea mays L. var. Cargill501),, no tratamento $1,00 \mathrm{~m} \times 0,20 \mathrm{~m}$.

\begin{tabular}{rccccccc}
\hline \multirow{2}{*}{ HORA } & \multicolumn{2}{c}{ Rad., acima da cobertura vegetal } & \multicolumn{2}{c}{ Rad. na sup. do solo } \\
\cline { 2 - 7 } & $\mathrm{K} \downarrow$ & $\mathrm{K}_{8} \downarrow$ & $\mathrm{K} \uparrow$ & $\mathrm{K}_{8} \uparrow$ & $\mathrm{K}_{\mathrm{T}}{ }^{\downarrow}$ & $\mathrm{K}_{\mathrm{T} 8}{ }^{\downarrow}$ \\
\hline $8: 00$ & 0,571 & 0,219 & 0,146 & 0,148 & 0,134 & 0,109 \\
$8: 30$ & 0,789 & 0,340 & 0,174 & 0,185 & 0,166 & 0,123 \\
$9: 00$ & 0,927 & 0,312 & 0,155 & 0,146 & 0,143 & 0,086 \\
$9: 30$ & 1,079 & 0,514 & 0,174 & 0,156 & 0,162 & 0,117 \\
$10: 00$ & 1,231 & 0,605 & 0,202 & 0,181 & 0,194 & 0,190 \\
$10: 30$ & 1,567 & 0,777 & 0,221 & 0,223 & 0,233 & 0,207 \\
$11: 00$ & 1,608 & 0,777 & 0,235 & 0,208 & 0,249 & 0,199 \\
$11: 30$ & 1,934 & 0,934 & 0,229 & 0,198 & & 0,256 & 0,195 \\
$12: 00$ & 1,921 & 0,946 & 0,221 & 0,180 & 0,260 & 0,222 \\
$12: 30$ & 1,837 & 0,908 & 0,229 & 0,202 & 0,373 & 0,261 \\
$13: 00$ & 1,899 & 0,953 & 0,259 & 0,269 & 0,319 & 0,204 \\
$13: 30$ & 1,634 & 0,950 & 0,216 & 0,207 & 0,267 & 0,198 \\
$14: 00$ & 1,637 & 0,793 & 0,210 & 0,156 & 0,299 & 0,214 \\
$14: 30$ & 1,233 & 0,598 & 0,180 & 0,153 & 0,192 & 0,131 \\
$15: 00$ & 1,188 & 0,583 & 0,215 & 0,195 & 0,190 & 0,183 \\
$15: 30$ & 1,034 & 0,532 & 0,219 & 0,196 & 0,188 & 0,156 \\
$16: 00$ & 0,934 & 0,486 & 0,195 & 0,190 & 0,159 & 0,146 \\
\hline
\end{tabular}


Tabela 7. Densidade dos fluxos de radiação global e fotossinte ticamente ativa $\left(\mathrm{cal} \cdot \mathrm{cm}^{-2} \cdot \mathrm{min}^{-1}\right)$ do dia 05-03-79 para milho (Zea mays L. var. Cargil1501), no trata mento $1,00 \mathrm{~m} \times 0,20 \mathrm{~m}$.

\begin{tabular}{|c|c|c|c|c|c|c|}
\hline \multirow{2}{*}{ HORA } & \multicolumn{3}{|c|}{ Rad. acima da cobertura } & vegetal & \multicolumn{2}{|c|}{ Rad. na sup. do solo } \\
\hline & $\mathrm{K} \downarrow$ & $\mathrm{K}_{8}{ }^{+}$ & $\mathrm{K} \uparrow$ & $\mathrm{K}_{8} \uparrow$ & $\mathrm{K}_{\mathrm{T}^{\downarrow}}^{\downarrow}$ & $\mathrm{K}_{\mathrm{T} 8}{ }^{+}$ \\
\hline $8: 00$ & 0,683 & 0,435 & 0,184 & 0,164 & 0,156 & 0,157 \\
\hline $8: 30$ & 0,851 & 0,538 & 0,198 & 0,199 & 0,182 & 0,161 \\
\hline $9: 00$ & 0,979 & 0,504 & 0,199 & 0,194 & 0,177 & 0,154 \\
\hline $9: 30$ & 1,110 & 0,578 & 0,221 & 0,214 & 0,209 & 0,175 \\
\hline $10: 00$ & 1,215 & 0,629 & 0,228 & 0,215 & 0,214 & 0,199 \\
\hline $10: 30$ & 1,376 & 0,685 & 0,229 & 0,219 & 0,220 & 0,189 \\
\hline $11: 00$ & 1,447 & 0,698 & 0,225 & 0,202 & 0,211 & 0,173 \\
\hline $11: 30$ & 1,441 & 0,726 & 0,209 & 0,202 & 0,211 & 0,167 \\
\hline $12: 00$ & 1,494 & 0,739 & 0,204 & 0,189 & 0,212 & 0,184 \\
\hline $12: 30$ & 1,501 & 0,743 & 0,193 & 0,179 & 0,178 & 0,134 \\
\hline $13: 00$ & 1,532 & 0,764 & 0,199 & 0,184 & 0,224 & 0,180 \\
\hline $13: 30$ & 1,486 & 0,578 & 0,207 & 0,190 & 0,250 & 0,175 \\
\hline $14: 00$ & 1,377 & 0,679 & 0,199 & 0,167 & 0,238 & 0,192 \\
\hline $14: 30$ & 1,229 & 0,611 & 0,178 & 0,156 & 0,217 & 0,145 \\
\hline $15: 00$ & 1,161 & 0,521 & 0,171 & 0,147 & 0,163 & 0,135 \\
\hline $15: 30$ & 0,920 & 0,463 & 0,163 & $.0,143$ & 0,145 & 0,107 \\
\hline $16: 00$ & 0,726 & 0,355 & 0,139 & 0,117 & 0,098 & 0,092 \\
\hline
\end{tabular}


Tabela 8. Variações médias em cada 30 minutos dẹ $K \downarrow, K_{8} \downarrow$ (cal $\cdot \mathrm{cm}^{-2} \cdot 30 \mathrm{~min}^{-1}$ ) e da razāo destas duas grandezas.

Tratamento: $\quad 1,00 \mathrm{~m} \times 0,20 \mathrm{~m}$

\begin{tabular}{rrrrr}
\hline HORA & $\mathrm{K} \downarrow$ & $\mathrm{K}_{8} \downarrow$ & $\mathrm{PI} \downarrow$ & $\frac{\mathrm{K}_{8} \downarrow}{\mathrm{K} \downarrow}$ \\
\hline $8: 00$ & 18,81 & 9,81 & 9,00 & 0,52 \\
$8: 30$ & 24,60 & 13,17 & 11,43 & 0,54 \\
$9: 00$ & 28,59 & 12,24 & 16,35 & 0,43 \\
$9: 30$ & 32,85 & 16,38 & 16,47 & 0,50 \\
$10: 00$ & 36,69 & 18,51 & 18,18 & 0,50 \\
$10: 30$ & 44,16 & 21,93 & 22,23 & 0,50 \\
$11: 00$ & 45,84 & 22,14 & 23,70 & 0,48 \\
$11: 30$ & 50,64 & 24,90 & 25,74 & 0,49 \\
$12: 00$ & 51,24 & 25,29 & 25,95 & 0,49 \\
$12: 30$ & 50,07 & 24,69 & 25,38 & 0,49 \\
$13: 00$ & 51,48 & 25,77 & 25,71 & 0,50 \\
$13: 30$ & 46,80 & 22,92 & 23,88 & 0,49 \\
$14: 00$ & 45,21 & 22,08 & 23,13 & 0,49 \\
$14: 30$ & 36,93 & 18,15 & 18,78 & 0,49 \\
$15: 00$ & 35,22 & 16,56 & 18,66 & 0,47 \\
$15: 30$ & 29,31 & 14,94 & 14,37 & 0,51 \\
$16: 00$ & 24,90 & 12,63 & 12,27 & 0,51 \\
\hline $\bar{M}$ & & & & 0,49 \\
\hline
\end{tabular}


Tabela 9. Variações médias em cada 30 minutos de $\mathrm{K} \downarrow, \mathrm{K}_{8} \downarrow$ $\left(\mathrm{cal} \cdot \mathrm{cm}^{-2} \cdot 30 \mathrm{~min}^{-1}\right)$ e da razão destas duas grandezas.

Tratamento: $1,00 \mathrm{~m} \times 0,50 \mathrm{~m} \times 0.20 \mathrm{~m}$

\begin{tabular}{rrrrr}
\hline HORA & $\mathrm{K} \downarrow$ & $\mathrm{K}_{8} \downarrow$ & $\mathrm{PI} \downarrow$ & $\frac{\mathrm{K}_{8} \downarrow}{\mathrm{K} \downarrow}$ \\
\hline $8: 00$ & 18,99 & 10,02 & 8,97 & 0,53 \\
$8: 30$ & 23,85 & 12,15 & 11,70 & 0,51 \\
$9: 00$ & 26,79 & 14,01 & 12,78 & 0,52 \\
$9: 30$ & 32,70 & 15,66 & 17,04 & 0,48 \\
$10: 00$ & 35,37 & 17,40 & 17,97 & 0,49 \\
$10: 30$ & 38,94 & 18,69 & 20,25 & 0,48 \\
$11: 00$ & 40,26 & 19,65 & 20,61 & 0,49 \\
$11: 30$ & 43,83 & 20,91 & 22,92 & 0,48 \\
$12: 00$ & 43,77 & 20,85 & 22,92 & 0,48 \\
$12: 30$ & 47,31 & 22,08 & 25,23 & 0,47 \\
$13: 00$ & 42,66 & 19,86 & 22,80 & 0,47 \\
$13: 30$ & 44,13 & 21,36 & 22,77 & 0,48 \\
$14: 00$ & 44,16 & 21,54 & 22,62 & 0,49 \\
$14: 30$ & 46,20 & 20,10 & 26,10 & 0,44 \\
$15: 00$ & 40,74 & 17,97 & 22,77 & 0,44 \\
$15: 30$ & 35,31 & 15,18 & 20,13 & 0,43 \\
$16: 00$ & 27,90 & 14,55 & 13,35 & 0,52 \\
\hline & & & & \\
\hline M & & & & 0,48 \\
\hline
\end{tabular}


Tabela 10. Variaçōes médias em cada 30 minutos de $\mathrm{K} \downarrow, \mathrm{K}_{8} \downarrow$ $\left(\mathrm{cal} \cdot \mathrm{cm}^{-2} \cdot 30 \mathrm{~min}^{-1}\right)$ e da razão destas duas grandezas.

Tratamento: Quincôncio

\begin{tabular}{rrrrr}
\hline HORA & $\mathrm{K} \downarrow$ & $\mathrm{K}_{8} \downarrow$ & $\mathrm{PI} \downarrow$ & $\frac{\mathrm{K}_{8} \downarrow}{\mathrm{K} \downarrow}$ \\
\hline $8: 00$ & 18,66 & 9,66 & 9,00 & 0,52 \\
$8: 30$ & 24,00 & 12,06 & 11,94 & 0,50 \\
$9: 00$ & 27,42 & 13,74 & 13,68 & 0,50 \\
$9: 30$ & 31,62 & 15,36 & 16,26 & 0,49 \\
$10: 00$ & 34,08 & 17,28 & 16,80 & 0,51 \\
$10: 30$ & 37,65 & 18,39 & 19,26 & 0,49 \\
$11: 00$ & 40,53 & 19,38 & 21,15 & 0,48 \\
$11: 30$ & 41,85 & 20,25 & 21,60 & 0,48 \\
$12: 00$ & 43,35 & 21,27 & 22,08 & 0,49 \\
$12: 30$ & 44,73 & 22,14 & 22,59 & 0,49 \\
$13: 00$ & 43,59 & 21,75 & 21,84 & 0,50 \\
$13: 30$ & 42,81 & 21,63 & 21,18 & 0,51 \\
$14: 00$ & 40,80 & 20,28 & 20,52 & 0,50 \\
$14: 30$ & 36,36 & 18,63 & 17,73 & 0,51 \\
$15: 00$ & 31,14 & 15,93 & 15,21 & 0,51 \\
$15: 30$ & 24,93 & 12,31 & 12,62 & 0,49 \\
$16: 00$ & 18,30 & 9,33 & 8,97 & 0,51 \\
\hline M & & & & 0,50 \\
\hline & & & & \\
\hline
\end{tabular}


Os balanços dos fluxos de radiação solar global e fotossinteticamente ativa em $\mathrm{cal} \cdot \mathrm{cm}^{-2} \cdot \mathrm{min}^{-1}$, para os três tratamentos estão descritos nás tabelas 11 a 13, como também os.valores de $\mathrm{PI}{ }^{*}$ que atingem a cobertura vegetal e $\mathrm{PI}^{*}$ retido pela planta.

Com a informação das tabelas anteriores chegouse a construir as tabelas 14 a 16 que mostram os valores percentuais médios da radiação global e fotossinteticamente ativa retidas pela cobertura vegetal em uma cultura de milho. Conclui-se que a maior porcentagem de radiação fotossinteticamente ativa retida pela cultura, corresponde as : parcelas de maior população, quincôncio e $1,00 \times 0,50 \times 0,20$ metros, com $96 \%$ de retenção contra $94 \%$ do tratamento com espaçamento tradi cional $(1,00 \mathrm{~m} \times 0,20 \mathrm{~m})$. Igualmente a maior porcentagem de radiação solar global retida pela cultura corresponde as parce las $1,00 \mathrm{~m} \times 0,50 \mathrm{~m} \times 0,20 \mathrm{~m} \operatorname{com} 85 \%$, quincôncio com $84 \%$ e com $80 \%$ o tratamento $1,00 \mathrm{~m} \times 0,20 \mathrm{~m}$. Nas figuras 6 e 7 pode-se ob servar as variações médias de radiação solar global e fotossin teticamente ativa em um intervalo de tempo de meia em meia hora.

$\mathrm{Na}$ tabela 17 apresenta-se, por tratamento, as porcentagens de radiação global e infra-vermelha próxima que atingem a superfície do solo ao transmitir-se através da folha gem. Estes valores correspondem à radiação que não é utiliza da pela planta, podendo-se apreciar que, na parcela de menor densidade, a transmissão para as duas faixas do espectro é maior, pela menor dificuldade que tem a energia solar de atra vessar a folhagem da planta devido ao menor índice de área fo1iar. Nas parcelas $1,00 \mathrm{~m} \times 0,50 \mathrm{~m} \times 0,20 \mathrm{~m}$ e quincôncio as por centagens que se apresentam são muito semelhantes e com valores menores que o tratamento anterior. Com base nestas últimas informações (radiação retida e transmitida pela cobertura vegetal) pode chegar-se às conclusões sobre produtividade. 


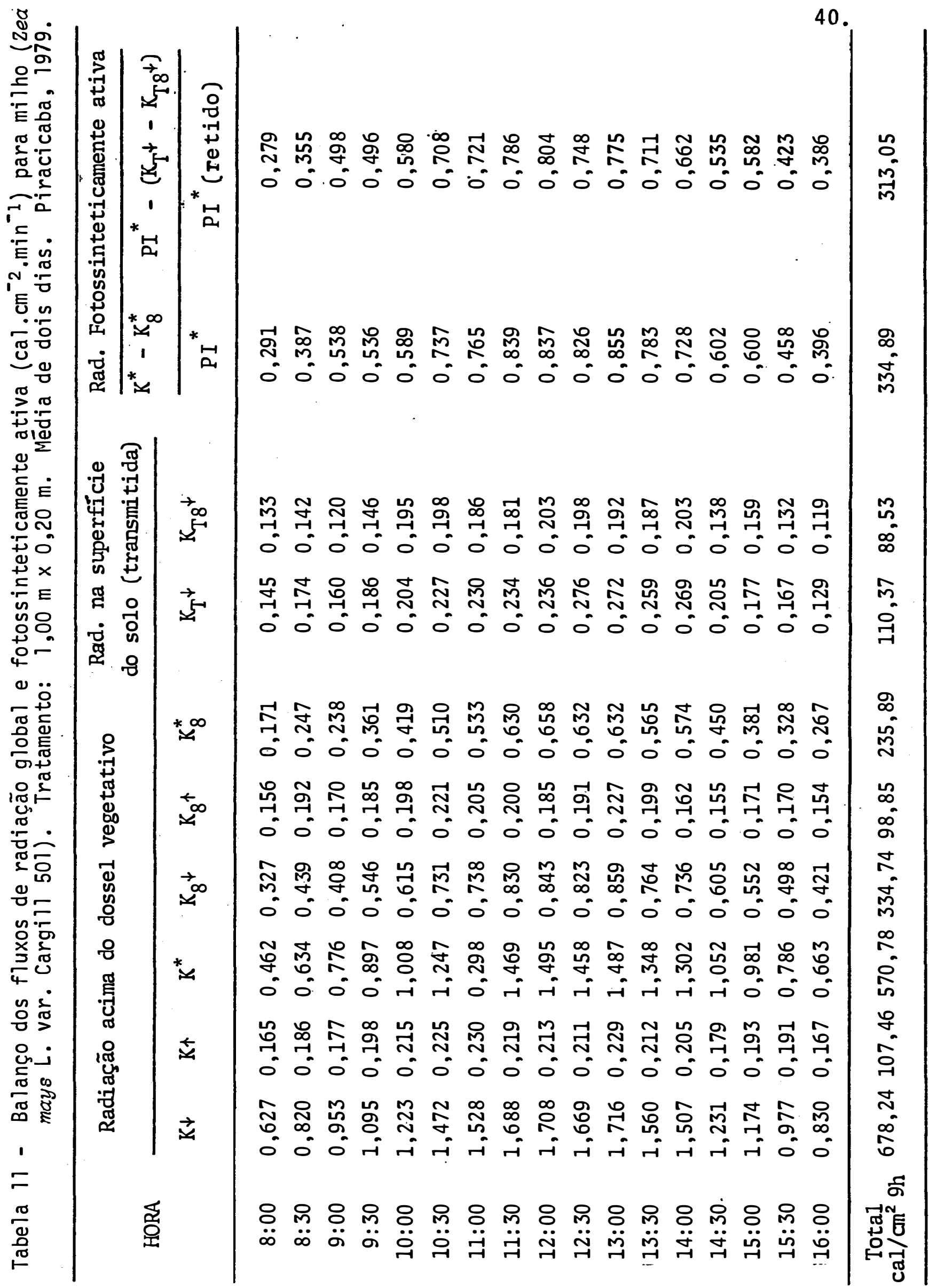




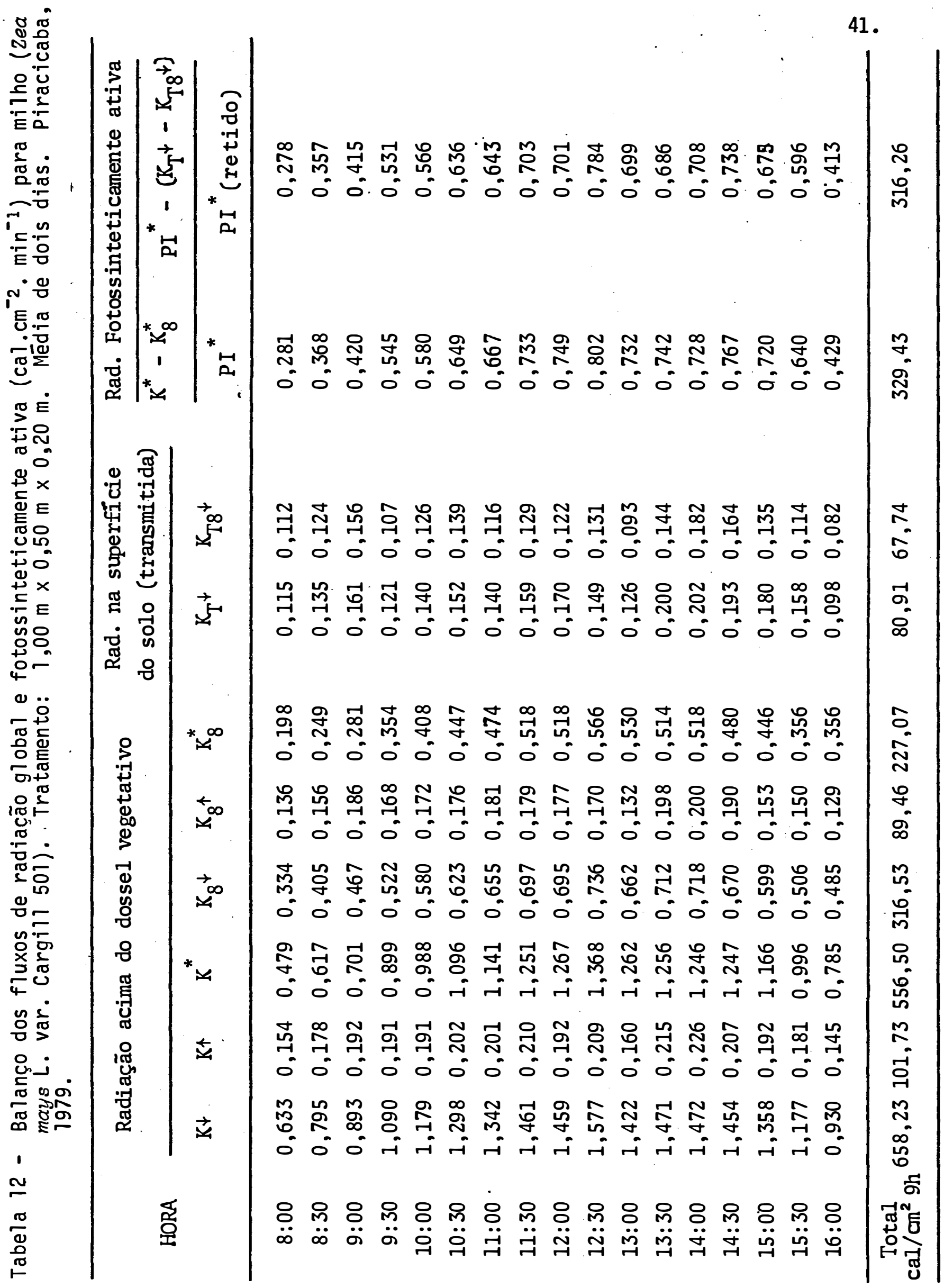




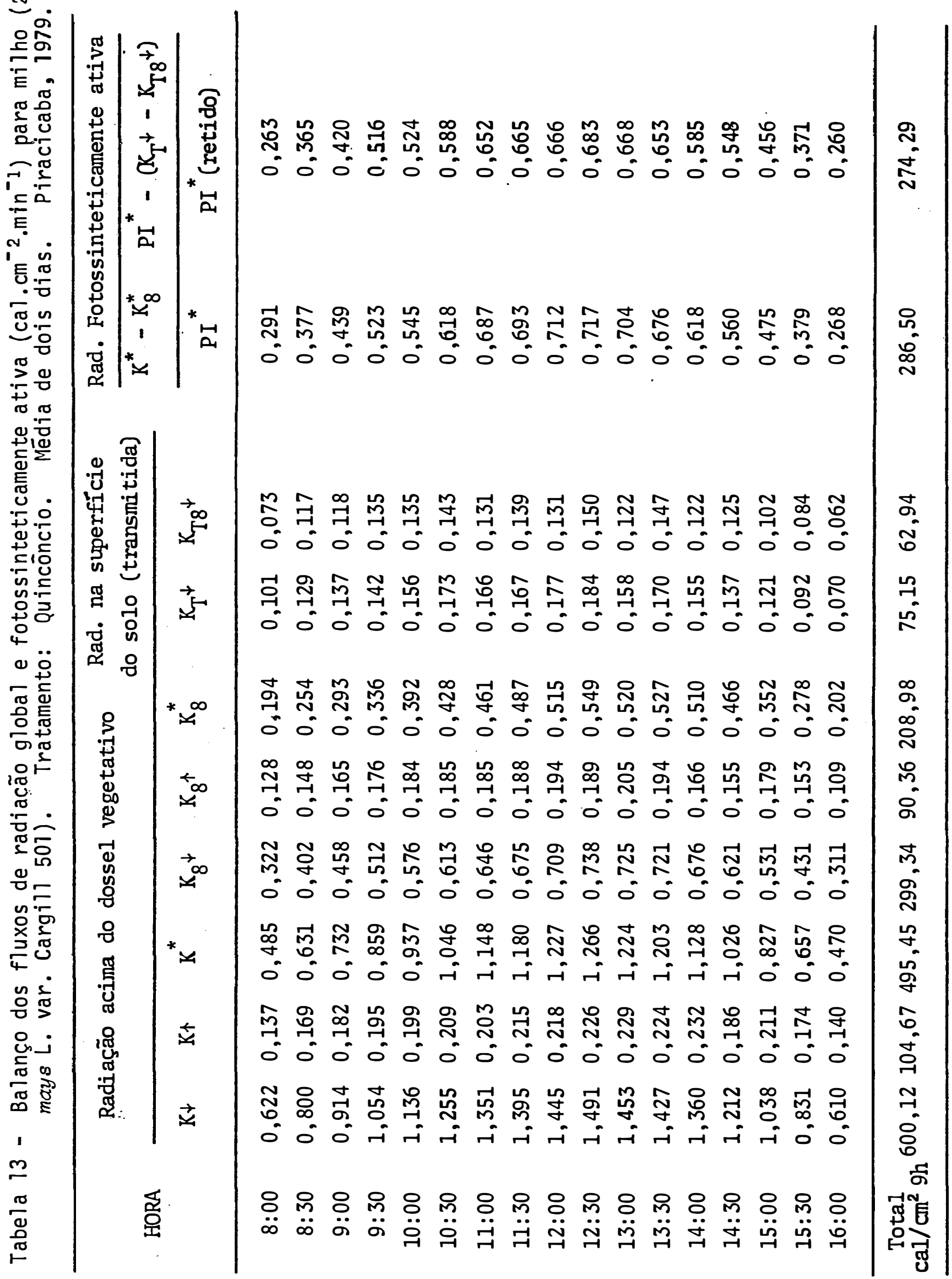


Tabela 14. Porcentagem média da radiação global e fotossinteticamente ativa retida por uma cultura de milho (Zea mays L. var. Cंargill 501).

Tratamento: $1,00 \mathrm{~m} \times 0,20 \mathrm{~m}$

\begin{tabular}{|c|c|c|c|c|c|c|}
\hline \multirow[b]{2}{*}{ HORA } & \multicolumn{3}{|c|}{ Rad. Global retida } & \multicolumn{3}{|c|}{ Rad. Fotoss. ativa retida } \\
\hline & $\begin{array}{l}\mathrm{K}^{*}-\mathrm{K}_{\mathrm{T}}{ }^{\dagger}= \\
\mathrm{K}_{(\text {retido })}\end{array}$ & $\mathrm{K}^{*}$ & $\frac{\mathrm{K}^{*}(\text { retido) }}{\mathrm{K}^{*}} \cdot 100$ & $\mathrm{PI}^{*}$ (ret.) & $\mathrm{PI}^{*}$. & $-\frac{\mathrm{PI}^{*}(\text { retido })}{\mathrm{PI}^{*}} \cdot 100$ \\
\hline $8: 00$ & 0,317 & 0,462 & 68,6 & 0,279 & 0,291 & 95,9 \\
\hline $8: 30$ & 0,460 & 0,634 & 72,6 & 0,355 & 0,387 & 91,7 \\
\hline 9:00 & 0,616 & 0,776 & 79,4 & 0,498 & 0,538 & 92,6 \\
\hline $9: 30$ & 0,711 & 0,897 & 79,3 & 0,496 & 0,536 & 92,5 \\
\hline $10: 00$ & 0,804 & 1,008 & 79,8 . & 0,580 & 0,589 & 98,5 \\
\hline $10: 30$ & 1,020 & 1,247 & 81,8 & 0,708 & 0,737 & 96,1 \\
\hline $11: 00$ & 1,068 & 1,298 & 82,3 & 0,721 & 0,765 & 94,2 \\
\hline $11: 30$ & 1,235 & 1,469 & 84,1 & 0,786 & 0,839 & 93,7 \\
\hline $12: 00$ & 1,259 & 1,495 & $84 ; 2$ & 0,804 & 0,837 & 96,1 \\
\hline $12: 30$ & 1,182 & 1,458 & 81,1 & 0,748 & 0,826 & $90,6^{6}$ \\
\hline $13: 00$ & 1,215 & 1,487 & 81,7 & 0,775 & 0,855 & 90,6 \\
\hline $13: 30$ & 1,089 & 1,348 & 80,8 & 0,711 & 0,783 & 90,8 \\
\hline $14: 00$ & 1,033 & 1,302 & 79,3 & 0,662 & 0,728 & 90,9 \\
\hline $14: 30$ & 0,847 & 1,052 & 80,5 & 0,535 & 0,602 & 88,9 \\
\hline $15: 00$ & 0,804 & 0,981 & 82,0 & 0,582 & 0,600 & 97,0 \\
\hline $15: 30$ & 0,619 & 0,786 & 78,8 & 0,423 & 0,458 & 92,4 \\
\hline $16: 00$ & 0,534 & 0,663 & 80,5 & 0,386 & 0,396 & 97,5 \\
\hline$\overline{\mathrm{M}}$ & & & $80 \%$ & & & $94 \%$ \\
\hline
\end{tabular}


Tabela 15. Porcentagem média da radiação global e fotossinteticamente ativa retida por uma cultura de milho (Zea mays L. var. Cargill 501).

Tratamento: $1,00 \mathrm{~m} \times 0,50 \mathrm{~m} \times 0,20 \mathrm{~m}$

\begin{tabular}{|c|c|c|c|c|c|c|}
\hline \multirow{3}{*}{ HORA } & \multicolumn{3}{|c|}{ Rad. Global retida } & \multicolumn{3}{|c|}{ Rad. Fotoss. ativa retida } \\
\hline & \multirow{2}{*}{$\begin{array}{l}\mathrm{K}^{*}-\mathrm{K}_{\mathrm{T}}{ }^{+}= \\
\mathrm{K}_{(\text {retido })}\end{array}$} & \multirow{2}{*}{$\mathrm{K}^{*}$} & \multirow{2}{*}{$\frac{\mathrm{K}^{*}(\text { retido) }}{\mathrm{K}^{*}} \cdot 100$} & \multirow{2}{*}{$\mathrm{PI}_{(\text {ret.) }}^{*}$} & \multirow{2}{*}{$\dot{\mathrm{PI}}^{*}$} & \multirow{2}{*}{$\frac{\mathrm{PI}^{*} \text { (retido) }}{\mathrm{PI}^{*}} \cdot 100$} \\
\hline & & & & & & \\
\hline $8: 00$ & 0,364 & 0,479 & 76,0 & 0,278 & 0,281 & 98,9 \\
\hline $8: 30$ & 0,482 & 0,617 & 78,1 & 0,357 & 0,368 & 97,0 \\
\hline $9: 00$ & 0,540 & 0,701 & 77,0 & 0,415 & 0,420 & 98,8 \\
\hline $9: 30$ & 0,778 & 0,899 & 86,5 & 0,531 & 0,545 & 97,4 \\
\hline $10: 00$ & 0,848 & 0,988 & 85,2 & 0,566 & 0,580 & 97,6 \\
\hline $10: 30$ & 0,944 & 1,096 & 86,1 & 0,636 & 0,649 & 98,0 \\
\hline $11: 00$ & 1,001 & 1,141 & 87,7 & 0,643 & 0,667 & 96,4 \\
\hline $11: 30$ & 1,092 & 1,251 & 87,3 & 0,703 & 0,733 & 95,9 \\
\hline $12: 00$ & 1,097 & 1,267 & 86,6 & 0,701 & 0,749 & 93,6 \\
\hline $12: 30$ & 1,219 & 1,368 & 89,1 & 0,784 & 0,802 & 97,8 \\
\hline $13: 00$ & 1,136 & 1,262 & 90,0 & 0,699 & 0,732 & 95,5 \\
\hline $13: 30$ & 1,056 & 1,256 & 84,1 & 0,686 & 0,742 & 92,5 \\
\hline $14: 00$ & 1,044 & 1,246 & 83,8 & 0,708 & 0,728 & 97,3 \\
\hline $14: 30$ & 1,054 & 1,247 & 84,5 & 0,738 & 0,767 & 96,2 \\
\hline $15: 00$ & 0,986 & 1,166 & 84,6 & 0,675 & 0,720 & 93,8 \\
\hline $15: 30$ & 0,838 & 0,996 & 84,1 & 0,596 & 0,640 & 93,1 \\
\hline $16: 00$ & 0,687 & 0,785 & 87,5 & 0,413 & 0,429 & 96,3 \\
\hline$\overline{\mathrm{M}}$ & & & $85 \%$ & & & $96 \%$ \\
\hline
\end{tabular}


Tabela 16. Porcentagem média da radiação global e fotossinteticamente ativa retida por uma cultura de milho (Zea mays L. var. Cargill 501). .

Tratamento: Quincôncio

\begin{tabular}{|c|c|c|c|c|c|c|}
\hline \multirow{3}{*}{ HORA } & \multicolumn{3}{|c|}{ Rad. Global retida } & \multicolumn{3}{|c|}{ Rad. Fotoss. ativa retida } \\
\hline & \multirow{2}{*}{$\begin{array}{l}\mathrm{K}^{*}-\mathrm{K}_{\mathrm{T}^{\dagger}}= \\
\mathrm{K}_{\text {(retido) }}\end{array}$} & \multirow{2}{*}{$\mathrm{K}^{*}$} & \multirow{2}{*}{$\frac{\mathrm{K}^{*}}{\mathrm{~K}^{*}} \cdot 100$} & \multirow{2}{*}{$\mathrm{PI}_{(\text {ret. })}^{*}$} & \multirow{2}{*}{$\mathrm{PI}^{*}$} & \multirow{2}{*}{$\frac{\mathrm{PI}^{*} \text { (retido) }}{\mathrm{PI}^{*}}$} \\
\hline & & & & & & \\
\hline $8: 00$ & 0,384 & 0,485 & 79,2 & 0,263 & 0,291 & 90,4 \\
\hline $8: 30$ & 0,502 & 0,631 & 79,6 & 0,365 & 0,377 & 96,8 \\
\hline $9: 00$ & 0,595 & 0,732 & 81,3 & 0,420 & 0,439 & 95,7 \\
\hline $9: 30$ & 0,717 & 0,859 & 83,5 & 0,516 & 0,523 & 98,7 \\
\hline $10: 00$ & 0,781 & 0,937 & 83,4 & 0,524 & 0,545 & 96,1 \\
\hline $10: 30$ & 0,873 & 1,046 & 83,5 & 0,588 & 0,618 & 95,1 \\
\hline $11: 00$ & 0,982 & 1,148 & 85,5 & 0,652 & 0,687 & 94,9 \\
\hline $11: 30$ & 1,013 & 1,180 & 85,8 & 0,665 & 0,693 & 96,0 \\
\hline $12: 00$ & 1,050 & 1,227 & 85,6 & 0,666 & 0,712 & 93,5 \\
\hline $12: 30$ & 1,082 & 1,266 & 85,5 & 0,683 & 0,717 & 95,3 \\
\hline $13: 00$ & 1,066 & 1,224 & 87,1 & 0,668 & 0,704 & 94,9 \\
\hline $13: 30$ & 1,033 & 1,203 & 85,7 & 0,653 & 0,676 & 96,6 \\
\hline $14: 00$ & 0,973 & 1,128 & 86,3 & 0,585 & 0,618 & 94,7 \\
\hline $14: 30$ & 0,889 & 1,026 & 86,6 & 0,548 & 0,560 & 97,9 \\
\hline $15: 00$ & 0,706 & 0,827 & 85,4 & 0,456 & 0,475 & 96,0 \\
\hline $15: 30$ & 0,565 & 0,657 & 86,0 & 0,371 & 0,379 & 97,9 \\
\hline $16: 00$ & 0,400 & 0,470 & 85,1 & 0,260 & 0,268 & 97,0 \\
\hline$\overline{\mathrm{M}}$ & & & $84 \%$ & & & $96 \%$ \\
\hline
\end{tabular}




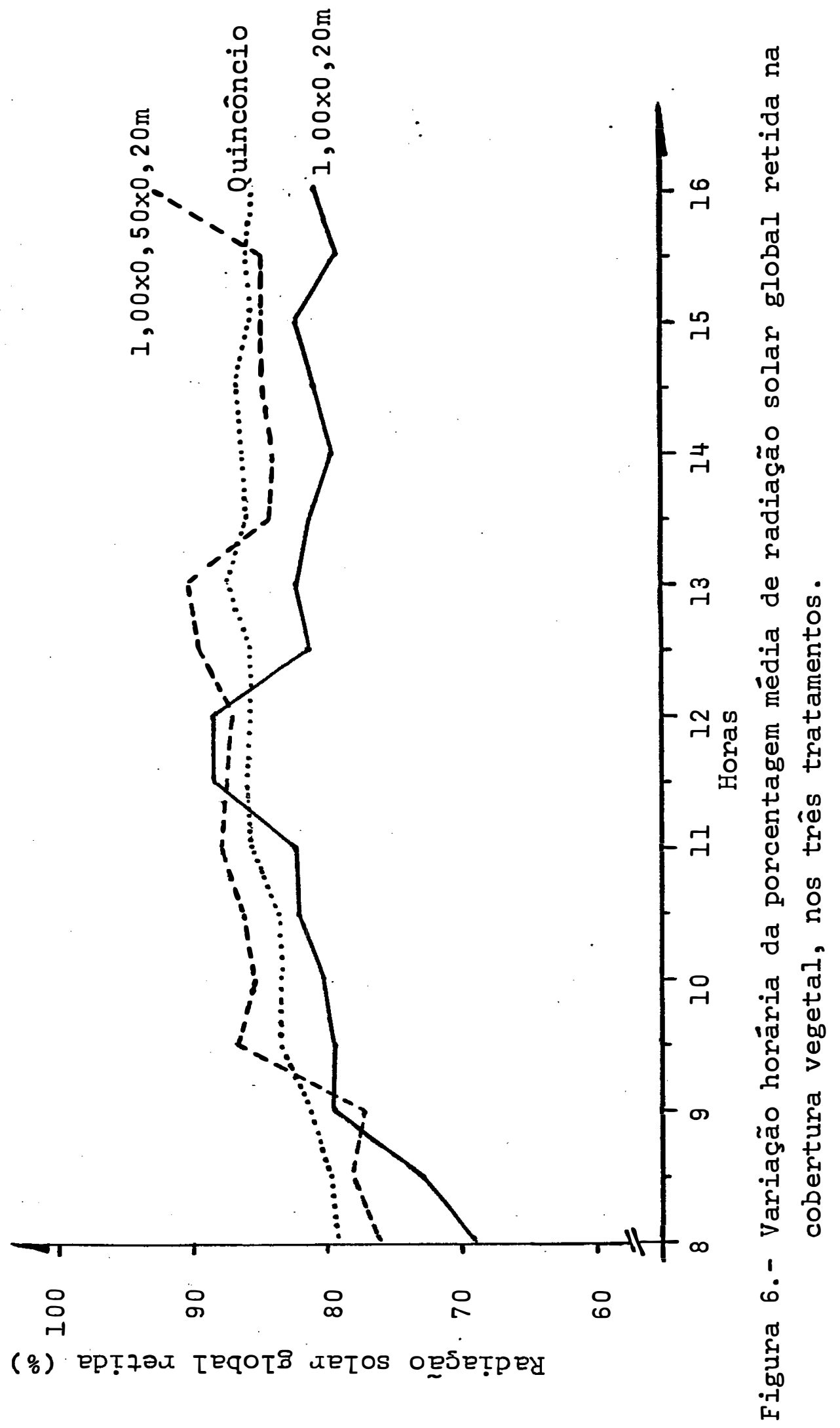




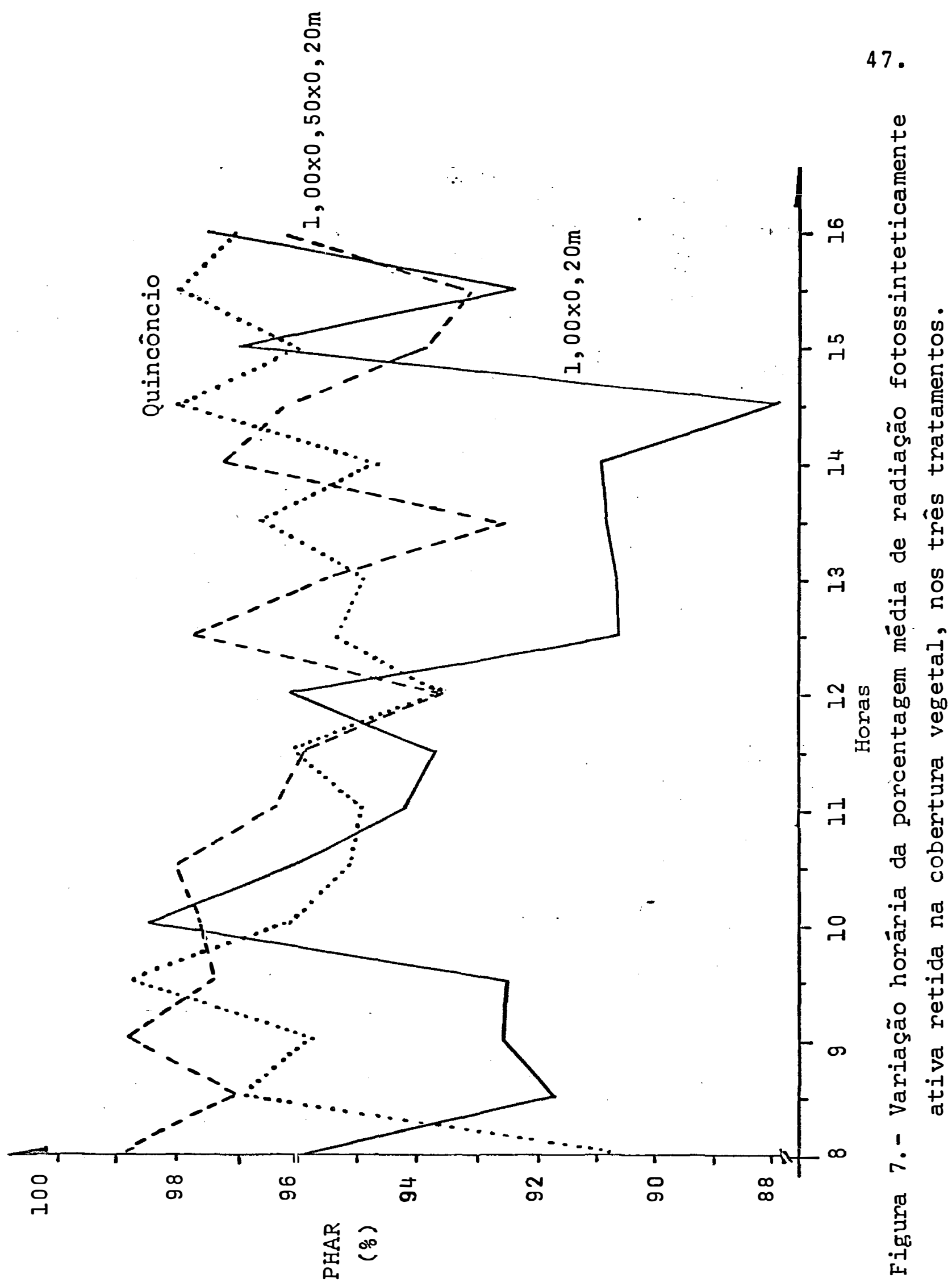


Tabela 17. Porcentagem de radiação transmitida através da folhagem do milho, variedade Cargill 501, nos três tratamentos para cada faixa do espectro.

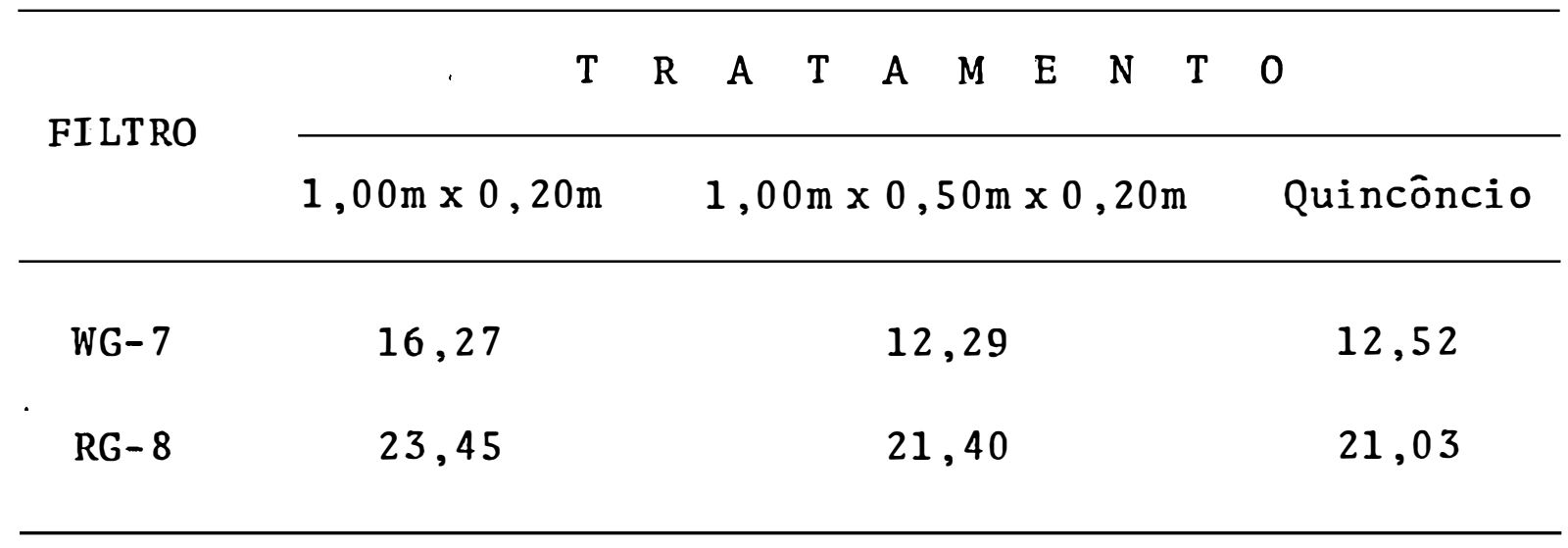


A quantificação dos valores mêdios do albedo de ondas curtas, por tratamento, resumiu-se na tabela $\mathbb{8}$ para a radiação solar global. Estes valores como os apresentados por GRAHAM e KING (1961); SANTOS (1978) e JARAMILLO (1999), em que os menores valores de albedo correspondem às horas próximas ao meio do dia, sendo os valores máximos observados de manhã e a tarde. Esta tendência foi observada nos três tratamentos (fig. 8). 0 albedo médio da radiação solar global de maior valor pertence à parcela quincôncio com $17,9 \%$, seguindo em ordem decrescente a parcela $1,00 \mathrm{~m} \times 0,20 \mathrm{~m}$ com $16,6 \%$ e por último o tratamento de $1,00 \mathrm{~m} \times 0,50 \mathrm{~m} \times 0,20 \mathrm{~m}$ com $16,1 \%$, concor dando esses valores com a pesquisa desenvolvida por SANTOS (1957) que especifica que o albedo para uma superfície verde é da ordem de $17 \%$, e em seu ültimo trabalho com milho encontra que o albedo vai de $16 \%$ a $19 \%$, SANTOS (1978).

De igual forma os valores de albedo de radiação infra-vermelha próxima, tabèla 19 , apresentaram a mesma tendên cia durante o dia que o albedo de radiação global, registrando se valores médios de $31 \%$ nas parcelas quincôncio e $1,00 \mathrm{mx} 0,20 \mathrm{~m}$, e de $29,2 \%$ para a parcela $1,00 \mathrm{~m} \times 0,50 \mathrm{~m} \times 0,20 \mathrm{~m}$. Pode-se citar que a variação média é muito pequena (fig. 9), concordando também estes valores com os obtidos por SANTOS (1978) em sua pesquisa anteriormente citada.

A diferença dos dados de albedo para uma mesma variedade pode-se explicar pela variação da refletividàde da superfície da planta e à diversidade do ângulo de incidência da radiação solar pois estes parâmetros são variáveis através do tempo. 
Tabela 18. Valores médios de albedo $(\xi)$, por tratamento de 30 em 30 minutos, sobre a cobertura vegetal em milho, var. Cargill 501 - Utilizandose piranômetro espectral Eppley sem filtro. (Radiaçāo global)

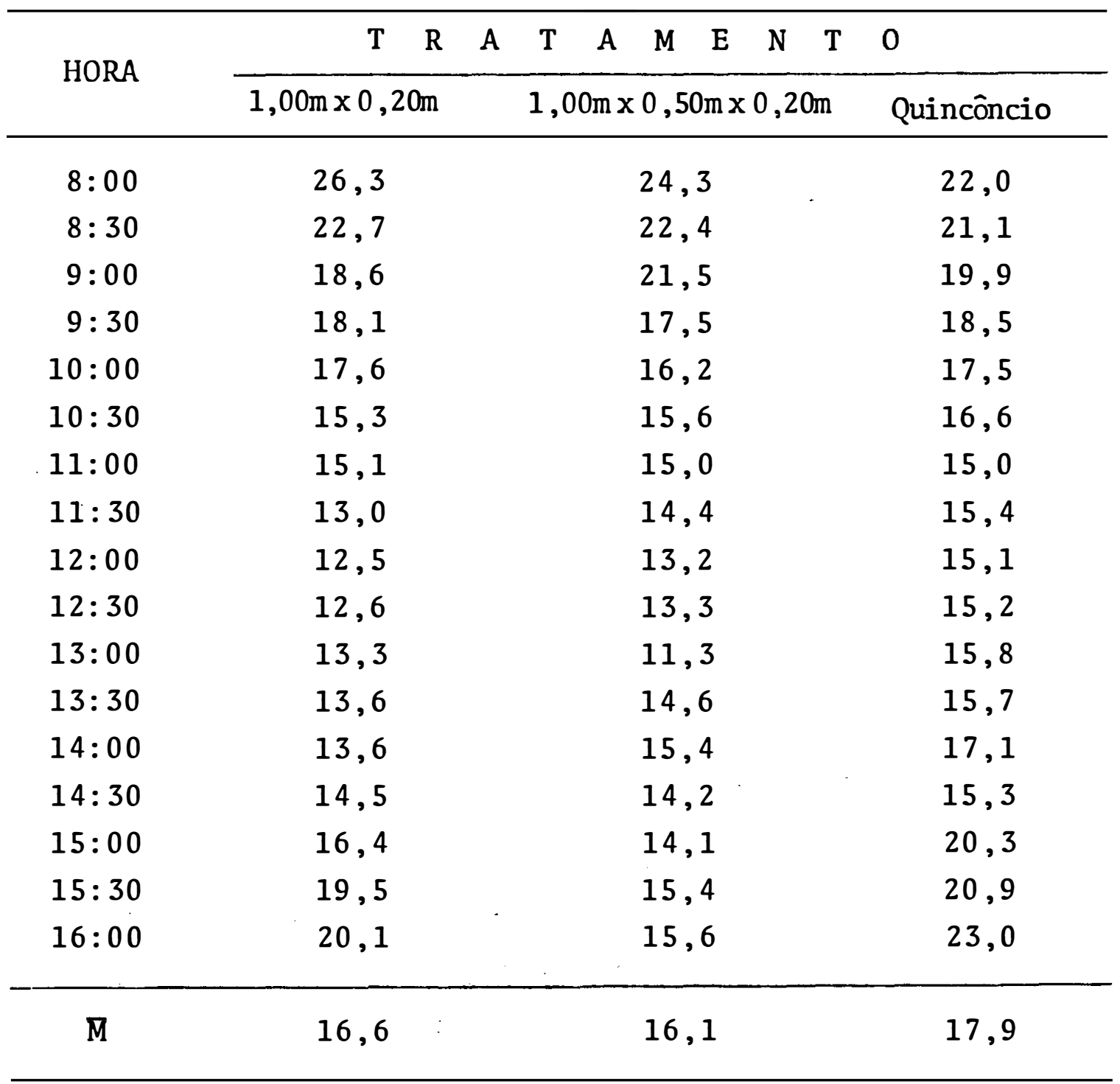




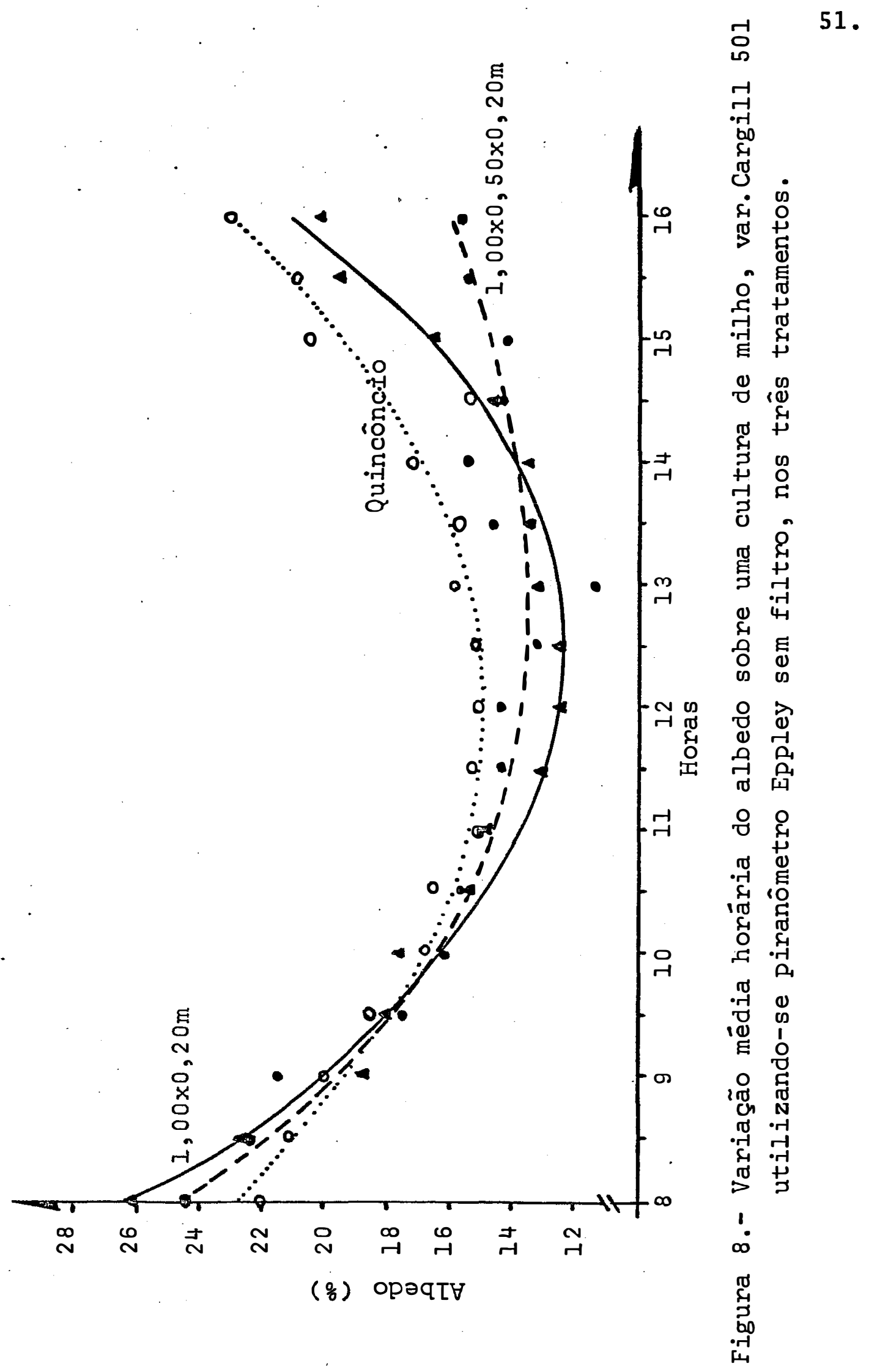


Tabela 19. Valores médios de albedo $\left(\frac{\circ}{b}\right)$, por tratamento de 30 em 30 minutos, sobre a cobertura vegetal em milho, var. Cargill 501 - Utilizandose piranômetro espectral Eppley com filtro. RG-8. (Radiação infra-vermelho próximo)

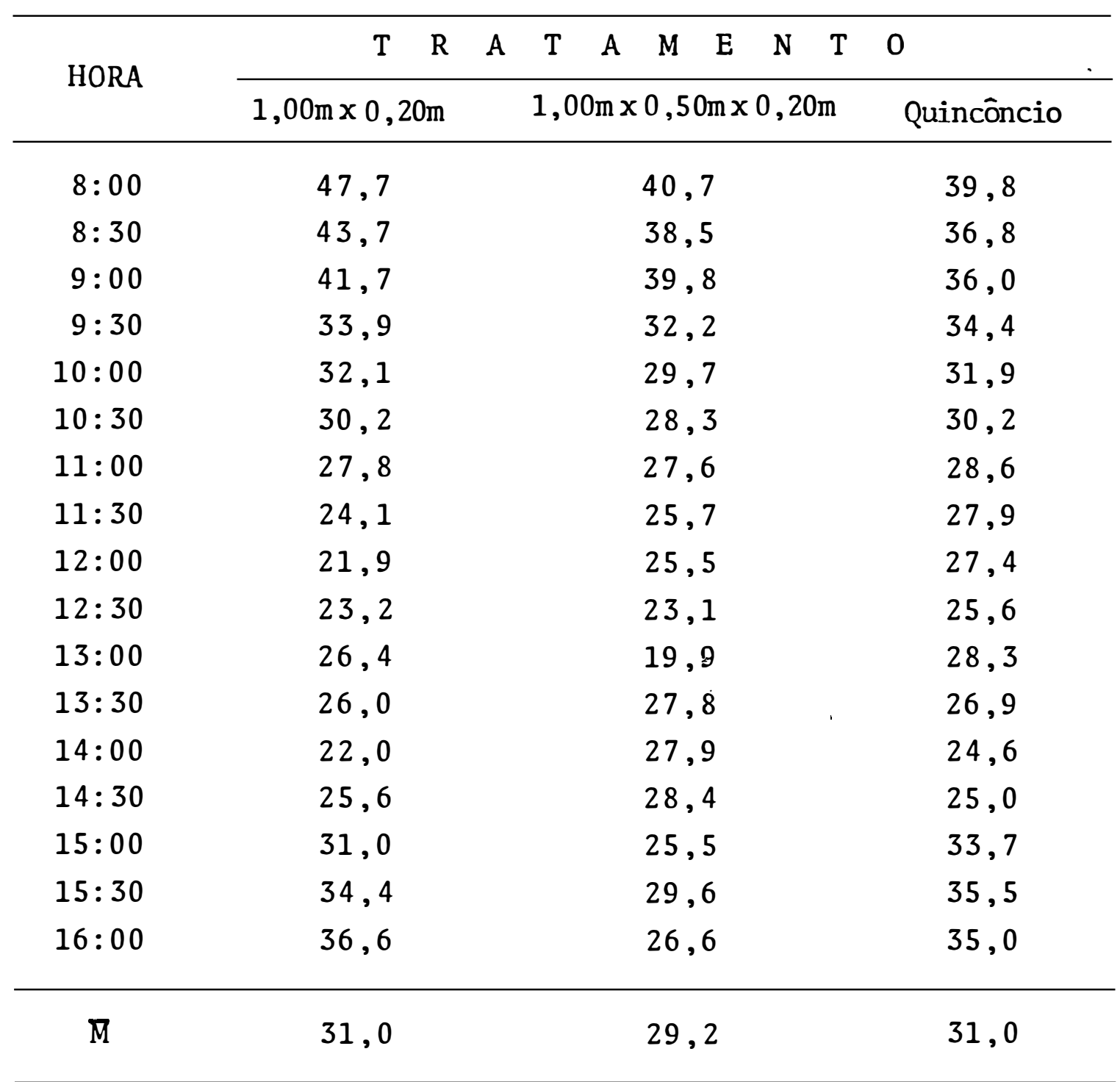


53.

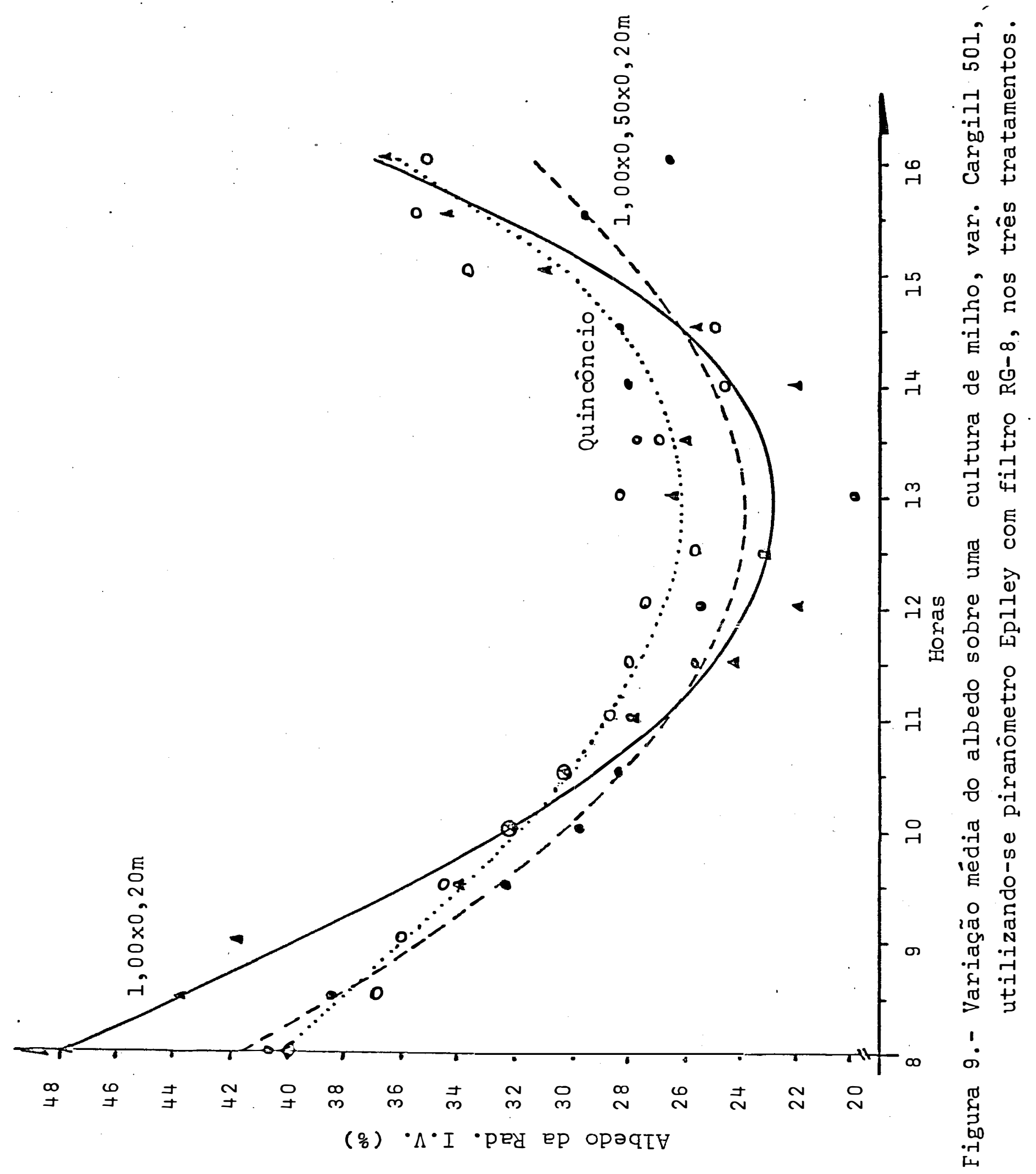


$\mathrm{Na}$ tabela 20 , pode-se observar que as plantas dos tratamentos de maior densidade de população alcançarammaio res alturas nas diferentes fases de desenvolvimento do milho, correspondendo as menores alturas às plantas da parcela de menor população. A altura média no tratamento quincôncio, aos 88 dias após o plantio, alcançou $244,3 \mathrm{~cm}$ enquanto que na parce 1a $1,00 \mathrm{~m} \times 0,20 \mathrm{~m}$, considerada como testemunha, somente alcançou $221,0 \mathrm{~cm}$. Na fig. 10 observa-se um crescimento acelerado das plantas no período do $17^{\circ}$ ao $60^{\circ}$ dia após o plantio.

A ārea foliar considerada um dos parâmetros de maior importância, por ser a folha o principal órgão fotossintético da planta, pois a variação na produção de matéria seca está a ela estreitamente vinculada. Na tabela 21 expõem-se va lores periódicos de área foliar média, nos quais se observam aumentos homogêneos para os três tratamentos até o $31^{\circ}$ dia após o plantio, a parcela $1,00 \mathrm{~m} \times 0,20 \mathrm{~m}$ alcançou um máximo de $7.122 \mathrm{~cm}^{2}$ para depois diminuir, enquanto que nos tratamentos $1,00 \mathrm{~m} \times 0,50 \mathrm{~m} \times 0,20 \mathrm{~m}$ e quincôncio conseguiram suas máximas áreas foliares acima de $7.300 \mathrm{~cm}^{2}$ para em seguida declinar suas áreas, pelo secamento e murcha das folhas mais velhas, fig. 11 .

$\mathrm{Na}$ tabela 22 , apresenta-se outro parâmetro importante que corresponde ao indice de ārea foliar nos três tra tamentos, observando-se nitidamente que a parcela mais densamente povoada apresenta maior índice de área foliar sendo o me nor valor para o tratamento $1,00 \mathrm{~m} \times 0,20 \mathrm{~m}$, fig. 12 . 
Tabela 20. Altura média por planta (cm), por tratamento, para períodos de 14 dias, em uma cultura de milho (Zea mays L. var. Cargi11 501).

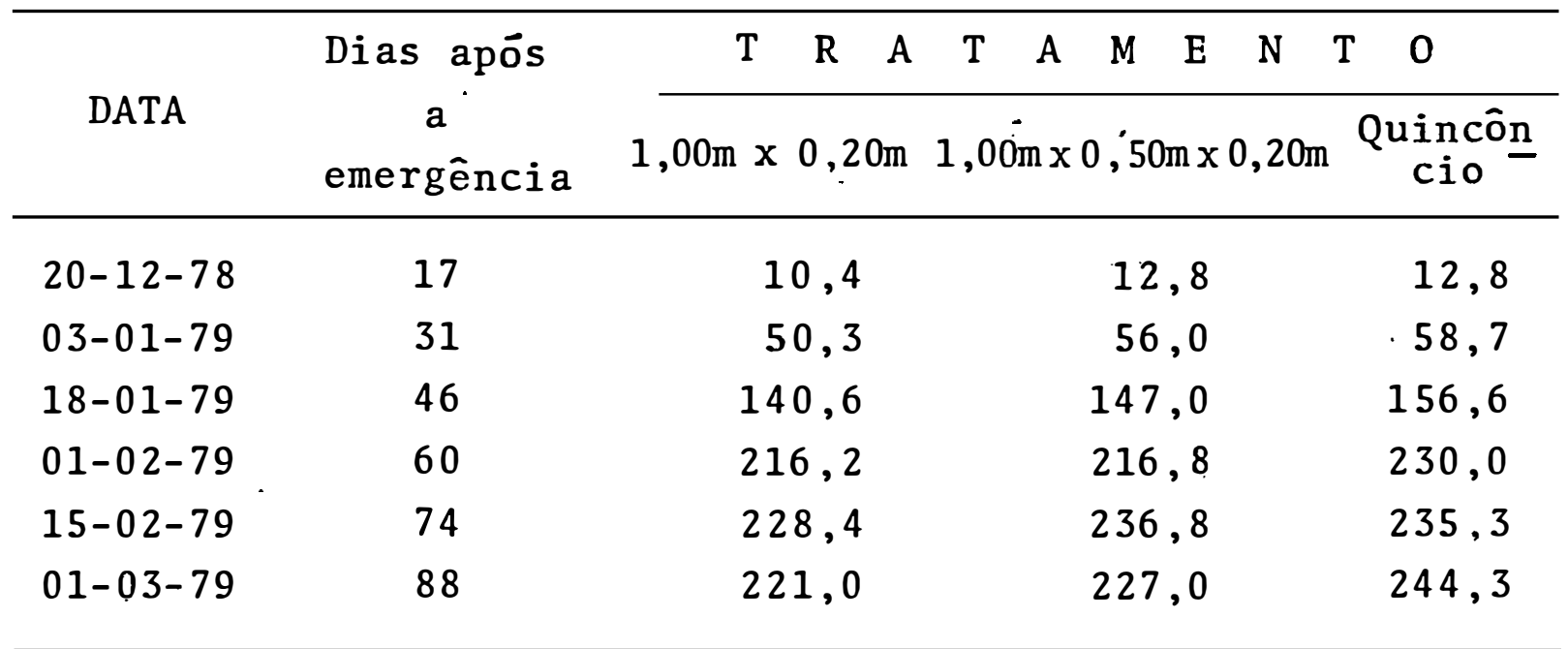

Tabela 21. Área foliar média por planta $\left(\mathrm{cm}^{2}\right)$, por tratamento, para períodos de 14 dias, em uma cultura de milho (Zea mays L. var. Cargill 501).

\begin{tabular}{|c|c|c|c|c|c|c|c|c|c|c|c|}
\hline \multirow[b]{2}{*}{ DATA } & \multirow{2}{*}{$\begin{array}{c}\text { Dias apōs } \\
\text { a } \\
\text { emergência }\end{array}$} & $\mathrm{T}$ & $\mathrm{R}$ & A & $\mathrm{T}$ & A & $M$ & $\mathrm{E}$ & $\mathrm{N}$ & $\mathrm{T}$ & 0 \\
\hline & & \multicolumn{4}{|c|}{$1,00 \mathrm{~m} \times 0,20 \mathrm{~m}$} & \multicolumn{4}{|c|}{$\begin{array}{c}1,00 \mathrm{~m} \times 0,50 \mathrm{mx} \\
\times 0,20 \mathrm{~m}\end{array}$} & \multicolumn{2}{|c|}{$\begin{array}{c}\text { Quincôn } \\
\text { cio }\end{array}$} \\
\hline $20-12-78$ & 17 & \multicolumn{4}{|c|}{738,28} & \multicolumn{4}{|c|}{754,21} & & 774,56 \\
\hline 03-01-79 & 31 & \multicolumn{4}{|c|}{$4.774,59$} & \multicolumn{4}{|c|}{$4.786,55$} & 4. & 700,94 \\
\hline $18-01-79$ & 46 & \multicolumn{4}{|c|}{$7.019,20$} & \multicolumn{4}{|c|}{$6.847,27$} & 6 . & 539,69 \\
\hline $01-02-79$ & 60 & \multicolumn{4}{|c|}{$7.058,57$} & \multicolumn{4}{|c|}{$7.349,99$} & & 326,87 \\
\hline $15-02-79$ & 74 & \multicolumn{4}{|c|}{$7.121,78$} & \multicolumn{4}{|c|}{$7.333,31$} & & 314,51 \\
\hline $01-03-79$ & 88 & \multicolumn{4}{|c|}{$6.837,19$} & \multicolumn{4}{|c|}{$6.521,09$} & & 592,64 \\
\hline
\end{tabular}




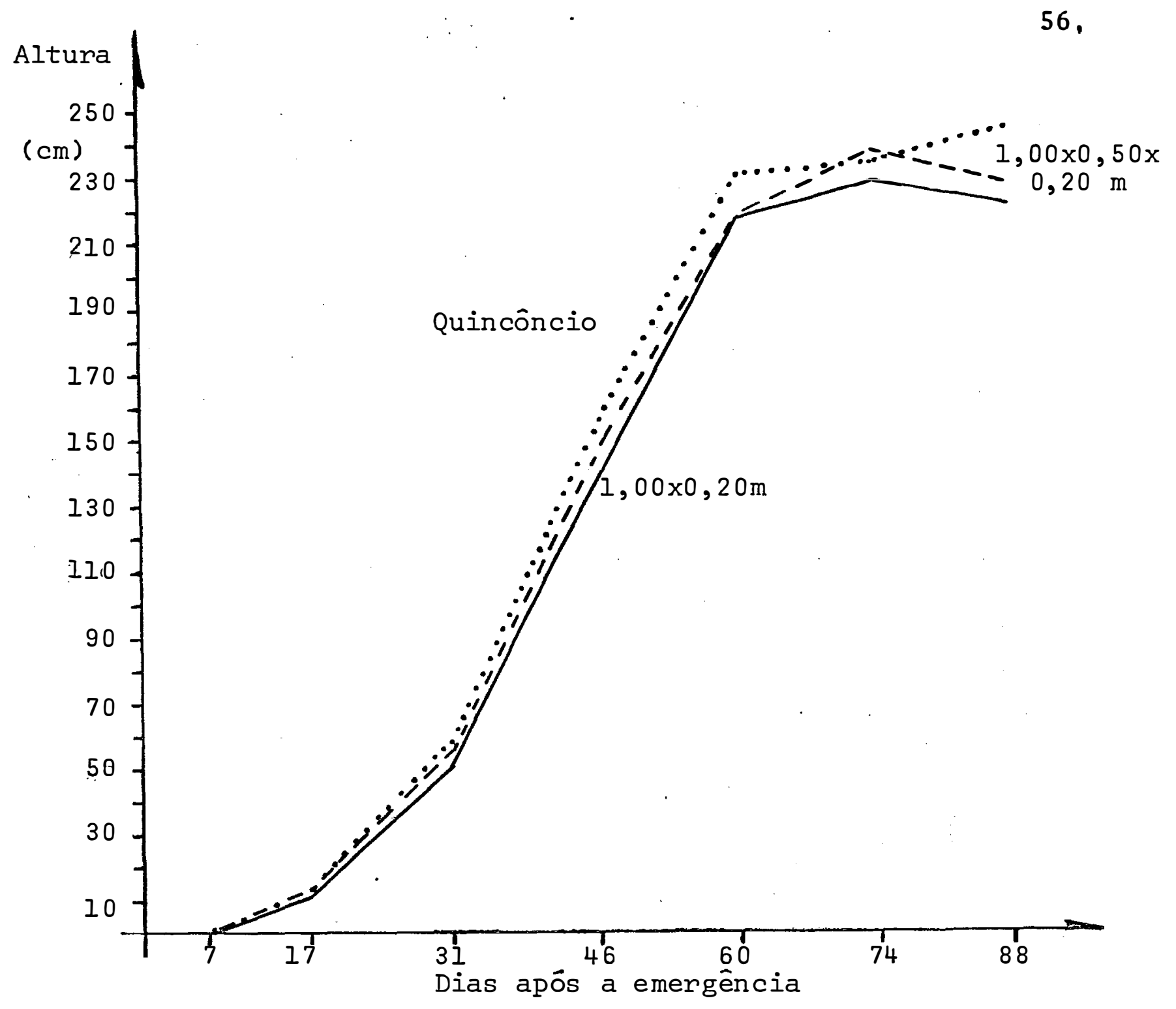

Figura 10.- Variação da altura média das plantas de milho, variedade Cargill 501, durante o ciclo vegetativo, nos três tratamentos. 


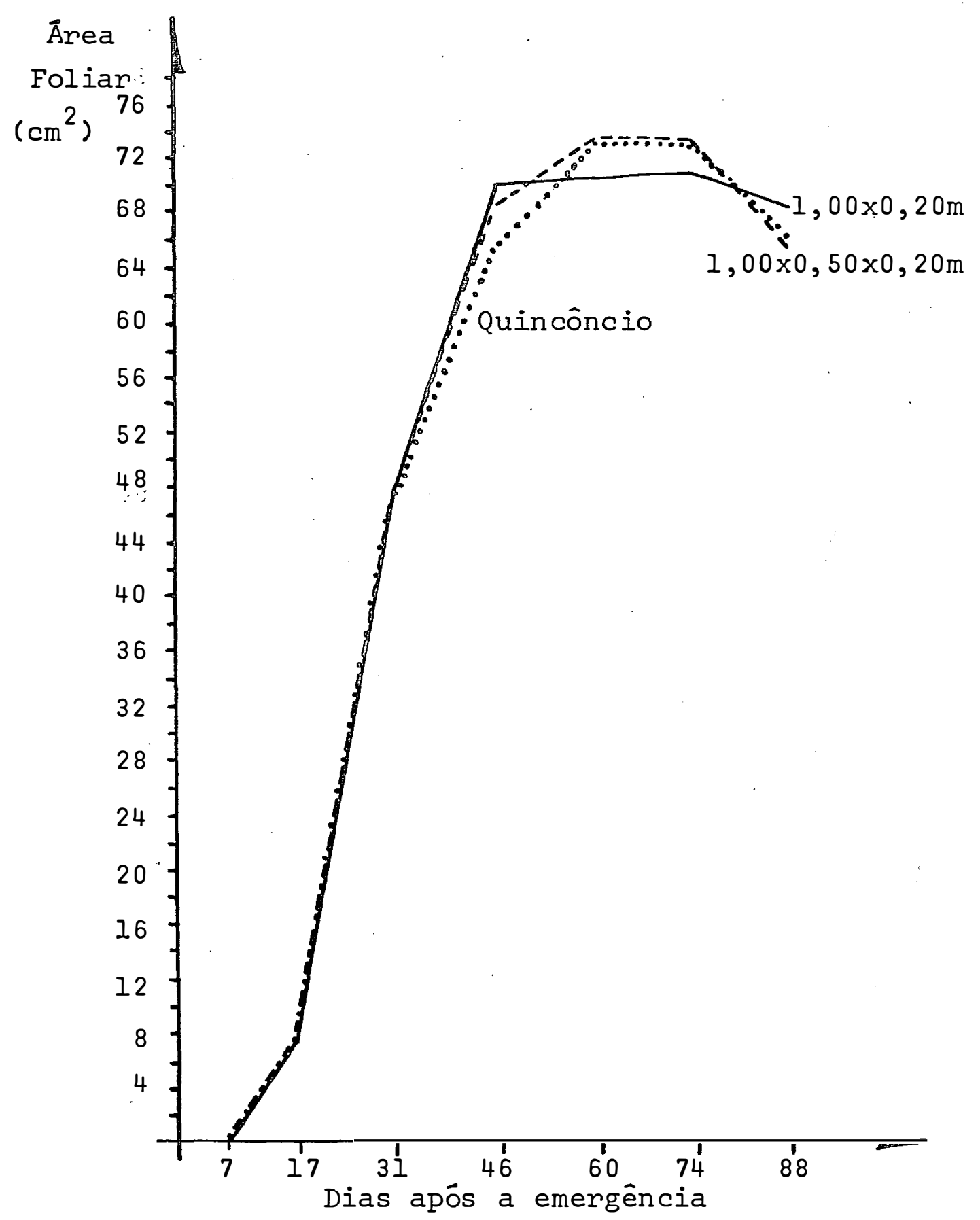

57.

Figura 11.- Variação da área foliar média das plantas de milho, var. Cargill 501, durante o ciclo vegetativo, nos três tratamentos. 
Tabela 22. Indice de Área Foliar médio $\left(\mathrm{cm}^{2} \cdot \mathrm{cm}^{-2}\right)$, por tratamento, para períodos de 14 dias, em uma cultura de milho (Zea mays L., var. Cargill 501).

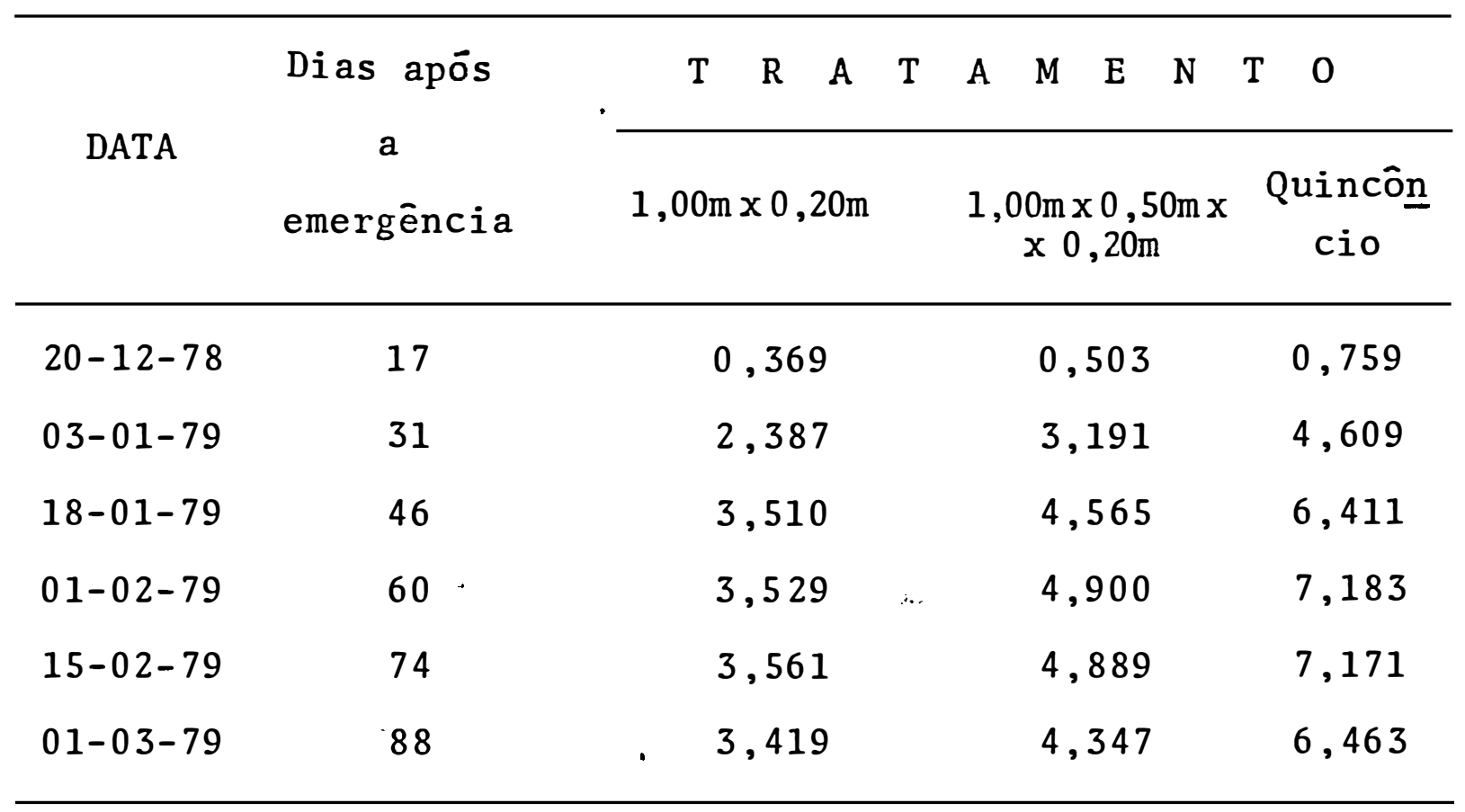




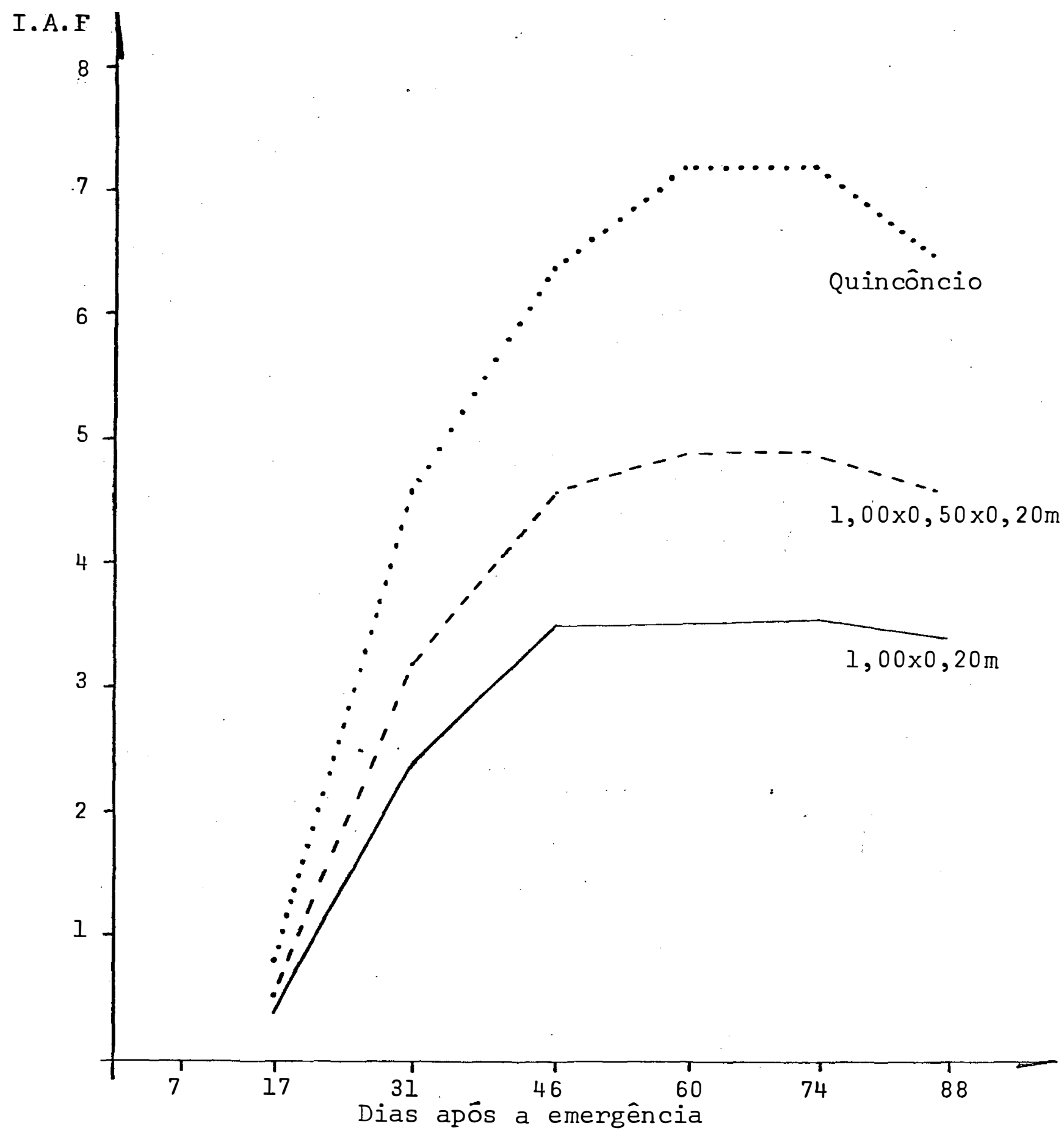

Figura 12.- Variação do índice de área foliar médio das plantas de milho, var. Cargill 501, durante o ciclo vegetativo, nos très tratamentos. 
As medidas do peso médio de matéria seca acumulada por planta e o peso médio da matéria seca por metro quadrado de área cultivada, encontram-se nas tabelas 23 e 24 respectivamente, concordando os resultados com LOOMIS e WILLIAMS (1963); SAEKI (1963); LEMEUR e ROSENBERG (1975); e outros au tores que assinalam que para maior índice de área foliar a pro dução de matéria seca é maior por unidade de área (fig. 13), trazendo em consequência maior produtividade.

A produção de matéria seca por metro quadrado por dia, denominada também, taxa de crescimento do cultivo, se apresenta na tabela 25 , onde pode-se notar que a máxima taxa ocorreu no tratamento quincôncio $\operatorname{com} 31,8 \mathrm{~g} \cdot \mathrm{m}^{-2} \cdot \mathrm{dia}^{-1}$, inferior do máximo valor encontrado por WILLIAMS em 1965, que foi de $52 \mathrm{~g} \cdot \mathrm{m}^{-2} \cdot \mathrm{dia}$, esta variação provavelmente deve-se a diversos fatores como: diferentes variedades empregadas, época do ano, área foliar, número de plantas por metro quadrado e carac terísticas físicas das plantas. Na pesquisa a produção de matéria seca por unidade de área e por dia, foi maior na parce la mais densamente povoada.

Nas figs. 14 a 16, tem-se a distribuição da matéria seca em porcentagem dos diferentes órgãos da planta através do tempo. "Para as três parcelas do experimento, encontrou-se que as porcentagens obtidas não diferem grandemente um do outro, a excessão da porcentagem de matéria seca das espigas no tratamento quincôncio que é menor que nos demais tratamentos. 
Tabela 23. Peso médio de matéría seca acumulada por planta ( $g$ ), por tratamento, para períodos de 14 dias, em uma cultura de milho (zea mays L. var. Cargill 501).

\begin{tabular}{|c|c|c|c|c|c|c|c|c|}
\hline \multirow{2}{*}{$\begin{array}{c}\text { Tratamen } \\
\text { to } \\
\text { (m). }\end{array}$} & \multirow{2}{*}{ DATA } & \multirow{2}{*}{$\begin{array}{c}\text { Dias após } \\
\text { a } \\
\text { emergência }\end{array}$} & \multicolumn{6}{|c|}{ MATÉRIA SECA ACUMULADA (g) } \\
\hline & & & Caule & Folhas & Espigas & $\begin{array}{l}\text { Palha das } \\
\text { espigas }\end{array}$ & Panícula & $\begin{array}{c}\text { Planta } \\
\text { toda }\end{array}$ \\
\hline \multirow[t]{6}{*}{$1,00 \times 0,20$} & $20-12-78$ & 17 & 0,69 & 2,41 & --- & --- & --- & 3,10 \\
\hline & 03-01-79 & 31 & 10,33 & 15,61 & --- & -- & -- & 25,94 \\
\hline & $18-01-79$ & 46 & 54,36 & 24,58 & 1,64 & --- & 4,80 & 85,38 \\
\hline & $01-02-79$ & 60 & 67,30 & 29,99 & 2,29 & 9,34 & 5,60 & 114,52 \\
\hline & $15-02-79$ & 74 & 77,39 & 32,38 & 51,58 & 28,69 & 6,05 & 196,09 \\
\hline & 01-03-79 & 88 & 117,55 & 32,61 & 136,46 & 52,89 & 5,70 & 345,21 \\
\hline \multirow{6}{*}{$\begin{array}{c}1,00 \times 0,50 x \\
x 0,20\end{array}$} & $20-12-78$ & 17 & 0,85 & 2,51 & -- & -- & --- & 3,36 \\
\hline & 03-01-79 & 31 & 8,64 & 15,57 & --- & -- & --- & 24,21 \\
\hline & $18-01-79$ & 46 & 43,39 & 23,60 & 0,69 & --- & 3,25 & 70,93 \\
\hline & $01-02-79$ & 60 & 66,50 & 29,81 & 2,03 & 11,77 & 5,78 & 115,89 \\
\hline & $15-02-79$ & 74 & 84,39 & 35,00 & 50,41 & 27,84 & 4,94 & 202,58 \\
\hline & $01-03-79$ & 88 & 91,26 & 38,03 & 121,98 & 23,52 & 5,86 & 280,65 \\
\hline \multirow[t]{6}{*}{ Quincôncio } & $20-12-78$ & 17 & 0,86 & 2,50 & --- & --- & --- & 3,36 \\
\hline & $03-01-79$ & 31 & 8,23 & 14,09 & -- & --- & -- & 22,32 \\
\hline & $18-01-79$ & 46 & 43,04 & 26,77 & 0,52 & --- & 2,72 & 73,05 \\
\hline & $01-02-79$ & 60 & 63,33 & 28,34 & 2,43 & 9,31 & 5,12 & 108,53 \\
\hline & $15-02-79$ & 74 & 76,44 & 30,95 & 46,13 & 20,58 & 4,51 & 178,61 \\
\hline & 01-03-79 & 88 & 108,90 & 38,09 & 106,69 & 29,74 & 5,29 & 288,44 \\
\hline
\end{tabular}


Tabela 24. Matéria seca acumulada em $g$ por metro quadrado de área cultivada com milho, por tratamento, para períodos de 14 dias em Zea mays L. var. Gargill 501).

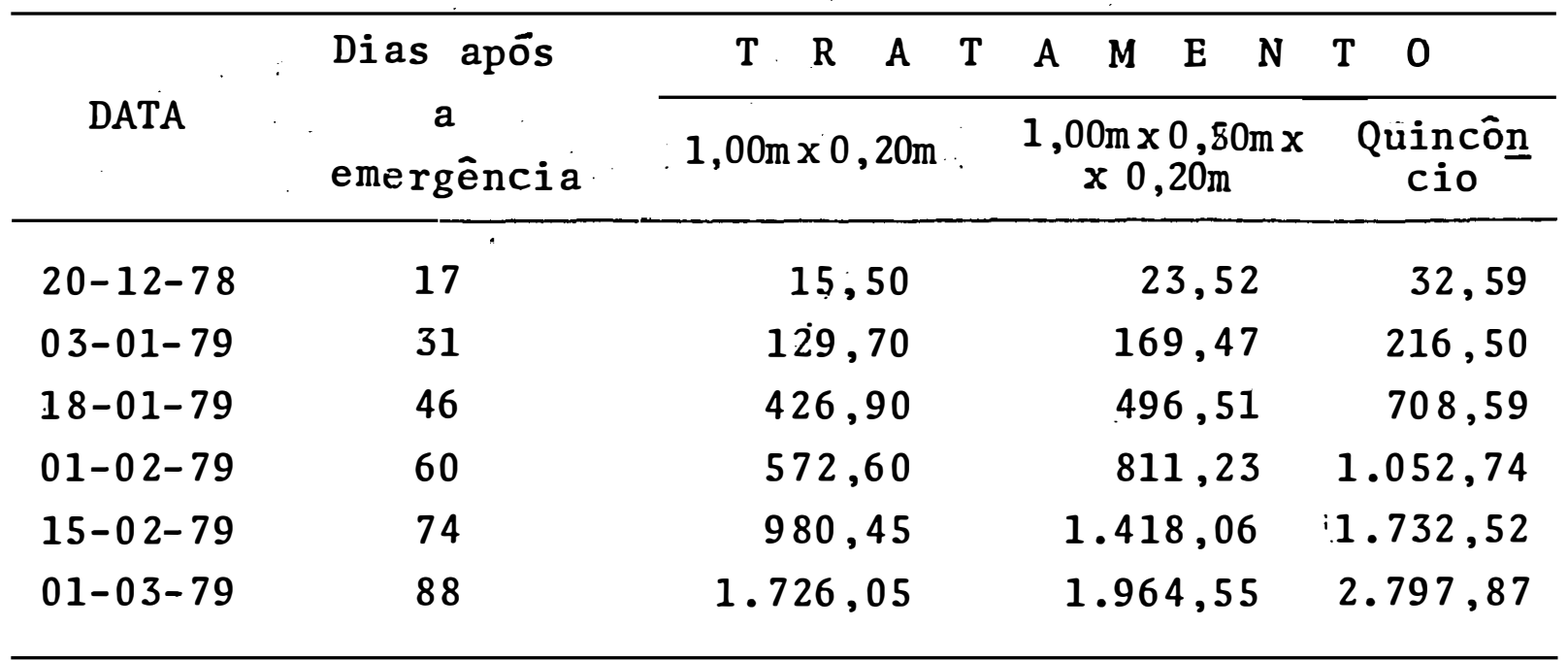

Tabela 25. Taxas de produção de matéria seca acumulado em $g$ por me tro quadrado por dia, por tratamento, em cultura de mitho (Zea mays L. var. Cargill 501).

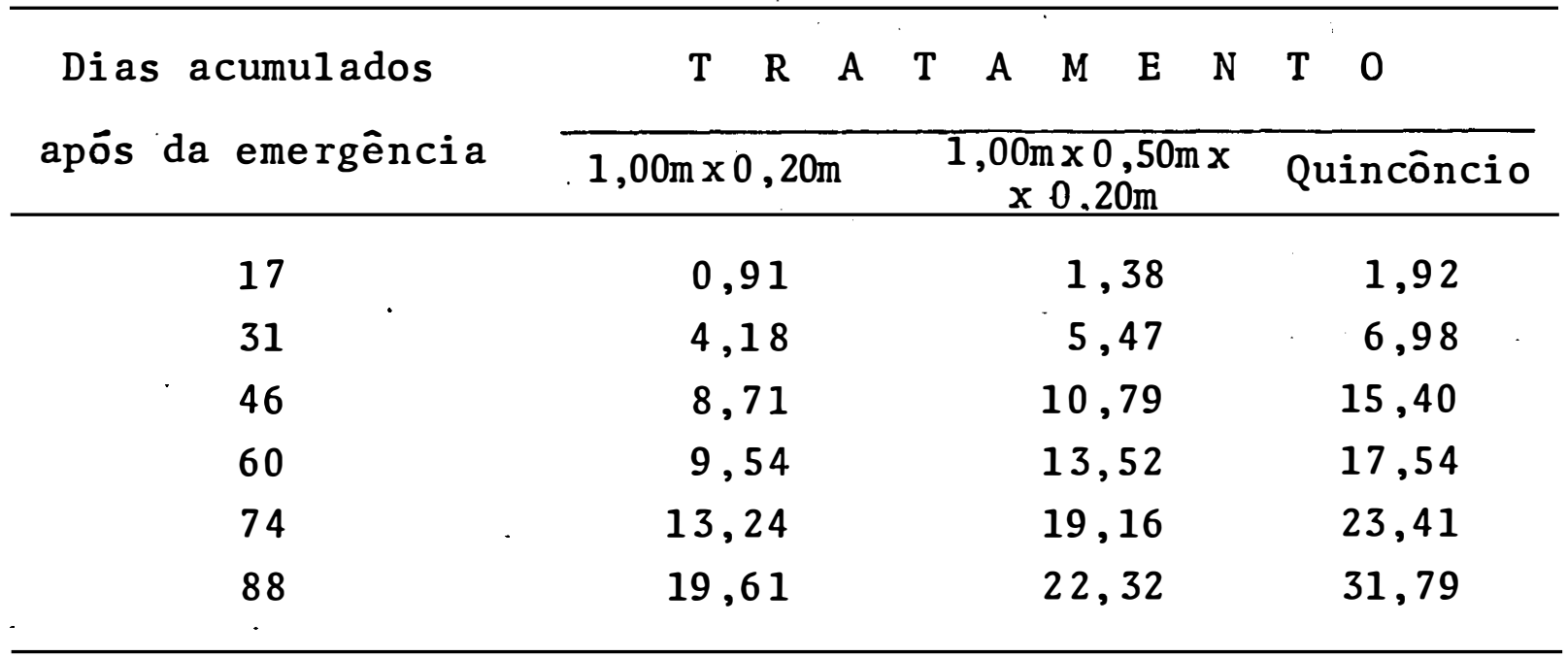


63.

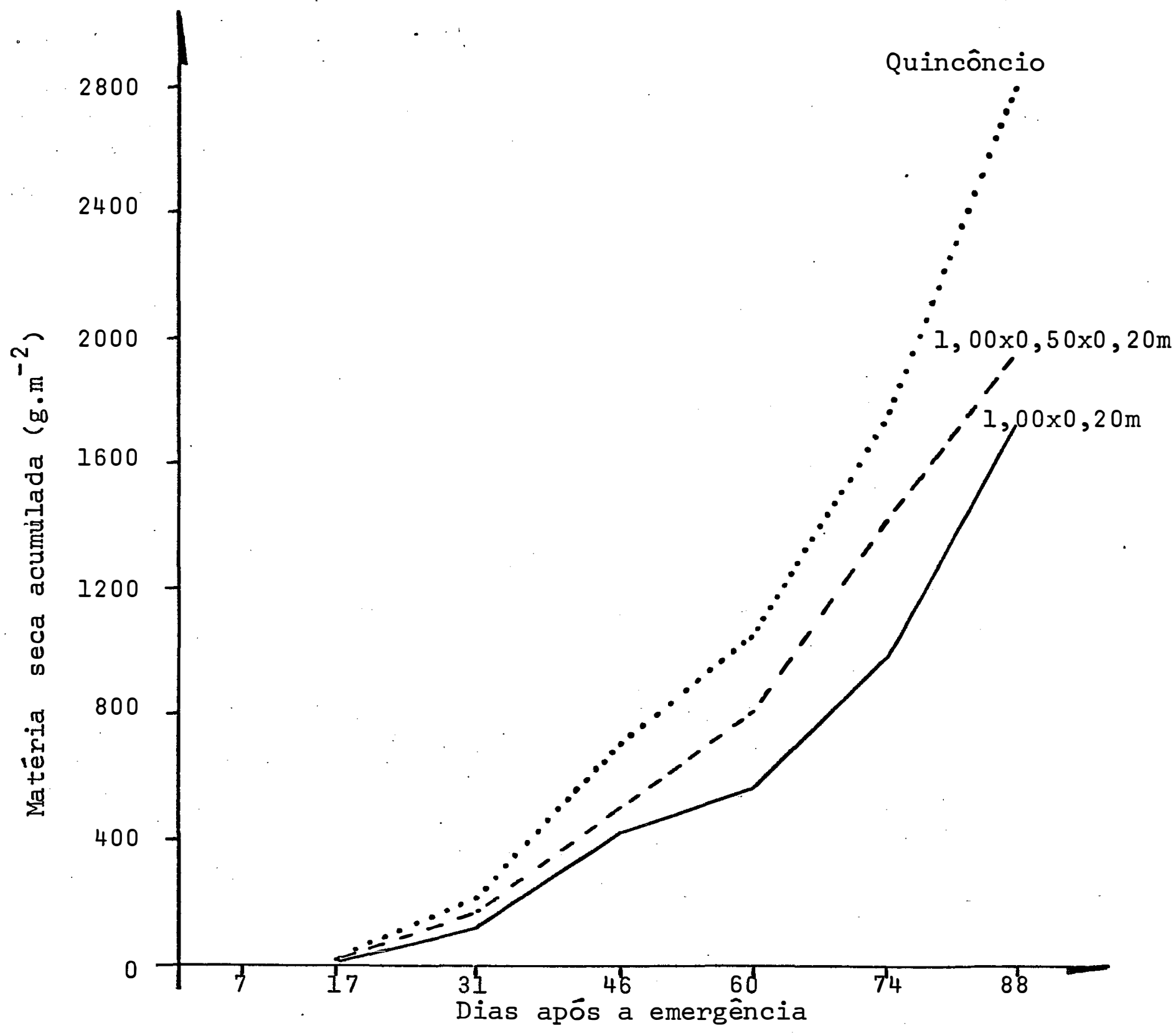

Figura 13.- Variação média de matéria seca acumulada nas plantas de milho, variedade Cargill 501, nos três tratamentos. 
64.

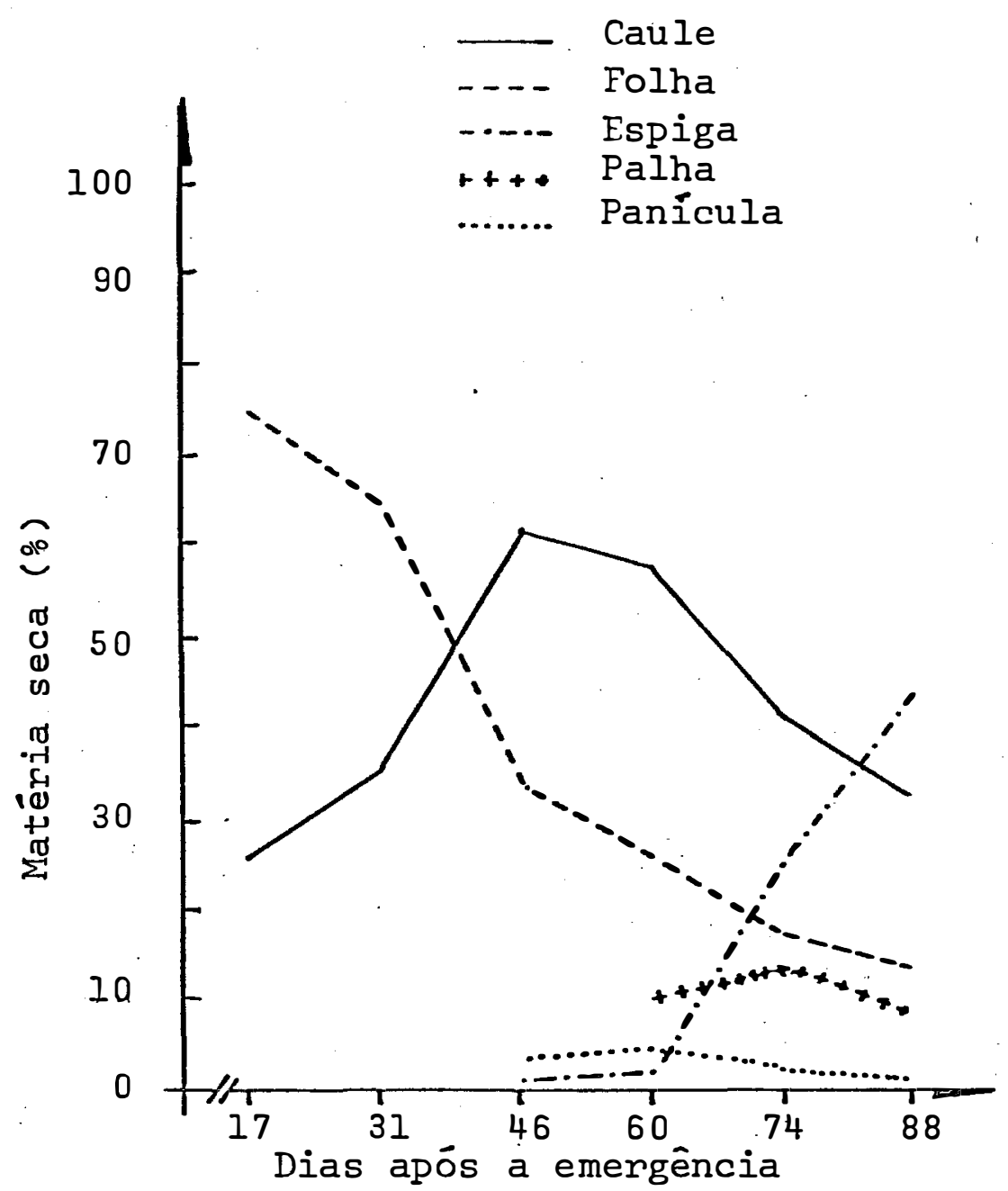

Figura 14.- Distribuição da matéria seca, em porcentagem, dos diferentes óngãos da planta de milho. em função do tempo, para o tratamento $1,00 \times 0,20 \mathrm{~m}$. 


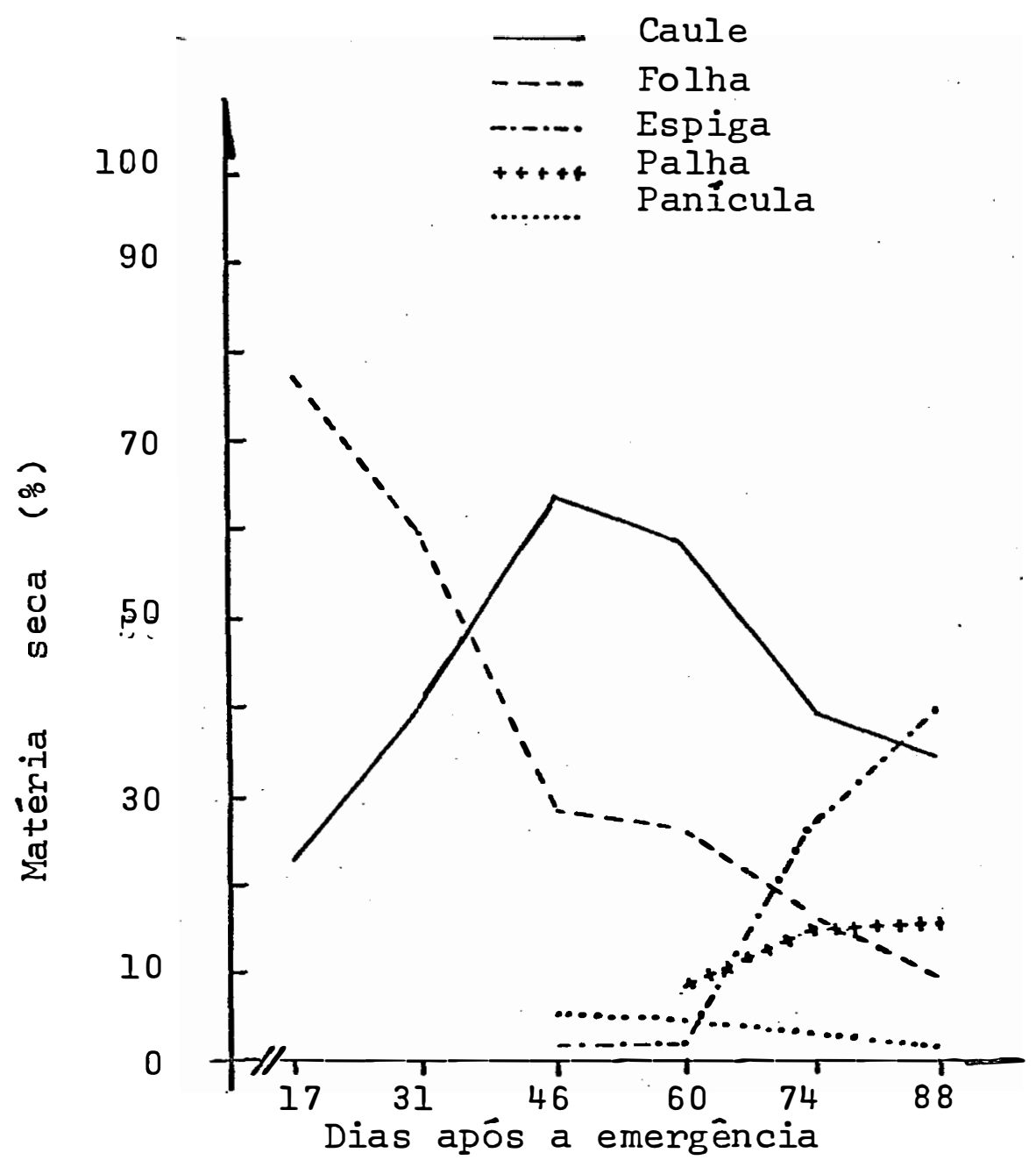

Figura 15.- Distribuição da matéria seca, em porcentagem, dos diferentes óngaõs da planta de milho. em função do tempo, para o tratamento $1,00 \times 0,50 \times 0,20 \mathrm{~m}$. 


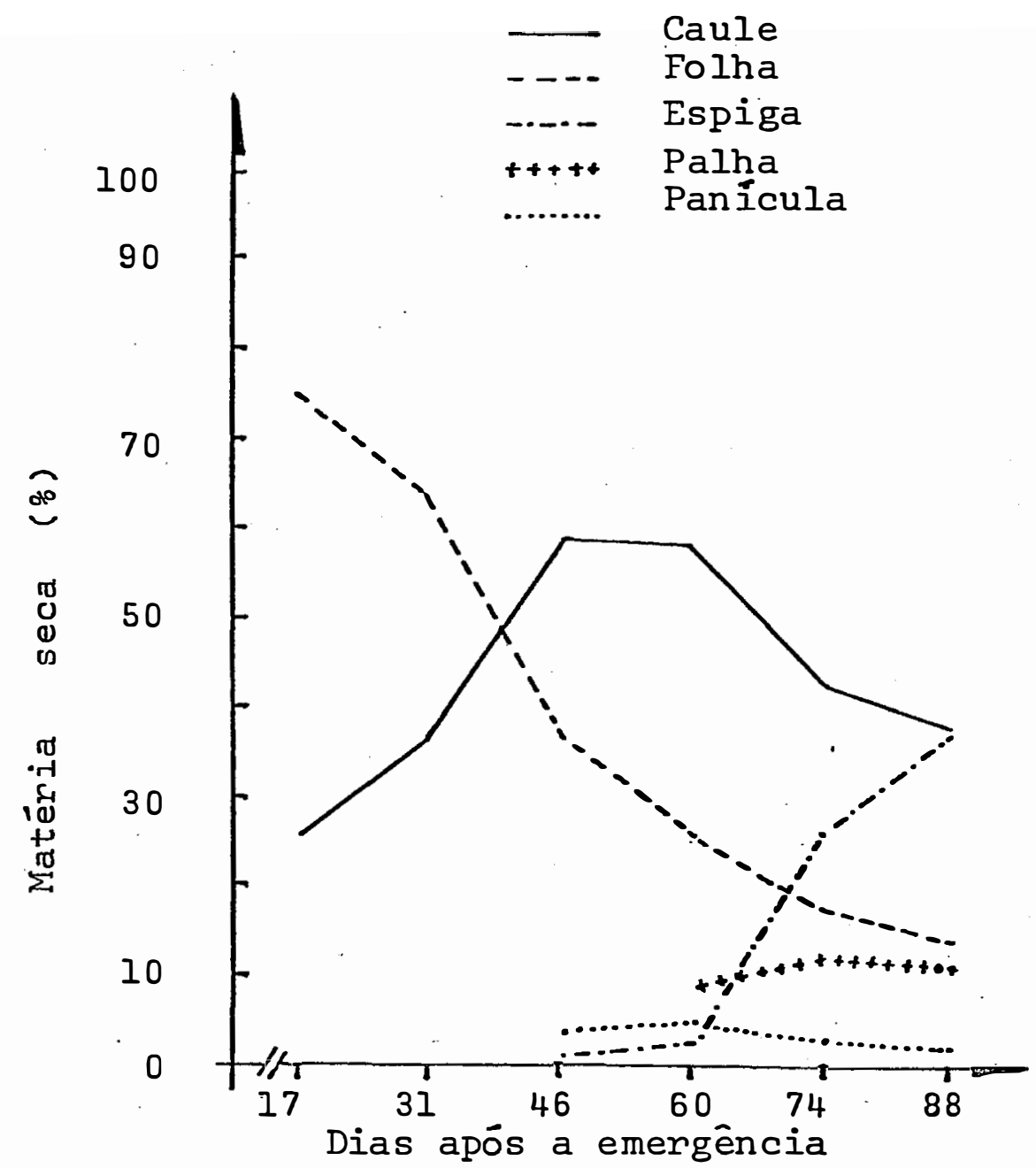

Figura 16. - Distribuição da matéria seca, em porcentagem, dos diferentes óngãos da planta de milho: em função do tempo, para o tratamento quincôncio. 
Para o cálculo de produção se planificou a co1heita das espigas para o dia 12-04-79 ou seja, 130 dias após o plantio, quando os grãos de milho encontravam-se praticamente com baixo teor de umidade, na ordem de $17 \%$, segundo especifica-se na tabela 26, realizou-se a colheita para uma área padrão de $10 \mathrm{~m}^{2}$, encontrando-se que quase todas as plantas tinham uma espiga. Na parcela quincôncio por ter maior número de plantas por unidade de área se colheu 103 espigas contra 52 espigas na parcela de entre-linhas tradicionais de $1,00 \mathrm{~m} \times 0,20 \mathrm{~m}$, quase $5.0 \%$ a menos que a parcela quincôncio, segundo especifica se na tabéla 27.

A totalidade das espigas foram medidas, tanto seu comprimento como seu diâmetro, encontrando-se concordante com a revisão bibliográfica, pois, nas parcelas com menor densidade de população os frutos apresentam-se com maiores dimensões, pela tabela 28 aprecia-se que no tratamento $1,00 \mathrm{~m} \times 0,20 \mathrm{~m}$ as dimensões das espigas são maiores que nos outros tratamentos, assim mesmo, o peso médio das espigas e o peso médio das sementes por espiga também foram maiores para o tratamento $1,00 \mathrm{~m} \times 0,20 \mathrm{~m}$, segundo verifica-se na tabela 29 .

Os dados de produção de grãos por hectare mostram-se na tabela 30 , produzindo um pouco mais de 12 ton/ha de matéria seca no tratamento quincôncio, contra 7 ton/ha para 0 tratamento $1,00 \mathrm{~m} \times 0,20 \mathrm{~m}$, a produção do tratamento $1,00 \mathrm{~m} \times$ $\times 0,50 \mathrm{~m} \times 0,20 \mathrm{~m}$ foi aproximadamente de 8 ton/ha, 0 rendimento, portanto, foi muito superior no tratamento quincôncio em $70 \%$ a mais que a produção obtida na parcela com distanciamento de en tre-linhas tradicionais, esta maior produção pode ser explicada pela maior densidade de plantas por hectare, pelo maior índice de área foliar e pelo maior aproveitamento da radiação solar que atinge a cobertura vegetal.

Tendo em conta o bom rendimento obtido no tratamen to quincôncio e considerando o reduzido número de repetições efetuadas é recomendável que se efetuem estudos mais profundos com as repetições pertinentes, para realizar anālises estatísticas apropriadas e estabelecer assim as vantagens do modelo quin côncio, tornando-1he comercial com as respectivas modificações agronômicas. 
Tabela 26. Umidade média $\left(\frac{q}{8}\right)$ das sementes, em uma cultura de milho, variedade Cargill 501 por tratamento.

\begin{tabular}{cccc}
\hline \multirow{2}{*}{$\begin{array}{c}\text { UMIDADE } \\
(8)\end{array}$} & T R A T A M E N T O \\
\cline { 2 - 4 } & $1,00 \mathrm{~m} \times 0,20 \mathrm{~m}$ & $\begin{array}{c}1,00 \mathrm{~m} \times 0,50 \mathrm{~m} \times \\
\times 0,20 \mathrm{~m}\end{array}$ & Quincôncio \\
\hline $\begin{array}{l}\text { Umidade média } \\
\text { das sementes }\end{array}$ & 16,7 & 16,4 & 17,2 \\
\hline
\end{tabular}


Tabela 27. Número de espigas colheitadas em uma cultura de mi 1ho, variedade Cargill 501, por tratamento, em uma área de $10 \mathrm{~m}^{2}$

\begin{tabular}{|c|c|c|c|}
\hline \multirow{2}{*}{ COLHE ITA } & \multicolumn{3}{|c|}{ T R A T A M E N T O } \\
\hline & $1,00 \mathrm{~m} \times 0,20 \mathrm{~m}$ & $\begin{array}{c}1,00 \mathrm{~m} \times 0,50 \mathrm{mx} \\
\times 0,20 \mathrm{~m}\end{array}$ & Quincôncio \\
\hline $\mathrm{N}^{\circ}$ plantas colhidas & 50 & 66 & 98 \\
\hline $\begin{array}{l}N^{\circ} \text { plantas com uma } \\
\text { espiga }\end{array}$ & 48 & 62 & 93 \\
\hline $\begin{array}{l}\mathrm{N}^{\circ} \text { plantas com duas } \\
\text { espigas }\end{array}$ & 2 & 4 & 5 \\
\hline $\begin{array}{l}\text { Total de espigas } \\
\text { colhidas }\end{array}$ & 52 & 70 & 103 \\
\hline
\end{tabular}

Tabela 28. Dimensões médias ( $\mathrm{cm}$ ) das espigas colhidas em uma cultura de milho - Variedade Cargill 501, por tratamento.

\begin{tabular}{|c|c|c|c|}
\hline \multirow{2}{*}{$\begin{array}{l}\text { DIMENSŌES } \\
\text { (cm) }\end{array}$} & \multicolumn{3}{|c|}{ T R A T A M E N T 0} \\
\hline & $1,00 \mathrm{~m} \times 0,20 \mathrm{~m}$ & $\begin{array}{c}1,00 \mathrm{~m} \times 0,50 \mathrm{mx} \\
\times 0,20 \mathrm{~m}\end{array}$ & Quincôncio \\
\hline $\begin{array}{l}\text { Comprimento médio } \\
\text { das espigas }\end{array}$ & 17,1 & 15,9 & 16,2 \\
\hline $\begin{array}{l}\text { Diâmetro médio } \\
\text { das espigas }\end{array}$ & 4,8 & 4,5 & 4,6 \\
\hline
\end{tabular}


Tabela 29. Peso médio ( $\mathrm{g}$ ) das espigas e das sementes por espiga, em uma cultura de milho, variedade Cargill 501, por tratamento.

\begin{tabular}{ccccc}
\hline PESO $(\mathrm{g})$ & $\mathrm{T}$ R A & $\mathrm{T}$ A $\mathrm{M}$ E $\mathrm{N}$ & $\mathrm{T}$ \\
\cline { 2 - 5 } & $1,00 \mathrm{~m} \times 0,20 \mathrm{~m}: \begin{array}{c}1,00 \mathrm{~m} \times 0,50 \mathrm{mx} \\
\times 0,20 \mathrm{~m}\end{array}$ & Quincôncio \\
\hline $\begin{array}{l}\text { Peso médio das } \\
\text { espigas }\end{array}$ & 205,0 & 169,8 & 185,3 \\
$\begin{array}{l}\text { Peso médio das } \\
\text { sementes por espiga }\end{array}$ & 164,9 & 135,3 & 142,6 \\
\hline
\end{tabular}

Tabela 30. Dados de produção em peso e rendimento comparativo por tratamento, em uma cultura de milho (zea mays L. var. Cargill 501).

\begin{tabular}{|c|c|c|c|}
\hline \multirow[b]{2}{*}{ PESO (kg/ārea) } & $\mathrm{T} \quad \mathrm{R} \quad \mathrm{A}$ & T A $\quad M \quad E \quad N$ & T 0 \\
\hline & $1,00 \mathrm{~m} \times 0,20 \mathrm{~m}$ & $\begin{array}{l}1,00 \mathrm{~m} \times 0,50 \mathrm{mx} \\
\times 0,20 \mathrm{~m}\end{array}$ & $\begin{array}{l}\text { Quin } \\
\text { côncĩo }\end{array}$ \\
\hline Peso das sementes $\left(\mathrm{kg} / 10 \mathrm{~m}^{2}\right)$ & 8,5734 & 9,4722 & 14,6854 \\
\hline Peso das sementes $(\mathrm{kg} / \mathrm{ha}) \cdot$ & $8.573,4$ & $9.472,2$ & $14.685,4$ \\
\hline Peso seco das sementes $(\mathrm{kg} / \mathrm{ha})$ & $7.141,6$ & $7.918,8$ & $12.159,5$ \\
\hline Rendimento comparativo $(\xi)$ & 100,0 & 110,9 & 170,3 \\
\hline
\end{tabular}




\section{CONCLUSÕES}

Com base nas discussões e resultados obtidos anota-se como principais conclusões as seguintes:

1) A relação entre a radiação infra-vermelha próxima e a radiação solar global que atingem a cobertura vegetal de uma cultura de milho é da ordem de $46 \%$.

2) As maiores porcentagens de radiação solar global e fotossinteticamente ativa retidas pela cobertura vegetal corresponderam aos tratamentos de maior densidade de população com 85 e $96 \%$ para as duas faixas do espectro e para o tratamento $1,00 \mathrm{~m} \times 0,20 \mathrm{~m}$ correspondeu uma retenção de 80 e $94 \%$.

3) As maiores porcentagens de radiação solar global e fotossinteticamente ativa medidas na superfície do solo corresponderam à parcela de menor densidade de população com 26 e $16 \%$ respectivamente e nos tratamentos 
$1,00 \mathrm{~m} \times 0,50 \mathrm{~m} \times 0,20 \mathrm{~m}$ e quincôncio corresponderam 21 e $12 \%$ para as duas faixas do espectro.

4) Os albedos de radiação solar global para os tratamentos quincôncio, $1,00 \mathrm{~m} \times 0,20 \mathrm{~m}$ e $1,00 \mathrm{~m} \times 0,50 \mathrm{~m} \times 0,20 \mathrm{~m}$ fo ram: 18,17 e $16 \%$.

5) A amplitude do albedo da radiação solar global no tratamento $1,00 \mathrm{~m} \times 0,20 \mathrm{~m}$ foi de 13 a $26 \%$. Para o tratamento $1,00 \mathrm{~m} \times 0,50 \mathrm{~m} \times 0,20 \mathrm{~m}$ observou-se uma variação de 11 a $24 \%$ e para o tratamento quincôncio de 15 a $23 \%$.

6) Para os três tratamentos os menores valores de albedo da radiação solar global corresponderam as horas próxí mas ao meio do dia, sendo os valores máximos observados de manhã e à tarde.

7) As plantas de maior altura $(244,3 \mathrm{~cm})$ corresponderam ao tratamento com maior população, enquanto que no tratamento de menor densidade $(1,00 \mathrm{~m} \times 0,20 \mathrm{~m})$ a altura média foi de $221,0 \mathrm{~cm}$.

8) O tratamento quincôncio apresentou o maior índice de área foliar com 7,2 . O tratamento $1,00 \mathrm{~m} \times 0,50 \mathrm{~m} \times 0,20 \mathrm{~m}$ apresentou um valor igual a 4,9, sendo de 3,5 o I.A.F. do tratamento $1,00 \mathrm{~m} \times 0,20 \mathrm{~m}$.

9) A maior produção de matéria seca por unidade de área correspondeu ao tratamento quincôncio com $2.798 \mathrm{~g} / \mathrm{m}^{2}$, seguindo os tratamentos $1,00 \mathrm{~m} \times 0,50 \mathrm{~m} \times 0,20 \mathrm{~m}$ com $1.964 \mathrm{~g} / \mathrm{m}^{2}$ e finalmente o tratamento $1,00 \mathrm{~m} \times 0,20 \mathrm{~m}$ com $1.726 \mathrm{~g} / \mathrm{m}^{2}$.

10) A maior taxa de crescimento do cultivo correspondeu ao tratamento quincôncio com $31,8 \mathrm{~g} / \mathrm{m}^{2} \cdot \mathrm{dia}$, seguindo os tratamentos $1,00 \mathrm{~m} \times 0,50 \mathrm{~m} \times 0,20 \mathrm{~m}$ e $1,00 \mathrm{~m} \times 0,2,0 \mathrm{~m} \mathrm{com}$ 23,3 e $1.9,6 \mathrm{~g} / \mathrm{m}^{2} \cdot$ dia respectivamente. 
73.

8. SUMMARY

Determinations of net fluxes for global solar radiation $(0.3-3.0 \mu \mathrm{m})$ and PI $(0.3-0.7 \mu \mathrm{m})$ and their relations to corn growth (2ea mays L. var. Cargill 501) planted in three different densities was the objectives of this research:

The following treatments were adapted:

a) 50,000 plants/ha $1.00 \mathrm{~m}$ between rows and $0.20 \mathrm{~m}$ between plants.

b) $66,667 \mathrm{plants} / \mathrm{ha} 1.00$ and $0.50 \mathrm{~m}$ between rows and $0.20 \mathrm{~m}$ between plants.

c) 98,039 plants $/$ ha with plants equally spaced, $0,34 \mathrm{~m}$ distant from one another.

For radiation fluxes determinations two Eppley pyranometers were used one with WG- 7 and the other with RG-8 
domes, as filters.

For growth analysis sampling was done

fortnightly on corn plants by measuring stalk leaf areas and heights.

The following conclusions were reached:

- The relation between $K_{8} \downarrow$ and $K \downarrow$ was $46 \%$;

- The highest percentage of global solar radiation and PI absorbed by the corn stand, was observed for equal spaced treatments (quincôncio);

- The highest percentage of global solar radiation and PI measured at soil the surface was observed in the plot with $50.000 \mathrm{plants} / \mathrm{ha}$;

- The mean albedo of global solar radiation varied between 16 and $18 \%$, the highest value :was observed in the "quincôn cio" treatment;

- The amplitude of albedo for global solar radiation wass 13 to $26 \%$ in the treatment $1,00 \mathrm{~m} \times 0,20 \mathrm{~m}$. For treatment $1,00 \mathrm{~m} \times 0,50 \mathrm{~m} \times 0,20 \mathrm{~m}$ a variation of $11-24 \%$ was observed, in the "quincôncio", a variation of 15 - 23\% was observed.

- The variation of albedo values showed a minimum at noon all the treatments.

- The "quincôncio" showed the highest values for plant height to be $244.3 \mathrm{~cm}$, and for other morfological parameters also. 
9. LITERATURA CITADA

ALLISON, J.C.S., 1964. A comparison between mayse and wheat in respect of leaf area after flowering and grain growth. Journal of Agricultural Science, 63:1-4.

ALLISON, J.C.S. e D.J.WATSON, 1966. The production and distribution of dry matter in maize after flowering. Annals. of Botany, 30:365-381.

ALVIM, R. e P.T.ALVIM, 1969. Efeito da densidade de plantio no aproveitamento da energia luminosa pelo milho (Zea mays L.) em culturas exclusivas e consorciadas. Túrrialba, 19: 389-393.

ANDERSON, M.C., 1970. Interpreting the fraction of solar radiation available in forest. Agricultural Meteorology, 7: $19-28$. 
AUBERTIN, G.M. e D.B.PETERS, 1961. Net radiation determinations in a cornfield. Agronomy Journal, 53:269-272.

BLACK, J.N:, 1963. The interrelationship of solar radiation and leaf area index in determing the rate of dry matter production of swards of subterraneum clover. Australian. Journal of Agricultural Research, $\therefore 14: 20-38$.

CHANG, J., 1968. Climate and Agriculture. Aldine Publishing Company (ed.). Chicago, USA, 304.

DAVIDSON, J.L. e C.M.DONALD, 1958. The growth of swards of subterraneum clover with particular reference to leaf area. Australian Journal Agronomy, 9: 53-72.

DUNCAN, W.G., 1967. Corn yields to meet the challenge. In: Maximum Crop Yields. The Challenge. American Society of Agronomy, 51-56.

DUNGAN, G.H., A.L.LANG e J.W.PENDLETON, 1958. Corn plant population in relation to soil productivity. Advances in Agronomy, 10: 435-474.

EVANS, G.C., 1966. Model and measurement in the study of woodland light climates. In: Light as an ecological factor. R. Bainbridge, G.r.Evans and O.Rackman (ed.). Blackwell Scientific Publications. Oxford and Edinburgo, 53-76.

FRANCIS, C.A., J.N.RUTGER e A.F.E.PALMER, 1969. A rapid method for plant leaf area estimation in maize (zea mays L.). Crop Science, 9 :537-539.

GALVĀO, J.D., S.S.BRANDĀO e F.R.GOMES, 1969. Efeito da popula ção de plantas e níveis de nitrogênio sobre a produção de grãos e sobre o peso médio das espigas de milho. Experientiae, 9: 39-82. 
GRAHAM, W.G. e K.N.KING, 1961. Short-wave reflection for a field of maize. Quartely Journal of the Royal Meteorology Society, 87:425-428.

HOYT, P. e R.BRADFIELD, 1962. Effect of varying leaf area by partial defoliation and plant density on dry matter production in corn. Agronomy Journa1, 54:523-525.

JARAMILLO, R.A., 1979. Balanço de radiação solar em Coffea arabica L., variedades Catuai e Bourbon amarelo (Tese de Mestrado), ESALQ - Piracicaba, SP. 68 p.

KASANAGA, A. e M.MONSI, 1954. On the light transmission of leaves, and its Meaning for the Production of matter in plant communities. Japanese Journal of Botany, 15:304-324.

LEMEUR, R. e N.J.ROSENBERG, 1975. Reflectant induced modification of soybean canopy radiation balance. II. A quantitative and qualitative analysis of radiation reflected from a green soybean canopy. Agronomy Journa1, 67:301-306.

LINVILL, D.E. e R.F.DALE, 1975. Population density and sampling location effects on net radiation measurements over corn. Agronomy Journa 1, 67:463-468.

LOOMIS, R.S. e W.A.WILLIAMS, 1963. Maximum crop productivity: An estimate, Crop Science, $3: 67-72$.

LOPES, N.F., 1973. Análise de crescimento e conversão da enẹ gia solar em população de milho (Zea mays L.) em Viçosa, MG (Tese de Magister Scientiae), $61 \mathrm{p}$.

MONTEITH, J.L., 1959. The reflection of short wave radiation by vegetation. Quartely Journal Royal Meteorology Society, $85: 386-392$. 
MONTEITH, J.L. e G.SZEICZ, 1961. The radiation balance of base soil and vegetation. Quartely Journal of the Royal. Meteorology Society, 87:159-169.

MONTEITH, J.L., 1965. Light distribution and photosynthesis in field crops. Annals of Botany, 29(113):17-37.

MONTEITH, J.L., 1969. Light interception and radiation exchange in crop stands. In: Physiological aspects of crop yield. J.D.Eastin (ed.). Madison. American Society of Agronomy, 89-115.

MOSS, D.M., R.B.MUSGRAVE e E.R.LEMON, 1961. Photosynthesis under field conditions: III. Some effects of light, carbon dioxide. Temperature of corn. Crop Science, 1:83-87 .

PRINE, G.M. e V.N.SCHRODER, 1964. Above soil environment limits yields of semiprolific corn as plant population increases. Crop Science, $4: 361-362$.

RANZANI, G., O.FREIRE e T.KINJO, 1966. Cartas de solos do Município de Piracicaba. Piracicaba, ESALQ-USP, 45-46.

REICHARDT, K. e P.L.LIBARDI, 1974. An analysis of soil water movement in the field: I. Hidrological field site characterization. CENA (BC-021), Piracicaba, SP. 21 p.

REICHARDT, K., F.GROHMANN, P.L. LIBARDI e S.V.QUEIROZ, 1976. Spatial variability of physical properties of a tropical soil: - I - Geometric Properties. CENA (BT - 004), Piracica ba, SP. $27 \mathrm{p}$.

ROSS, J., 1975. Radiative transfer in plant communities. In: Vegetation and the atmosphere. J.L.Monteith (ed.). Academy Press, London, (1) :13-56. 
SAEKI, T., 1963. Light relations in plant communities. In: Environmental control of plant growth. L.T.Evans (Ed.). Academic Press, N.Y., 79-94.

SANTOS, J.M. dos, 1957. Contribuição aos estudos para determi nação do albedo. (Tese de Doutorado). ESALQ-USP, Piracica ba, SP. 42 p.

SANTOS, J.M. dos, 1978. Estudos de b.alanço de radiação solar em āreas cultivadas com milho (Zéa mays L.) var. Piranão. Piracicaba, SP, ESALQ-USP. (Tese de Livre-Docência). 114 p.

SINCLAIR, T.R. e E.R.LEMON, 1974. Penetration of photosynthetically active radiation in corn canopies. Agronomy Journa1, 66:201-205.

STERN, W.R. e C.M.DONALD, 1962. The influence of leaf area and radiation of the growth of clover in swards. Australian Journal of Agricultural Research, 13:615-623.

VERHAGEN, A.M.W., J.H.WILSON e E.J.BRITTEN, 1963. Plant production in relation to foliage illuminator. Annals of Botany, 27(108):62 7-640.

WATSON, D.J., 1952. The physiological basis of variation in yield. Advances in Agronomy, 4:101-145.

WHIGHAM, D.K. e D.G.WOOLEY, 1974. Effect of leaf orientation, leaf area, and plant densities on corn production. Agronomy. Journal, $66: 482-486$.

WILLIAMS, W.A., R.S.LOOMIS e C.R.LEPEY, 1965a. Vegetative growth of corn as affect by population density. I. Productivity in relation to interception of solar radiation. Crop Science, 5:211-215. 
WILLIAMS, W.A., R.S.LOOMIS e C.R.LEPLEY, 1965b. Vegetative growth of corn as affect by population density. II. Components of growth, net assimilation rate and leaf area index. Crop, Science, 5 :215-219.

WILLIAMS, C.N. e R.T. JOSEPH, 1974. Climate soil and crop production in the humid tropics. Oxford University Press, London, $177 \mathrm{p}$.

YAO, P., 1977. Evolução do sistema foliar e resposta à radiação em três variedades de soja (Glycine max L.). Piracicaba, SP, ESALQ-USP (Tese de Mestrado), $57 \mathrm{p}$. 